\title{
Fundamental Study on Transient Bubble (Slug) Behavior by Characterizing Transient Forces of Solid Particles in Fluidized Beds
}

\section{Topical Report}

January 1991 - June 1992

\section{Hisoshi Kono}

October 1992

Work Performed Under Contract No.: DE-FC21-87MC24207

For

U.S. Department of Energy

Office of Fossil Energy

Morgantown Energy Technology Center

Morgantown, West Virginia

By

West Virginia University

Department of Chemical Engineering

Morgantown, West Virginia 


\section{DISCLAIMER}

This report was prepared as an account of work sponsored by an agency of the United States Government. Neither the United States Government nor any agency thereof, nor any of their employees, makes any warranty, express or implied, or assumes any legal liability or responsibility for the accuracy, completeness, or usefulness of any information, apparatus, product, or process disclosed, or represents that its use would not infringe privately owned rights. Reference herein to any specific commercial product, process, or service by trade name, trademark, manufacturer, or otherwise does not necessarily constitute or imply its endorsement, recommendation, or favoring by the United States Government or any agency thereof. The views and opinions of authors expressed herein do not necessarily state or reflect those of the United States Government or any agency thereof.

This report has been reproduced directly from the best available copy.

Available to DOE and DOE contractors from the Office of Scientific and Technical Information, P.O. Box 62, Oak Ridge, TN 37831; prices available at (615) $576-8401$.

Available to the public from the National Technical Information Service, U.S. Department of Commerce, 5285 Port Royal Rd., Springfield, VA 22161; phone orders accepted at (703) 487-4650. 


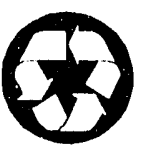

This cover stock is $30 \%$ post-consumer waste and $30 \%$ pre-consumer waste, and is recyclable. 


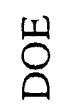

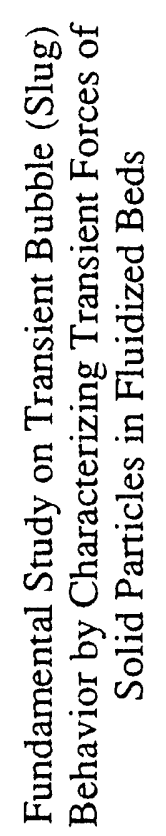

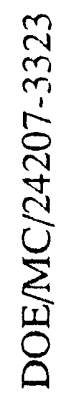




\title{
Fundamental Study on Transient Bubble (Slug) Behavior by Characterizing Transient Forces of Solid Particles in Fluidized Beds
}

\author{
Topical Report \\ January 1991 - June 1992
}

Hisoshi Kono

Work Performed Under Contract No.: DE-FC21-87MC24207

\author{
For \\ U.S. Department of Energy \\ Office of Fossil Energy \\ Morgantown Energy Technology Center \\ P.O. Box 880 \\ Morgantown, West Virginia 26507-0880 \\ By \\ West Virginia University \\ Department of Chemical Engineering \\ Box 6101 \\ Morgantown, West Virginia 26506-6101
}

October 1992 


\section{ABSTRACT}

The objective of this work is to recognize and interpret the signals of transient motion of bubbles (slugs) in fluidized beds (METC/DOE) by measuring and utilizing the signals of transient gas phase pressure fluctuation, and also by taking the video pictures of transient motions of the bubbles and emulsion phase in fluidized beds.

The two signals were measured simultaneously in a three dimensional fluidized bed. Correlation study on the voidage signal and pressure fluctuation was carried out. A domain concept was introduced and new bubble classification was suggested.

A video recording approach was also developed to record the transient bubble motion in a two dimensional fluidized bed with a special consideration. This new approach enhances the understanding of bubble image and the physical meaning of transient particle forces. The fundamental mechanism of bubble flow was experimentally investigated and interesting new findings of the transient bubble flow were obtained.

Images obtained from the video tape for a two dimensional fluidized bed (together with the bubble images obtained in three dimensional fluidized bed by capacitance method at METC/DOE) were studied to analyze the transient changes of bubble velocity and volume, especially in the cases of bubble coalescence and splitting. To our surprise, the new phenomena of the bubble disappearance into the emulsion phase and its reappearance from the emulsion phase were unexpectedly found in addition to well known coalescence and splitting mechanisms. At least several different bubble flow mechanisms are coexisting in parallel. This shows that these phenomena are really stochastic in nature. The classical two phase flow theory of fluidization should be expanded to explain our new findings.

Very clear continuous pictures with the time interval of 0.033 seconds were taken for fluidized beds of fine and coarse fluidized particles under various fluidization conditions. The experimentally obtained actual images showed the disappearance and reappearance of bubbles into and from the emulsion phase.

Also, the synchronized transient gas phase pressure fluctuation signals were analyzed together with the bubble images, and number of observations were obtained. As a conclusion, there are considerable transient changes of bubble size (volume), and in 
some cases the disappearance and reappearance of bubbles into and from the emulsion phase. Therefore, there is a significant gas interaction between the bubble and the emulsion phase. Based upon these new experimental findings, an improved understanding on transient behavior of fluidization phenomena has been obtained. 


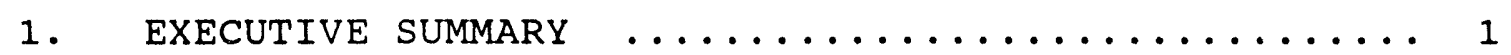

2. TECHNICAL BACKGROUND $\ldots \ldots \ldots \ldots \ldots \ldots \ldots \ldots \ldots$

3. EXPERIMENTAL METHODOLOGY $\ldots \ldots \ldots \ldots \ldots \ldots \ldots \ldots \ldots$

4 EXPERIMENTAL RESULTS AND DISCUSSIONS $\ldots \ldots \ldots \ldots \ldots 11$

4.1. Transient Bubble Volume and Velocity Change in Two Dimensional Fluidized Beds ............................ 11

4.2. Transient Bubble Behavior in Coarse and Fine Particle systems in Two

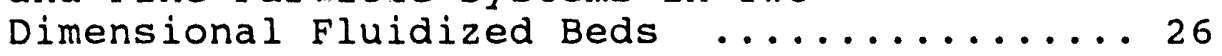

4.3. Bubble Behavior and Pressure Fluctuation in Two Dimensional

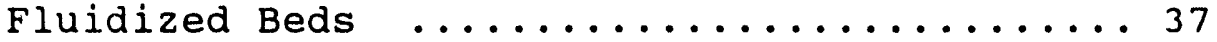

4.4. Correlation Analysis on Synchronized Bubble Image and Pressure Fluctuation .....5 53

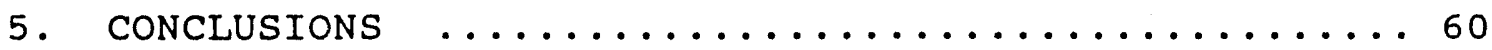

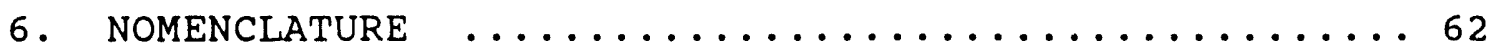

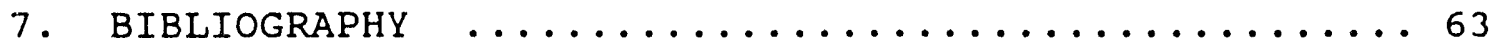




\section{LIST OF FIGURES}

Figure

Page No.

Figure 1. Experimental Apparatus $\ldots \ldots \ldots \ldots \ldots \ldots$

Figure 2. Schematic Diagram of the Experiment

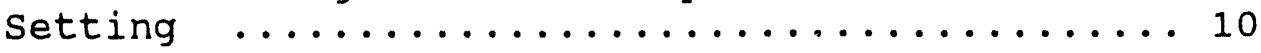

Figure $3(\mathrm{a})$. Bubble Velocity versus Time (Case 1a) .... 13

Figure $3(b)$. Bubble Velocity versus Time (Case 1b) .... 14

Figure $4(\mathrm{a})$. Bubble Velocity versus Time (Case 2a) .... 15

Figure $4(\mathrm{~b})$. Bubble Velocity versus Time (Case 2b) .... 16

Figure $5(\mathrm{a})$. Bubble Velocity versus Time (Case $3 a$ ) .... 17

Figure $5(b)$. Bubble Velocity versus Time (Case $3 b$ ) ... 18

Figure 6. Bubble Velocity versus Time (Case 4 ) ....... 19

Figure $7(a)$. Bubble Volume versus Time (Case 1a) ..... 20

Figure $7(b)$. Bubble Volume versus Time (Case 1b) ..... 21

Figure $8(a)$. Bubble Volume versus Time (Case $2 a$ ) ..... 22

Figure $8(b)$. Rlioble Volume versus Time (Case 2b) ..... 23

Figure 9. Bubble Volume versus Time (Case 3) ........ 24

Figure 10. Bubble Volume versus Time (Case 4) ....... 25

Figure 11. Bubble Volume Change (A Special Case) ..... 27

Figure 12. Schematic Diagram of Bubble Volume Change

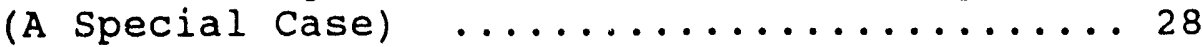

Figure 13.a Case 1 Series $1-1, \mathrm{~T}=0.000$ second $\ldots \ldots . .31$

Figure 13.b Case 1 Series $1-2, \mathrm{~T}=0.033$ second $\ldots \ldots \ldots 31$

Figure 13.c Case 1 Series $1-3, T=0.066$ second ...... 32 


\section{LIST OF FIGURES}

(Continued)

Figure

Page No.

Figure 13.d Case 1 Series $1-4, T=0.100$ second ..... 32

Figure 13.e Case 1 Series $1-5, T=0.133$ Second $\ldots \ldots . .33$

Figure 13.f Case 1 series $1-6, \mathrm{~T}=0.166$ second ...... 33

Figure 14.a Case 1 Series $2-1, \mathrm{~T}=0.000$ second ...... 34

Figure $14 . \mathrm{b}$ Case 1 Series $2-2, \mathrm{~T}=0.033$ Second $\ldots \ldots . .34$

Figure $14 . \mathrm{c}$ Case 1 Series $2-3, \mathrm{~T}=0.066$ second ...... 35

Figure 14.d Case 1 Series $2-4, \mathrm{~T}=0.100$ second ...... 35

Figure 14.e Case 1 Series $2-5, \mathrm{~T}=0.133$ second $\ldots \ldots . .36$

Figure 14.f Case 1 Series $2-6, \mathrm{~T}=0.166$ second ...... 36

Figure 15.a Case 2 Series $1-1, \mathrm{~T}=0.000$ second $\ldots \ldots . .38$

Figure 15.b Case 2 Series $1-2, T=0.033$ second $\ldots \ldots . .38$

Figure 15. C Case 2 series $1-3, T=0.066$ second ...... 39

Figure 15.d Case 2 series $1-4, \mathrm{~T}=0.100$ second ...... 39

Figure 15.e Case 2 Series $1-5, \mathrm{~T}=0.133$ second ..... 40

Figure 16.a Case 2 Series $2-1, \mathrm{~T}=0.000$ second ......4 4

Figure 16.b Case 2 Series $2-2, \mathrm{~T}=0.033$ second ......4 41

Figure 16.c Case 2 Series 2 - 3, $\mathrm{T}=0.066$ second ..... 42

Figure 16.d Case 2 Series $2-4, T=0.100$ second $\ldots \ldots . .42$

Figure 16. e Case 2 Series $2-5, \mathrm{~T}=0.133$ second $\ldots \ldots . .43$

Figure 17. a Case 2 series $3-1, \mathrm{~T}=0.000$ second $\ldots \ldots . .44$

Figure 1\% b Case 2 Series $3-2, \mathrm{~T}=0.033$ second $\ldots \ldots \ldots 44$ 


\section{LIST OF FIGURES}

(Continued)

Figure

Page No.

Figure 17. C Case 2 Series $3-3, \mathrm{~T}=0.066$ second ..... 45

Figure $17 . \mathrm{d}$ Case 2 Series $3-4, \mathrm{~T}=0.100$ second $\ldots \ldots .45$

Figure 18. Pressure Fluctuation $(0-2$ second $) \ldots \ldots \ldots$

Figure 19. Pressure Fluctuation $(2-4$ second $) \ldots \ldots \ldots 4$

Figure 20. Pressure Fluctuation $(4-6$ second $\ldots \ldots \ldots \ldots 48$

Figure 21. Pressure Fluctuation $(6-8$ second $) \ldots \ldots . \ldots 49$

Figure 22. Pressure Fluctuation $(8-10$ second $) \ldots . \ldots 50$

Figure 23. Pressure Fluctuation (10-12 second) ...... 51

Figure 24. Local Voidage versus Time $\ldots \ldots \ldots \ldots \ldots \ldots$

Figure 25. Pressure Fluctuation versus voidage ...... 55

Figure 26. Pressure Fluctuation $\ldots \ldots \ldots \ldots \ldots \ldots$

Figur 227. Pixel Definitions $\ldots \ldots \ldots \ldots \ldots \ldots \ldots \ldots$

Figure 28. Regular Bubble in Nearby Domain ......... 58 


\section{EXECUTIVE SUMMARY}

The objectives of this work was:

1) To characterize and recognize the capacitance image signals of transient motion of bubble (slug) in a three dimensional fluidized beds by synchronously measuring the transient gas phase pressure fluctuation in the same bed and also by taking the continuous video pictures of transient motions of bubbles and emulsion phases in two dimensional fluidized beds under the corresponding fluidization condition.

2) To measure the transient gas phase pressure fluctuation by synchronizing with the capacitance image recordings accomplished in the fluidized bed at METC.

3) To measure and analyze the transient gas phase pressure fluctuation in our (WVU) laboratory fluidized beds under the similar or corresponding fluidized bed conditions as METC's fluidized beds.

4) To record and analyze the transient bubble images and the emulsion in the two dimensional fluidized bed at our (WVU) laboratory under the wide range of fluidization conditions.

5) To interpret the bubble image generated with the capacitance method in three dimensional fluidized beds by using the transient gas phase pressure fluctuation signals and characterizing the transient bubble image obtained in two dimensional fluidized beds.

The significance of this approach is 1 ) to recognize the transient behavior of bubble (slug) in terms of transient gas phase pressure fluctuation, which can quantitatively and more easily be expressed in a form of digital numbers, and 2) to record the continuous motion video pictures of transient bubble motion in two dimensional fluidized beds.

From the first approach it was found that the capacitance voidage images obtained by METC's capacitance method (substantially the bubble image) has some correlation with the transient gas phase pressure fluctuation but with a meaningful scattering, which will be interpreted later, comprehensively together with the transient bubble motion.

From the second approach we came to the following basic experimental finaings. Namely the transient bubble behavior in a 
freely bubbling fluidized beds was fourd to be considerably different from the classical theory of fluidization developed by Davidson (1963).

In addition to the reported bubble flow mechanisms of splitting and coalescence, there are several other mechanisms in parallel, e.g., the bubble disappearance into the emulsion phase, the bubble reappearance from the emulsion phase, and the abrupt transient change of the size and shape of bubbles.

It is important to understand that those newly found disappearance and reappearance mechanisms and already known splitting and coalescence mechanisms are coexisting in parallel simultaneously in the fluidized beds.

These new findings can be explained by a newly developed "Powder Structure Model" by Kono et al. (1992).

As a conclusion, the experimental fact shows that ther 2 is a considerable gas phase abrupt transient exchange between the bubble and emulsion phase, and that the transient local voidage of the emulsion phase is not at all constant, but varies transiently in a wide range, e.g., in the range of $25-458$ possibly (Kono et al. 1992).

Based upon our work in this project, the following accomplishments of new findings have been achieved.

1) From the two dimensional fluidized beds it was found that there are several bubble flow mechanisms in freely bubbling fluidized beds. Namely, the mechanism of bubble disappearance and reappearance into and from the emulsion phase, do actually exist in addition to the known splitting and coalescence mechanisms.

2) There is some correlations between the bubble images (from capacitance signal obtained in three dimensional fluidized beds) and transient gas phase pressure fluctuation with the meaningful scattering. These experimental results of the meaningful scattering can be explained by the above mentioned simultaneously coexisting bubble flow mechanisms in fluidized beds.

3) The bubble rising velocity and the bubble volume change during the passage of the emulsion phase were also found to be very transient. It seems that there are many types of bubble flow mechanisms coexisting simultaneously in freely butbling fluidized beds. 
4) The general tendency of transient behavior of bubbles was found to be approximately identical both for fine powder (FCC) fluidized beds and coarse particle ( $1 \mathrm{~mm}$ glass beads) fluidized bed in view of the bubble flow mechanisms.

5) There are the significantly rapid transient gas phase exchanges between the emulsion phase and gas phase. Accordingly the voidage of the emulsion phase should transiently change. 


\section{TECHNICAL BACKGROUND}

Since 1960's many papers have been published on the behavior of bubbles in fluidized beds. Most fundamental and pioneering papers are probably these of Davidson and Rowe, who developed the fundamental of classical fluidization theory ili 1960's. Since then the bubble motion and bubble properties (size, shape, cloud, wake, etc.) in fluidized beds have been investigated very intensively.

However, these researchers investigated mostly the steady state behavior of the bubble and only a few studies have been conducted for the unsteady transient motion of the bubble. Their focuses were mostly on the behavior of bubbles injected into the incipient fluidized beds. The bubble motion under the incipient fluidization was found to be steady. Accordingly the properties of fluidized beds were understood by the so-called two phase flow model of fluidization. It was supposed that the fluidized bed consists of "bubble phase" and "emulsion phase". Furthermore, a hypothesis was introduced by making the analogy of the gas-liquid two phase flow, which defined the bubbles and emulsion phases. Thus, it assumes that the bubble has practically no particles in it and the emulsion phase maintains the constant voidage equivalent to that of packed bed at minimum fluidization velocity. These were the basic assumptions of classical fluidization model.

When a bed of particles is fluidized at a gas velocity much higher than the minimum fluidization, then a freely bubbling fluidization occurs. In this freely bubbling fluidization, there are a lot of transient behaviors of bubbles occurring. Rowe et al. (1962) pointed out the significance of the transient behavior of bubble's shedding but the actual experimental results did not follow. Unfortunately, the above classical fluidization concepts of bubble behavior defined at the incipient fluidization were introduced to the freely bubbling fluidized bed without much deliberate consideration. Even recent review paper (Clift and Grace 1985) still kept maintaining the above classical understanding.

In three dimensional fluidized beds the transient motion of bubbles becomes very much enhanced at high gas velocity particularly in coarse particle fluidized beds, in which the past observation could have only been accomplished by using $x-r a y$ without much success due to its limitation of $x$-ray intensity.

Recently, Hallow et al. (1989) made an experimental break-through 
by developing an observation method for the transient bubble motion by using a capacitance imaging method. Their data provided the transient bubble images in three dimensional fluidized beds for the first time in the open literature. The experimental results using capacitance imaging in fluidized bed in METC/DOE by Halow et al. (1991) showed the transient voidage change of the emulsion phase and bubbles.

To help understand the transiently changing capacitance bubble images, we started measuring the transient gas pressure fluctuation (Kono et al. 1987, 1988, 1989). We found that there are very intensive transient gas phase pressure fluctuation, which could not be explained by using the classical two phase flow model.

A new video approach was developed and initiated in our lab in a two dimensional fluidized bed (Kono et al. 1991). We observed the bubble transient motion in this two dimensional fluidized bed. The bubble coalescence and splitting are very active at high superficial gas velocity. The advantage of the utilization of two dimensional fluidized beds is that the actual bubble images can directly be obtained by using a relatively simple video equipment. Although the two dimensional fluidized bed's fluidization is different from three dimiisional, still it is very convenient to understand the fundamental mechanism.

Accordi:, to our recent finding, the emulsion phase's voidage can transiently change over a wide range. The maximum voidage of the emulsion phase can transiently be much higher (Kono et al. 1992) or can transiently be much lower. 


\section{EXPERIMENTAL METHODOLOGY}

The following approaches were developed and used.

1). Recognition of Transient Bubble Motions in Three Dimensional Fluidized Beds.

Now the only available method to investigate the transient motion of bubbles for three dimensional fluidized beds is the capacitance method developed by Hallow et al. (1989). When two dimensional fluidized bed is used, the intrinsic transient bubble motion may be affected more or less due to the enhanced wall effect.

2). Recognition of Transient Bubble Motions in Two Dimensional Fluidized Beds.

For the systematic study of bubble image, together with transient forces of solid particles and gas pressure fluctuation, two dimensional fluidized bed has its advantages. It is easy to record the transient motion of bubbles, and provides direct, first hand images. Similar bubble image can be collected together with force and pressure signals. The collection of continuous images can provide reliable information. We also observed the transient change of bubble size and shape together with the transient bubble rising velocity. Using the video recorded image, a very detail observation of transient changes of bubble size and shape was accomplished. Particularly the bubble size changes during coalescence and/or splitting were oiserved. The transiently changing bubble rising velocity was also measured by the video display. As will be described in the following chapters, various bubble flow mechanisms were recorded, e.g., coalescence, splitting, appearance, disappearance, etc..

Some details can be observed thiough enlarged video images. For example, the bubble coalescence can be observed to the particle level, i.e., the particle motion inside the bubble can be observed. Another example is that some transient gas channeling channels between two bubbles was also observed.

\section{3). Bubble classification}

\section{3. a) In three dimensional fluidized beds}

In the capacitance method the bubble behavior is expressed by the voidage change of the specific local volume element. Voidage data of cells and levels are recorded in computer. With the help 
of the computer graphics image, the recorded bubble behavior can be re-displayed and studied. A proper classification of the emulsion phase and bubble phase was necessary, on which only very few papers were published.

We defined the property of the emulsion phase with much higher voidage than that of packed bed as "pseudo-bubble". We classified these pseudo-bubbles into two classes by tileir voidage; regular bubbles have the voidage range above 0.74 , type $A$ pseudo-bubbles in the voidage range of 0.74-0.65, and type $B$ pseudo-bubbles in the voidage range of $0.65-0.60$. Based upon the above definition, the transient behavior of the emulsion phase (pseudo-bubbles) could also be characterized in a similar way.

\section{3.b) In two dimensional fluidized beds}

In two dimensional fluidized beds, the voidage of emulsion phase near the bubble can sometimes be recognized by changing the contrast and brightness of video display. The recognition of type $A$ and $B$ Pseudo-bubbles could sometimes be observed.

\section{4). Bubble Images in Coarse and Fine Particle Systems}

The transient behavior of bubbles was investigated in two dimensional fluidized beds, using two different fluidized particles.

The fluidization phenomena of Powder Type $A$ and $B$ is very significantly different, whereby the type A, B, C powder were defined by Geldart (1973).

In this project, two particles, ramely FCC powder (Fluid Catalytic Cracking catalyst, mean diameter 70 microns, type $A$ powder) and Glass Beads (mean diameter 1000 microns, type B powder) were used as fluidized particles.

The effect of fluidized particle size on the bubbling phenomena was investigated also by many researchers but the conclusions contradict each other. Further the published data were mostly concerning with the mean diameter of bubble and not directly relating to the transient behavior. Qualitatively speaking, their conclusion was that the finer the fluidized particle size, the smaller the bubble size, the more stable the fluidization. This general rule of thumb seems to hold true. Therefore we used FCC and glass beads as representative sample powders of fine and coarse. 
The transient motion of bubbles was recorded by video camerarecorder (RCA model CC510) at the time interval of 0.033 second. The light resources were controlled as shown in Figure 1 . The video images were taken by camera as pictures and also scanned by PC as Computer Graphics Pictures.

\section{5). Recognition of Transient Gas Pressure Fluctuation}

Although the measurement methods of transient gas pressure fluctuation have already been developed (Kono et al. 1990), these methods were directed to measure the peaks of the forces. Now a recognition of transient gas pressure fluctuation should be developed to characterize the transient motions of bubbles. The characteristics of transient gas phase pressure fluctuation could be expressed by peaks, frequencies, intensity distributions, etc.

Even though the fluidization condition in two and three dimensional fluidized beds is different from each other, the correlations between transient bubble images and transient gas phase pressure fluctuation signals should be corresponding in both cases. We developed a video approach to study the transient force signals as well as the bubble images in a two dimensional fluidized bed. We intended to correlate the transient forces of solid and gas directly to the bubble image in terms of video displays (not by indirectly using the voidage signals).

A multiple data taking system was established, and three signals (displays) were synchronized by using TTL trigger signals. This new approach provides an efficient way for a systematic correlation among the transient motion of gas bubble, and transient gas pressure fluctuation. The schematic diagram of the experiment setting is shown in Figure 2. We successfully synchronized the transient gas pressure fluctuation signals with the bubble image in video displays. The transient gas pressure fluctuation signals were obtained by a computer data acquisition system, and the video images were recorded by a video recorder. A timer was associated with the video display. A trigger signal started the timer, and simultaneously set a starting point for the computer data acquisition system. By doing so, we could obtain the video picture in every 0.033 seconds, together with the synchronized transient gas pressure fluctuation data. 


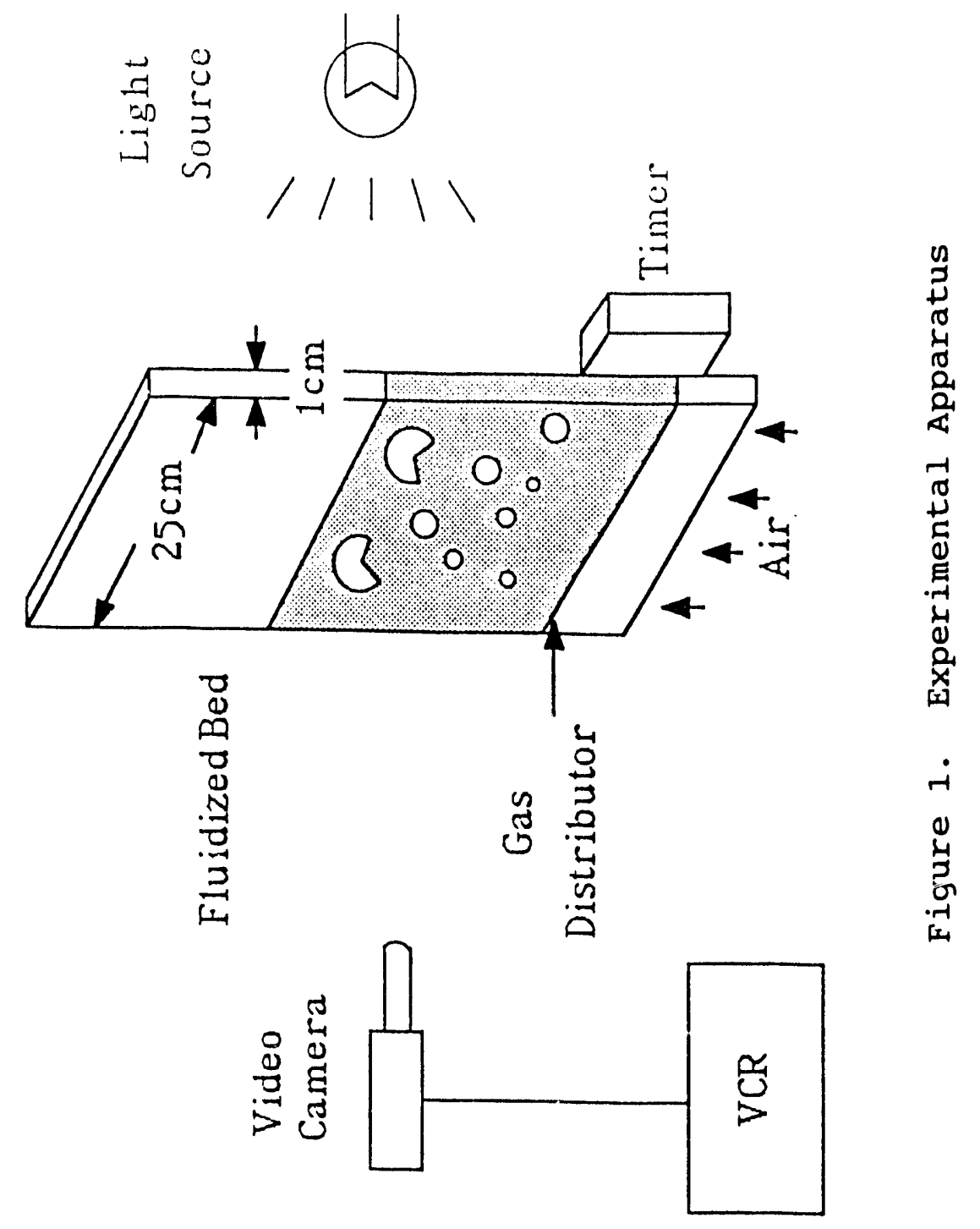




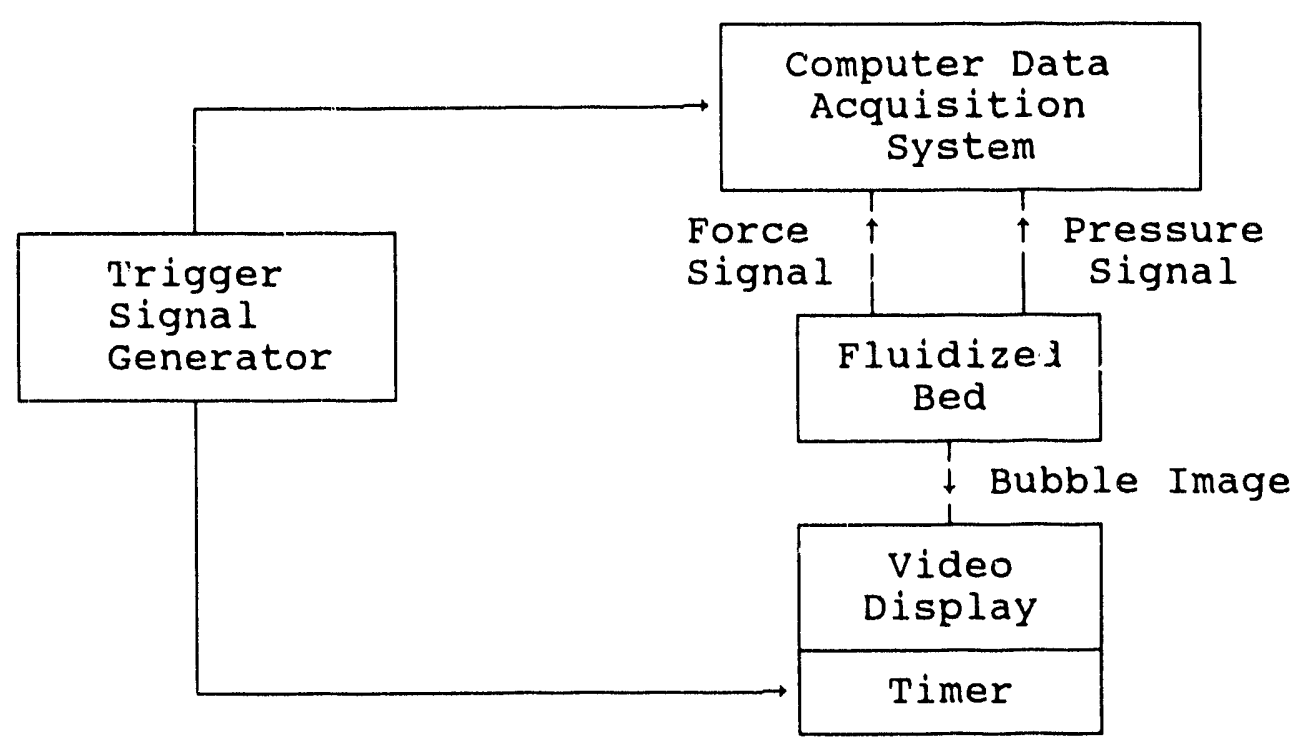

Figure 2. Schematic Diagram of the Experiment setting 


\section{EXPERIMENTAL RESULTS AND DISCUSSIONS}

4.1. Transient Bubble Volume and Velocity Change in Two Dimensional Fluidized Beds

Systematic experiments were carried out to investigate the bubble behavior in a two dimensional fluidized bed. The experiments were focused on the following aspects:

1) The transient velocities of the ahead-going (or leading) bubble and the following (or approaching) bubbles before and after the coalescence were observed by the video recording system.

2) The transient volume changes of bubbles at the corresponding time were also simultaneously recorded.

A schematic diagram of the experimental apparatus is shown in Figure 1 (on page 8). A two dimensional fluidized bed, made of plexi-glass ( $1 \mathrm{~cm}$ depth $\times 25 \mathrm{~cm}$ width $\times 75 \mathrm{~cm}$ height), was used. A sintered porous metal plate was used for the gas distributor. spherical glass beads (particle size $1 \mathrm{~mm}$, particle density 2.49 $\mathrm{g} / \mathrm{cm}^{3}$ ) were used as fluidized particles. The fluidization velocity was maintained in the range of $U_{0} / U_{m f}=1.62-2.17$. The minimum fluidization velocity of the glass beads used was $0.46 \mathrm{~m} / \mathrm{sec}$. The bed aspect ratio (bed height/bed width) was kept at unity.

The video camera-recorder (RCA Model CC510) was used to continuously record the motion of bubbles in fluidized beds. The motion was recorded at the time interval of 0.033 seconds.

The bubble motion in the video display showed a great discrepancy against the classical theory. Bubble size was not at all constant, the direction of bubble movement changed frequently, and bubbles were shedding, twisting, splitting and coalescing. These phenomena indicated a complicated mechanism of the transient bubble behavior. Results are summarized as below.

1) Transient Bubble Velocity Change Before and After the Coalescence

The bubble velocity's transient changes around the two bubble's coalescence were systematically investigated by changing the gas velocity.

As the bubble coalescence is to be affected by the adjacent bubbles (Orcutt and Capenter 1971; Allahwala 1975; Singh 1970 and Grace et 
al. 1974), the relative position of interacting bubbles was intentionally varied.

The transient changes of bubble velocities were shown in Figures 3 , 4,5 and 6 . Figures 3, 4, 5(a) and 6 show the bubble velocity's transient changes at various combination of two adjacent bubbles at $U_{\mathrm{o}} / U_{\mathrm{mf}}=2.17$. Where $U_{\mathrm{o}}$ is the superficial gas velocity and $U_{\mathrm{mf}}$ denotes the minimum fluidization velocity. Figure 4 (b) only shows the same transient changes at $U_{0} / U_{m f}=1.62$. From these results, we could understand that there were no single but several mechanisms of bubble coalescence, which coexist in the same fluidized bed.

On the contrary to the past reported results, the bubble rising velocity was not simply a function of bubble diameters. The bubble velocities were transiently changing in the range of $20-100$ $\mathrm{cm} / \mathrm{sec}$. This is not due to the experimental error but due to the stochastic and transient characteristics of bubbling phenomena.

only one systematic tendency is that the following (or approaching) bubble accelerates itself and catches up the aheadgoing bubble.

When we define the "catch-up time" $T_{c}$ as the time necessary to coalescence the two bubbles after the velocities of the two bubbles get the same, $T_{c}$ was in the range of $0.06-0.145$ seconds. The maximum bubble velocity sometimes reached $1.0-1.2 \mathrm{~m} / \mathrm{sec}$.

From these results it seems that the bubble coalescence phenomena were really transient and stochastic.

\section{2) Transient Bubble Volume Change Before and After the Coalescence}

According to the classical theory of fluidization (e.g., Davidson 1963), the total volume of bubbles participating before and after the coalescence should remain the same. This mass balance concept of bubbles, which holds true only in case of the gas-liquid systems, did not hold true under the fluidization condition of gassolid system accomplished in this study, as shown in Figures 7,8 , 9 and 10. The total volume of two interacting bubbles keeps increasing in Figures 7 and 8 . On the contrary, the total volume of bubbles keeps decreasing in Figure 9 and constant in Figure 10.

These results indicated that there were several bubble growth mechanisms which could coexist in the same way described in the preceding section with respect to the bubble velocity.

It should be stressed that such monotonically increasing bubble 


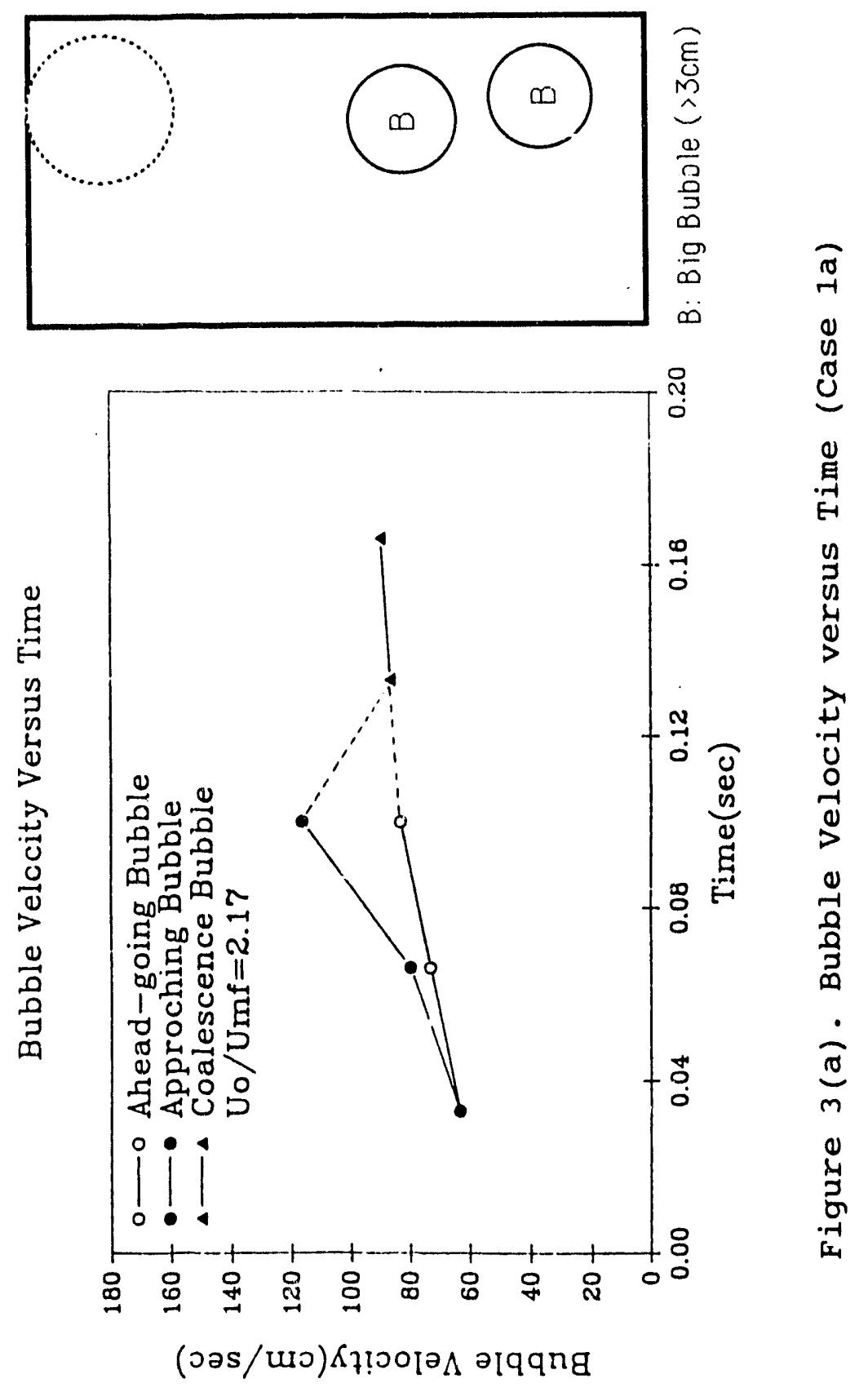



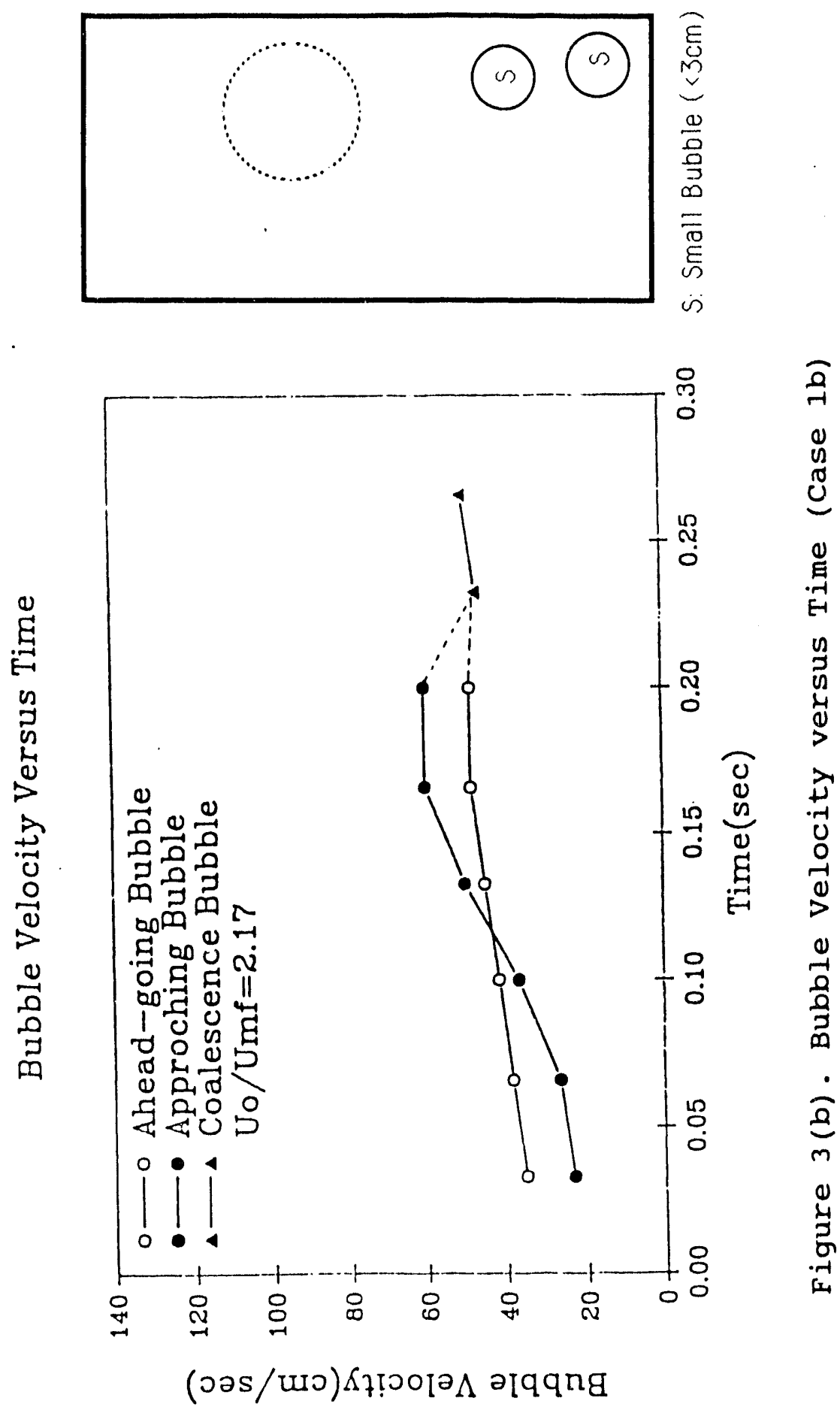


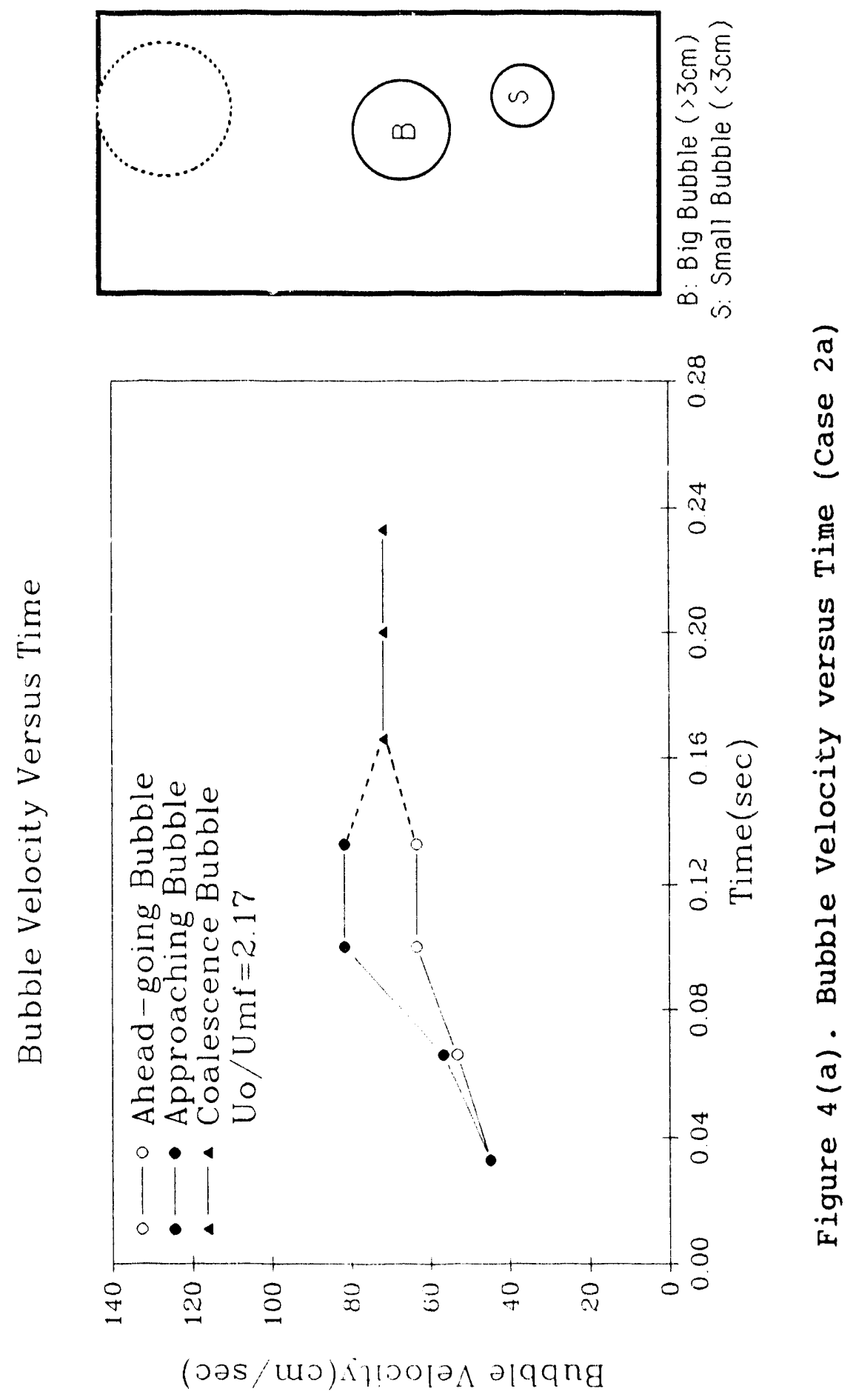




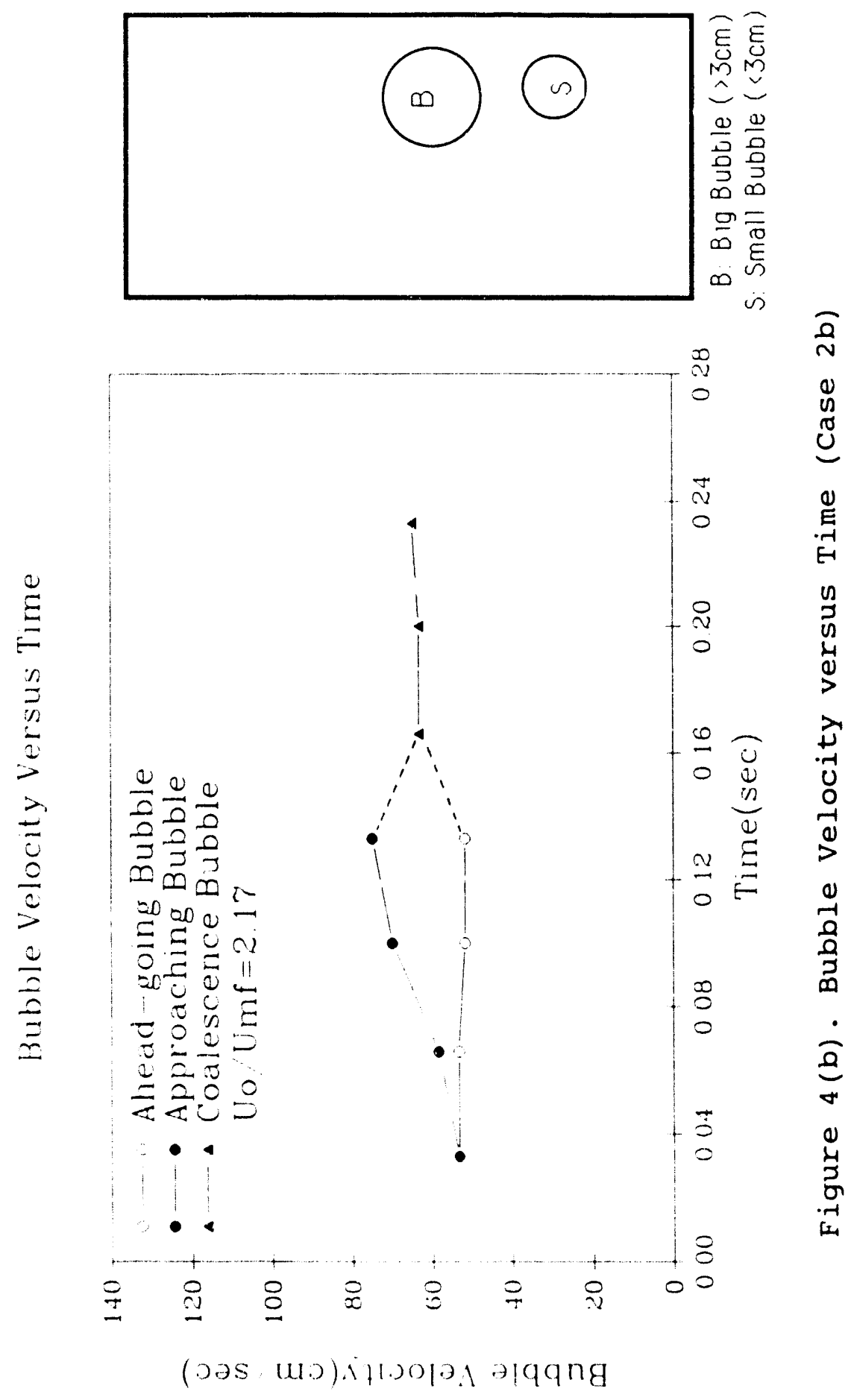




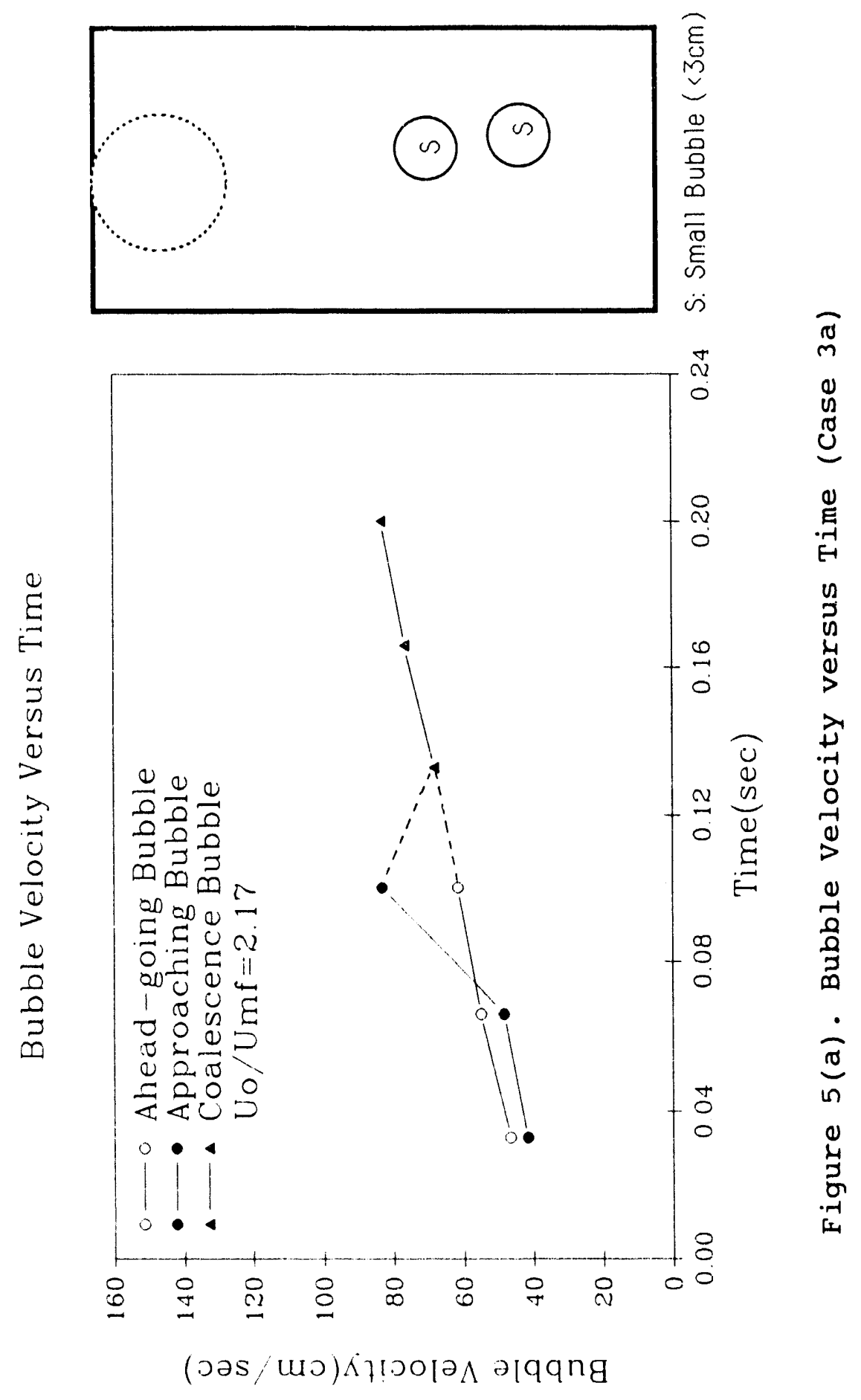








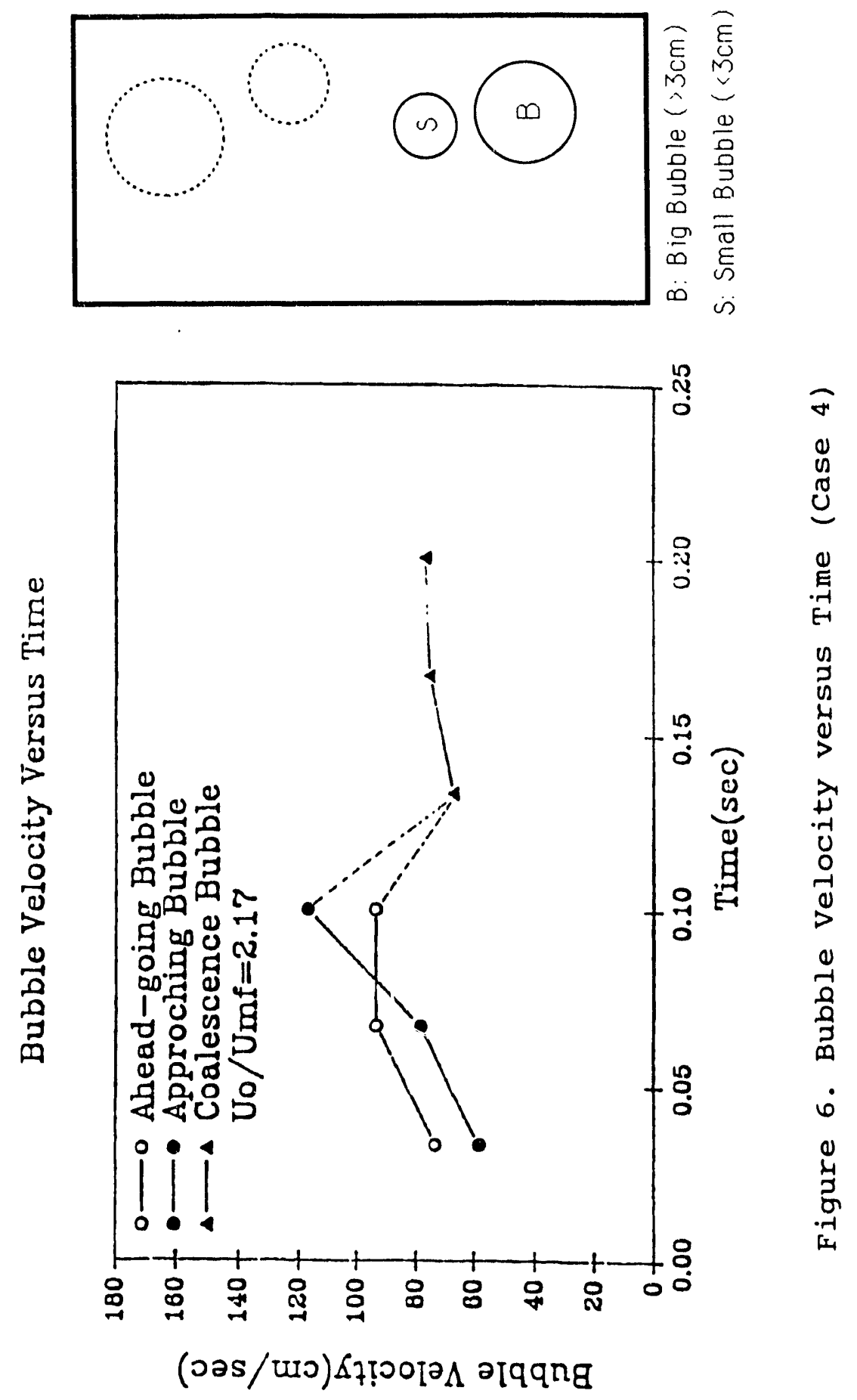


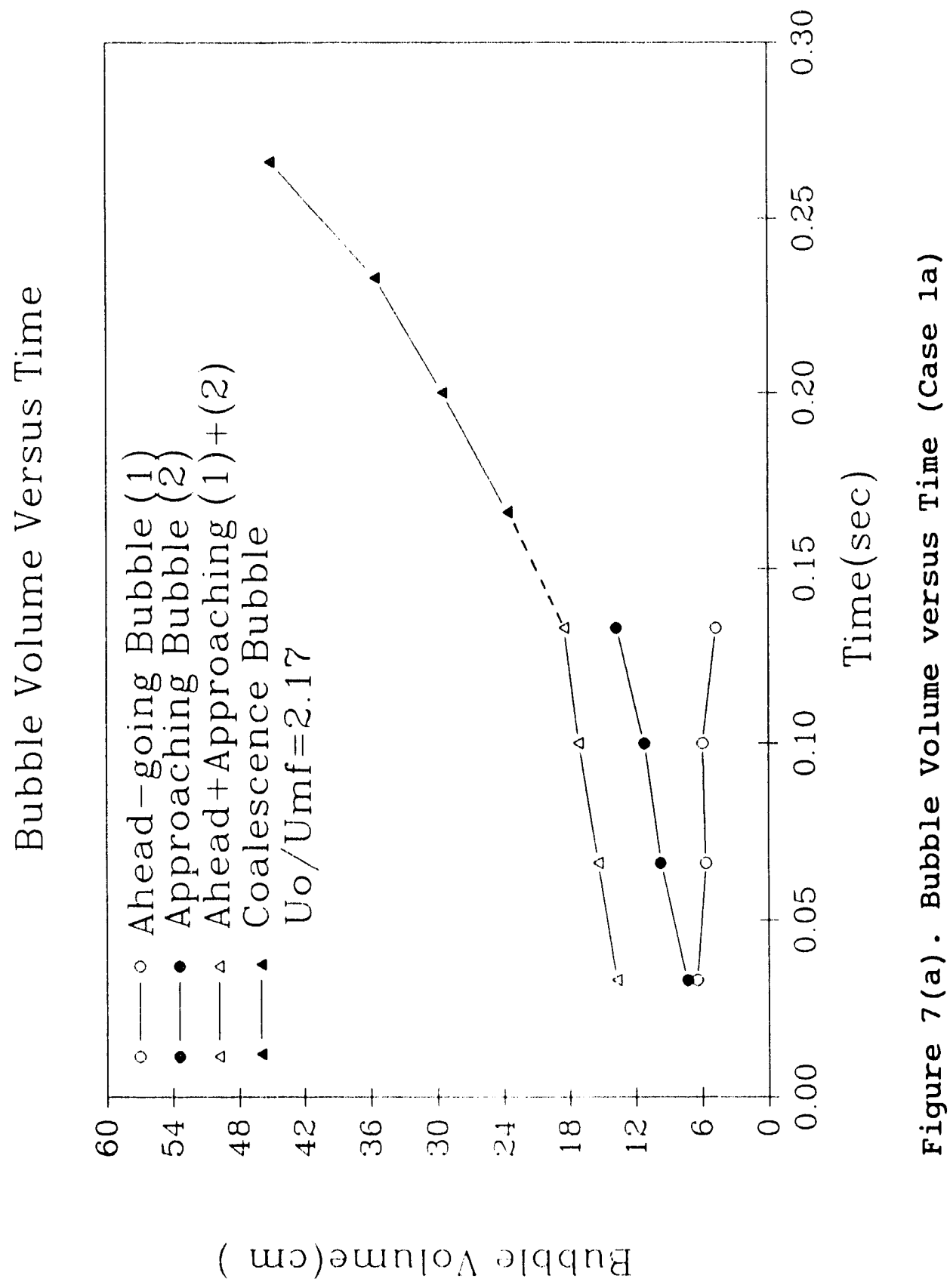




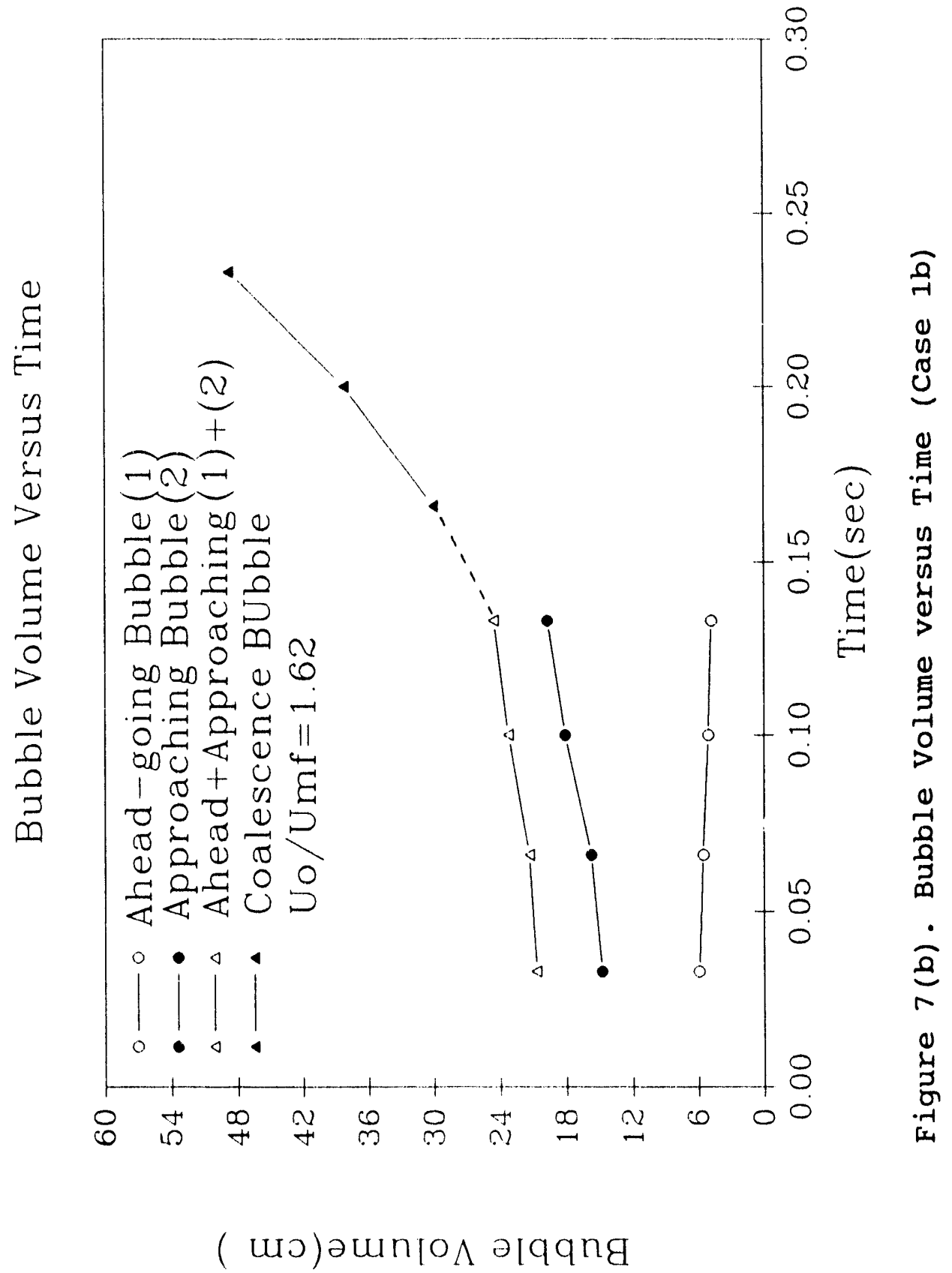




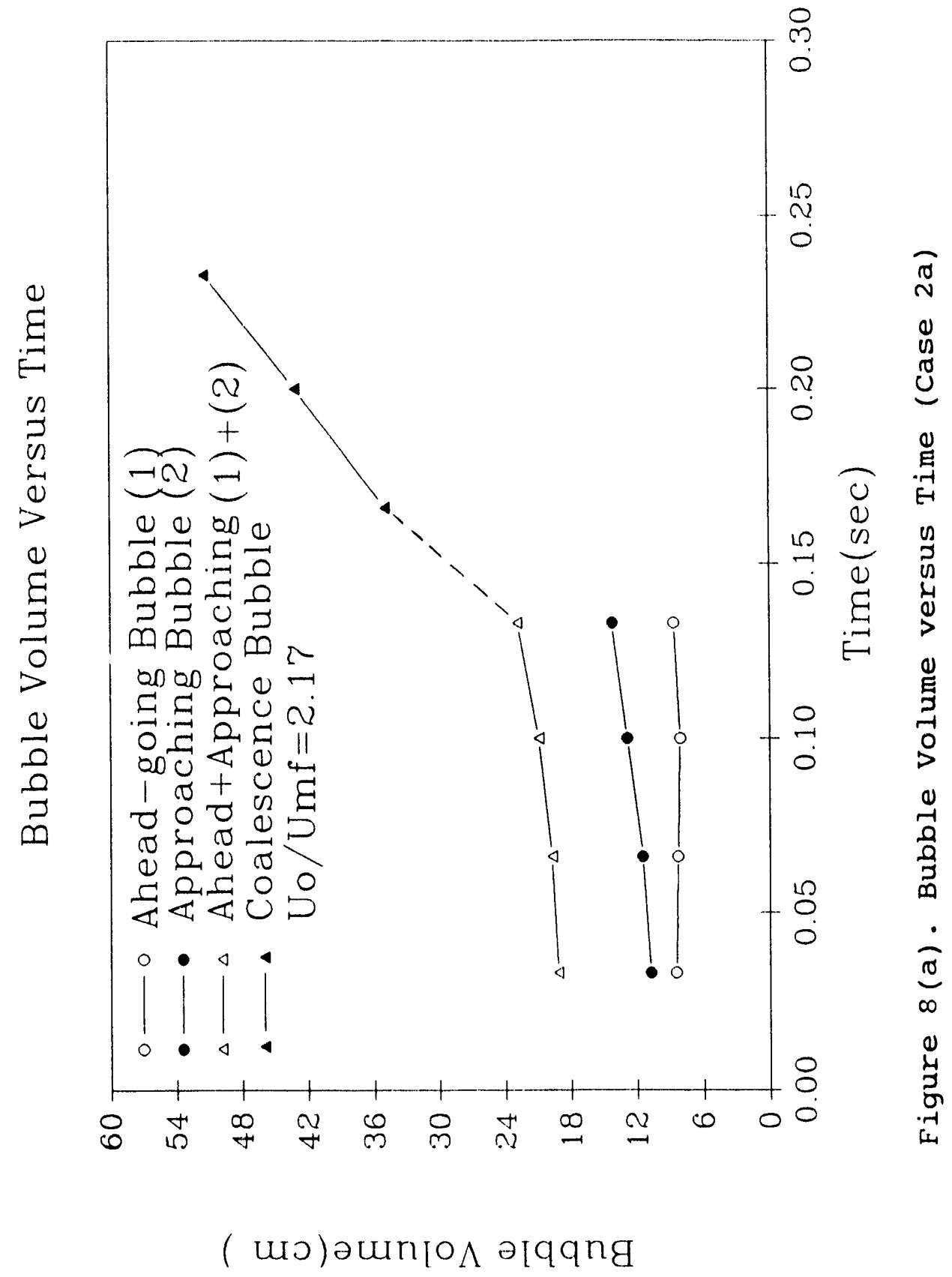




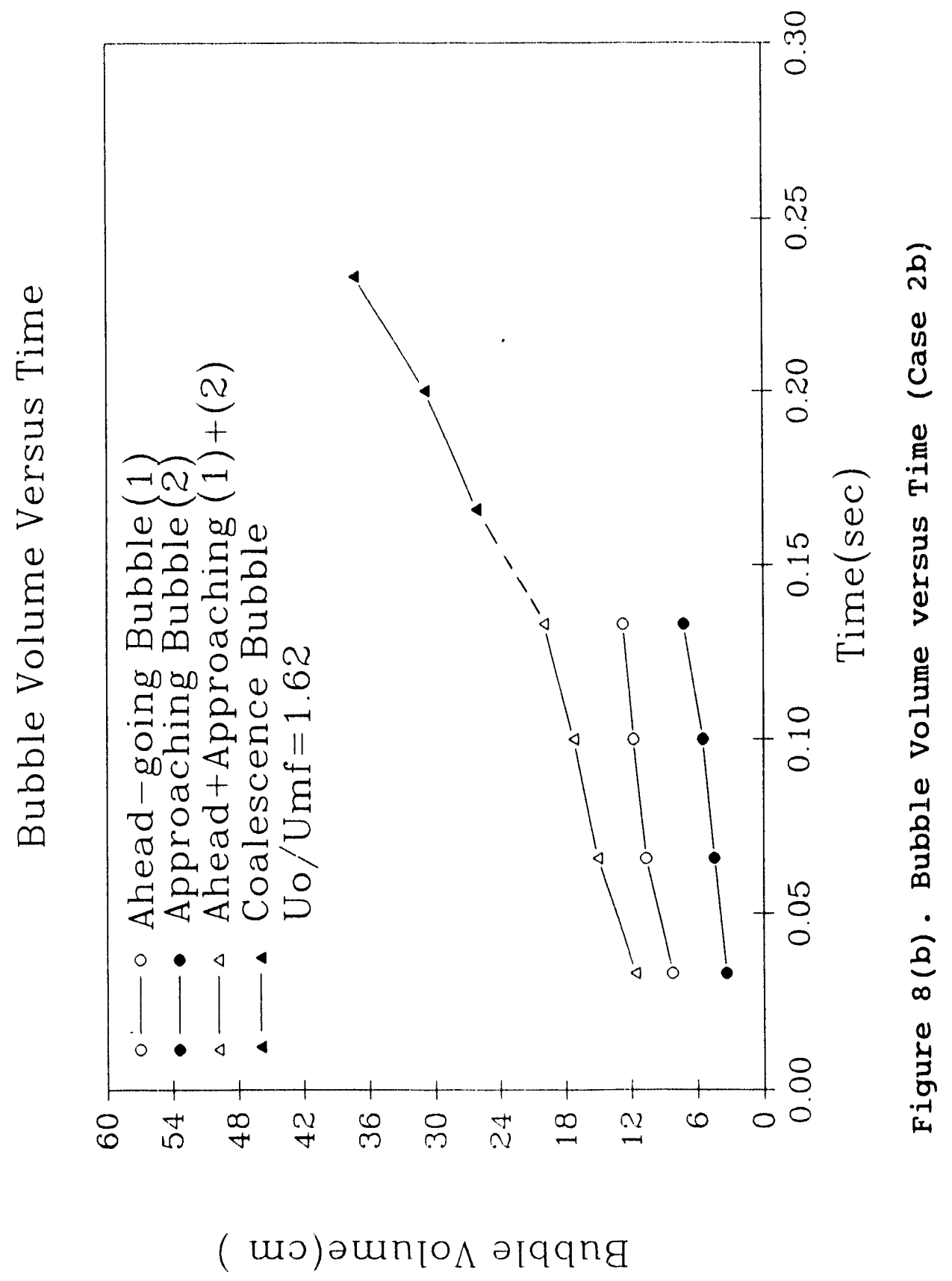




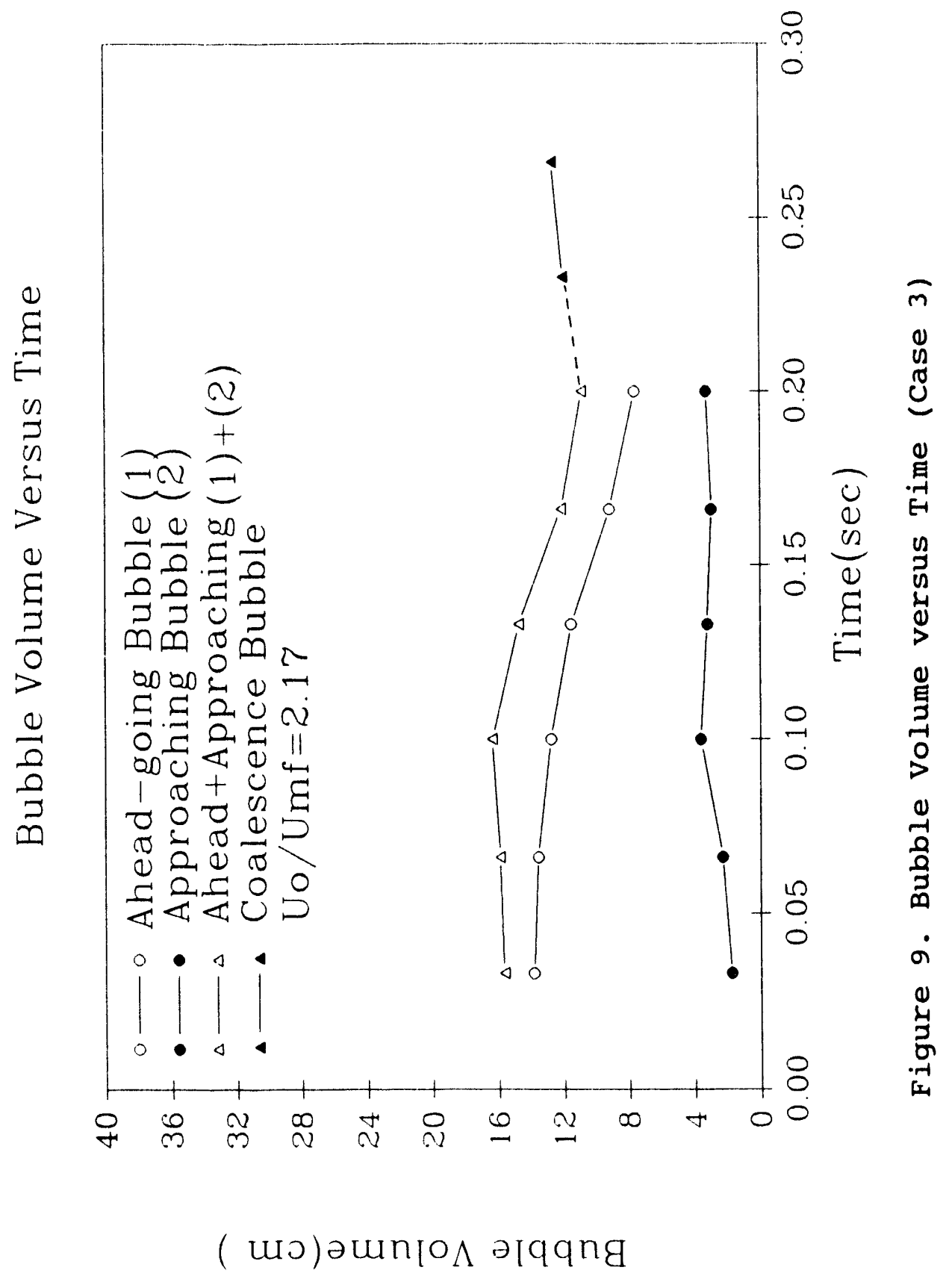




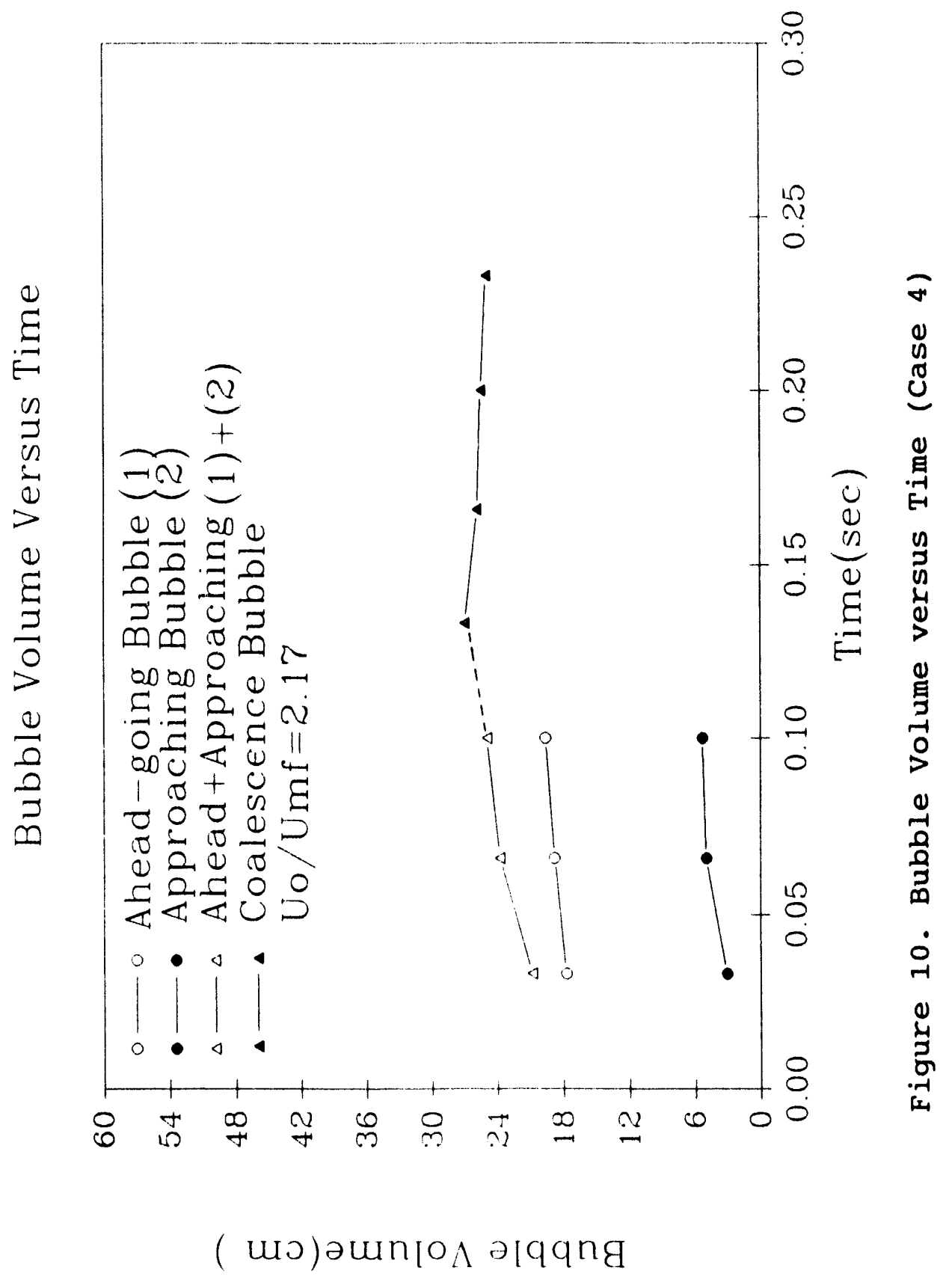


volume was not caused by another secondary coalescence. To explain this phenomenon, we have to admit that there should be a significant flow of gas sometimes from the emulsion phase into the bubble phase, sometimes in the reverse direction, and sometimes no substantial bulk flow. The interesting phenomena to be stressed were the interaction of two bubbles before coalescence in Figure 7 , 8 (a) and 9. On the other hand, there was no substantial interaction between bubbles in cases of Figure $8(b)$ and 10 .

\section{3) Transient Bubble Volume Decrease by splitting}

Although the occurrence of the phenomena was not much frequent, a bubble with the volume of $5.5 \mathrm{~cm}^{3}$ can disappear in 0.5 second as shown in Figure 11 and 12. As schematically shown in Figure 12, that bubble behaves as if it exploded and disappeared in the emulsion phase.

4.2. Transient Bubble Behavior in Coarse and Fine Particle Systems in Two Dimensional Fluidized Beds

The transient behavior of bubbles was investigated in both coarse and fine particle systems in two dimensional fluidized beds. Two particles, namely FCC powder (Fluid Catalytic cracking catalyst, mean diameter 70 microns, type $A$ powder) and Glass Beads (mean diameter 1000 microns, type B powder) were used as fluidized particles.

Because the bubble mean diameter for the fluidization of glass beads was much larger than $10 \mathrm{~mm}$, the fluidized bed with the size of $10 \mathrm{~mm}$ (depth) $\times 250 \mathrm{~mm}$ (width) X $250 \mathrm{~mm}$ (height) was used. For the fluidization of FCC powders, fluidized beds with the size of 3 to $10 \mathrm{~mm}$ (depth) X $250 \mathrm{~mm}$ (width) X $375 \mathrm{~mm}$ (height) were tested. The fluidized bed with the depth of $3 \mathrm{~mm}$ was found to be appropriate to observe the transient behavior of small bubbles generated at the fbuidization of FCC.

The fluidization conditions of the tests are summarized as follows:

Case 1. When glass beads are fluidized:

Bed aspect ratio:

Bed height:

Gas velocity:

Minimum fluidization velocity:

$$
\begin{aligned}
& \mathrm{H} / \mathrm{D}_{1}=1 \\
& \mathrm{H}=250 \mathrm{~mm} \\
& \mathrm{U}_{0} / \mathrm{U}_{\mathrm{mf}}=1.79 \\
& \mathrm{U}_{\mathrm{mf}}=0.46 \mathrm{~m} / \mathrm{s}
\end{aligned}
$$




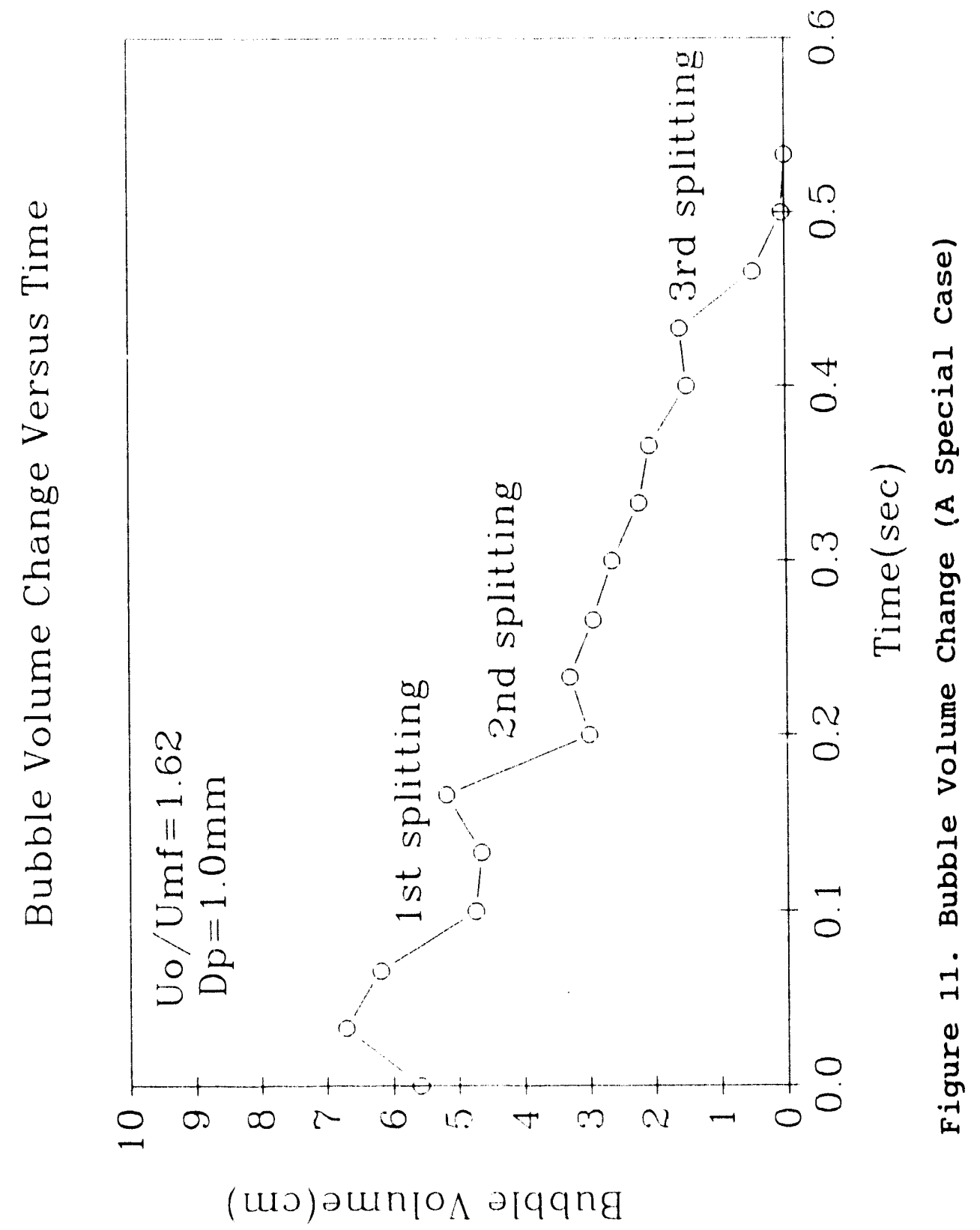




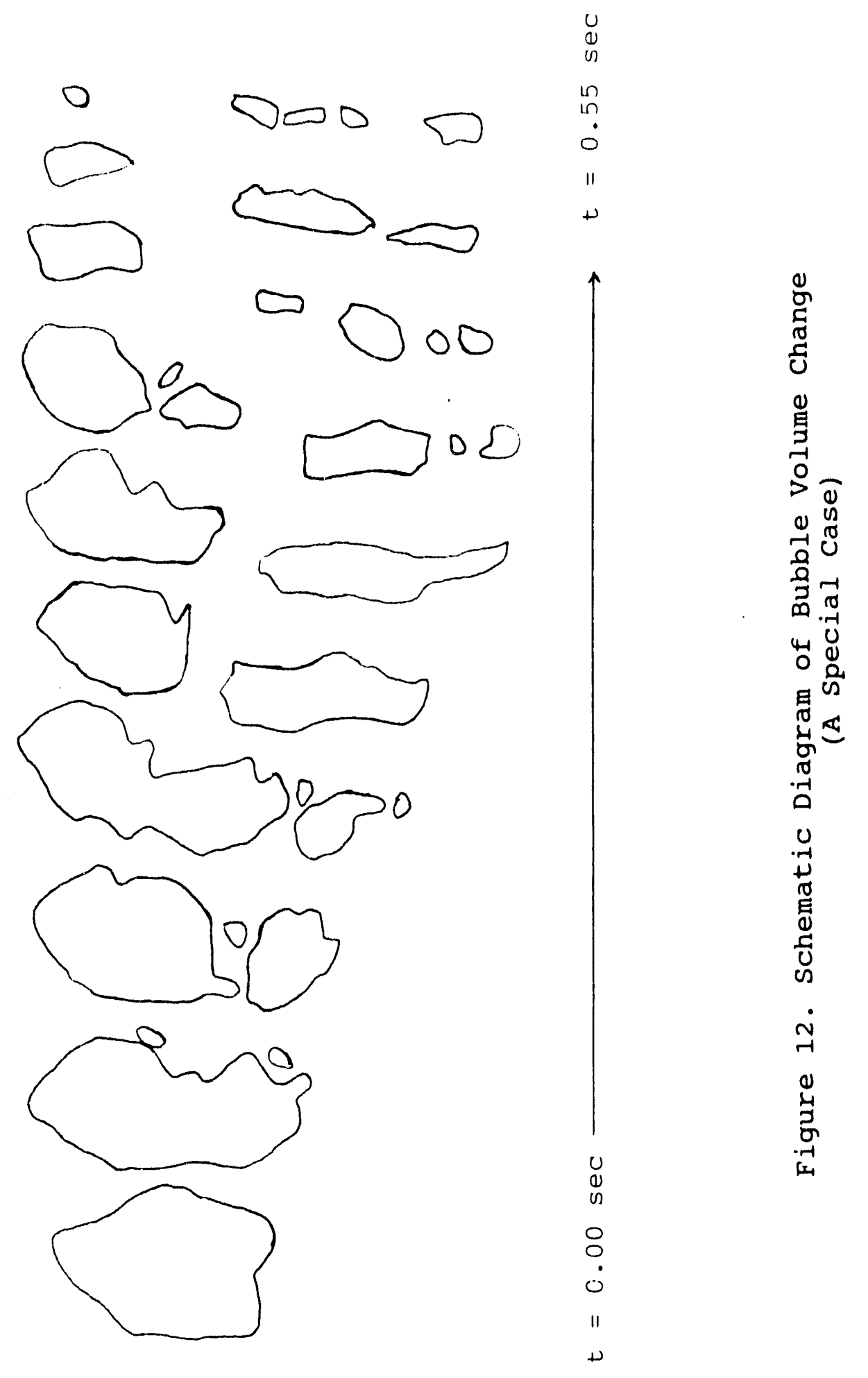


Case 2. When FCC pr,wlers are fluidized:

Bed aspect ratio:

Bed height:

Gas velocity:

Minimum fluidization velocity:

$$
\begin{aligned}
& \mathrm{H} / \mathrm{D}_{1}=1.5 \\
& \mathrm{H}=375 \mathrm{~mm} \\
& \mathrm{U}_{0} / \mathrm{U}_{\mathrm{mf}}=11.4 \\
& \mathrm{U}_{\mathrm{mf}}=0.007 \mathrm{~m} / \mathrm{s}
\end{aligned}
$$

The transient motion of bubbles was recorded by a video camerarecorder ( $R C A$ model CC510) at the time interval of 0.033 second. The light resources were controlled as shown in Figure 2 (on page 8). The video image was taken by camera as Pictures and also scanned by PC as Computer Graphics Pictures.

In freely bubbling fluidized beds, the transient behavior of bubbles were recorded and shown as pictures here. Two cases of the transient motion of bubbles in the bed using coarse spherical glass bead particles $\left(d_{p}=1 \mathrm{~mm}\right)$ are shown. Three cases of those using fine FCC particles $\left(d_{p}=65 \mu\right)$ are also illustrated (Figures 13 through 17) .

In these series of experiment, we first focused our attention on the transient changes of bubble shapes, bubble sizes and splitting and coalescence. To our surprise, the disappearance and reappearance of bubbles from or into the emulsion phase did unexpectedly happen in addition to the known bubble flow mechanism of splitting and coalescence.

These observation results lead us to the following discussion: There should be sjgnificantly transient gas exchanges between the bubble phase and emulsion phase in fluidized beds. These recently found experimental results are inconsistent with the classical fluidization of Davidson et al. (1963) and Rowe et al. (1965).

To understand these new findings, we have to improve or overcome the hypothesis of classical two phase flow of fluidization. Particularly, the hypothesis that the voidage of the emulsion is constant and uniform, seems to be unrealistic. According to the new particle packing model proposed by Kono et al. (1992), it seems that the emulsion phase voidage can be significantly changing during the dynamic fluidization conditions. Namely, the time averaged voidage (or porosity) of the emulsion phase may remain approximately the same, but the voidage should be changing transiently with respect to time and location in the range of $25-$ 49\%, assuming a uniform sized fluidized particles. 
1). Case 1: Transient Behaviors of Bubbles in Freely Bubbling Fluidized Beds with Coarse Particles (glass bead, $d_{p}=1 \mathrm{~mm}$ )

Figures 13.a through $13 . \mathrm{f}$ show a series of pictures with a time interval of 0.033 seconds. The series of pictures show two types ofi transient motions of bubbles. On the left hand side of each picture, the coalescence of bubbles was occurring. On the right hand side, an example of a bubble disappeared into the emulsion phase is shown. In this disappearance case, the bubble with the size of $45 \mathrm{~mm} \times 25 \mathrm{~mm}$ could practically disappear in 0.133 seconds into the emulsion. From the picture, we could clearly identify that the phenomenon was neither coalescence nor splitting but disappearance of the bubble into the emulsion phase.

Figures 14 .a through 14 .f show another series of pictures with time interval of 0.033 seconds. The pictures also show the coalescence phenomena on the left side and disappearance on the right side of each picture.

However, the disappearance of the bubble was to some extent associated with the splitting at the first three pictures (Figure $14 . a, b$, and $c$, time span 0.066 second), then the typical disappearance of bubble into the emulsion phase took place in the following 0.066 second.

Both picture series of Figure 13 (a through $f$ ) and Figure 14 (a through $f$ ) show that the well known bubble coalescence, splitting and disappearance (and also bubble size change) were taking place simultaneously. We should recognize these types of bubbling phenomena consist of multi-bubble flow mechanism and it is not at all as simple as described in the classical theory of two ihase flow. The bubble size could sometimes change significantly in the time grid of 0.033 second for all the bubbles in the pictures, but sometimes not really. The voidage of emulsion phase seems to be transiently changing as shown in Figures 14 .a through 14. C.

2). Case 2: Transient Behaviors of Bubbles in Freely Bubbling Fluidized Beds with Fine Particles (FCC, $d_{p}=65 \mu$ )

Three kinds of series are shown in this case. The transient changes of bubble was found to be more or less the same tendency as those of coarse particle fluidized beds (as discussed in Case 1). Namely, the well known coalescence and splitting took place, and the disappearance and reappearance of the bubbles into and from the emulsion phase also took place. The size and shape of bubbles kept changing transiently in each time interval of 0.033 seconds. 


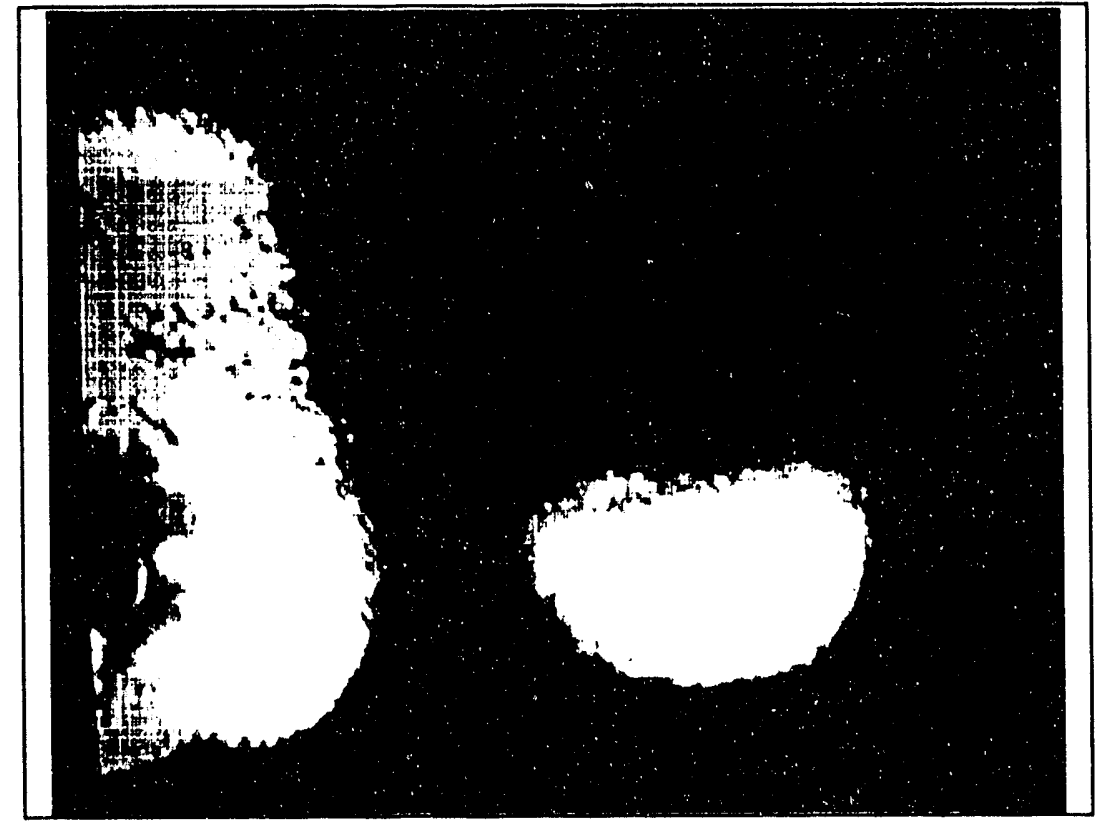

Figure 13.a Case 1 Series $1-1, \mathrm{~T}=0.000$ Second

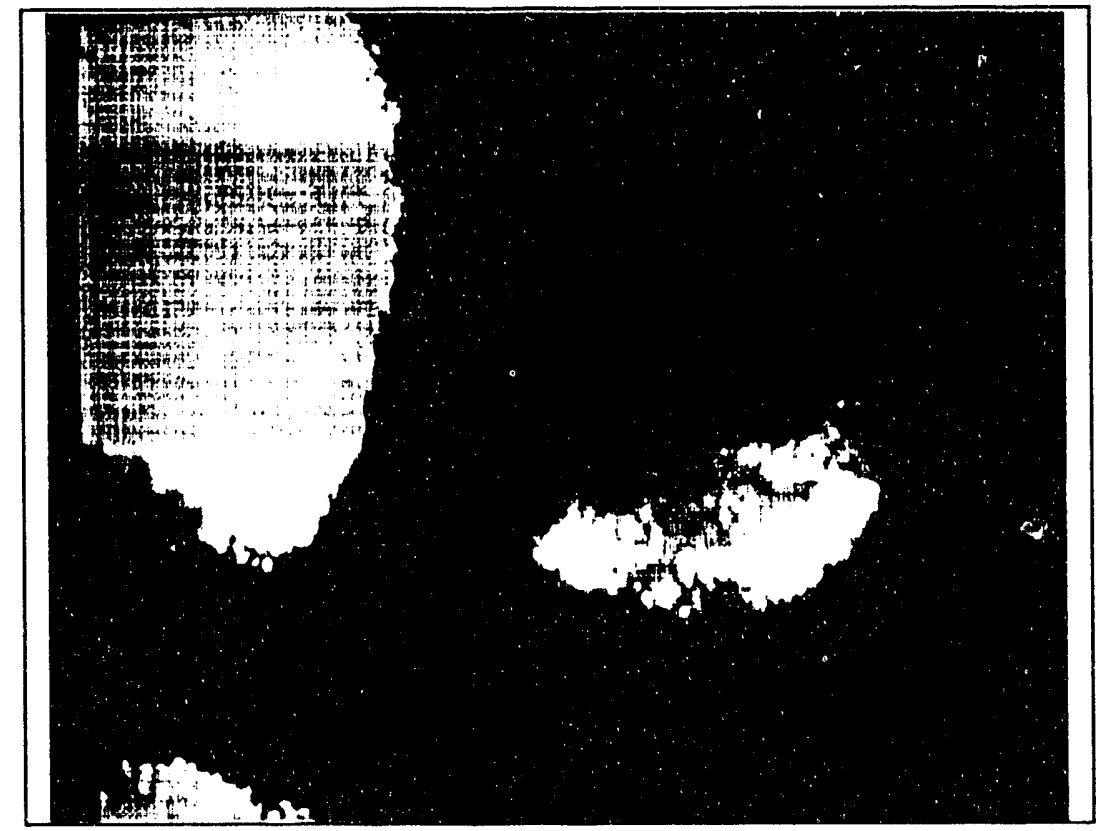

Figure 13.b Case 1 Series $1-2, T=0.033$ Second 


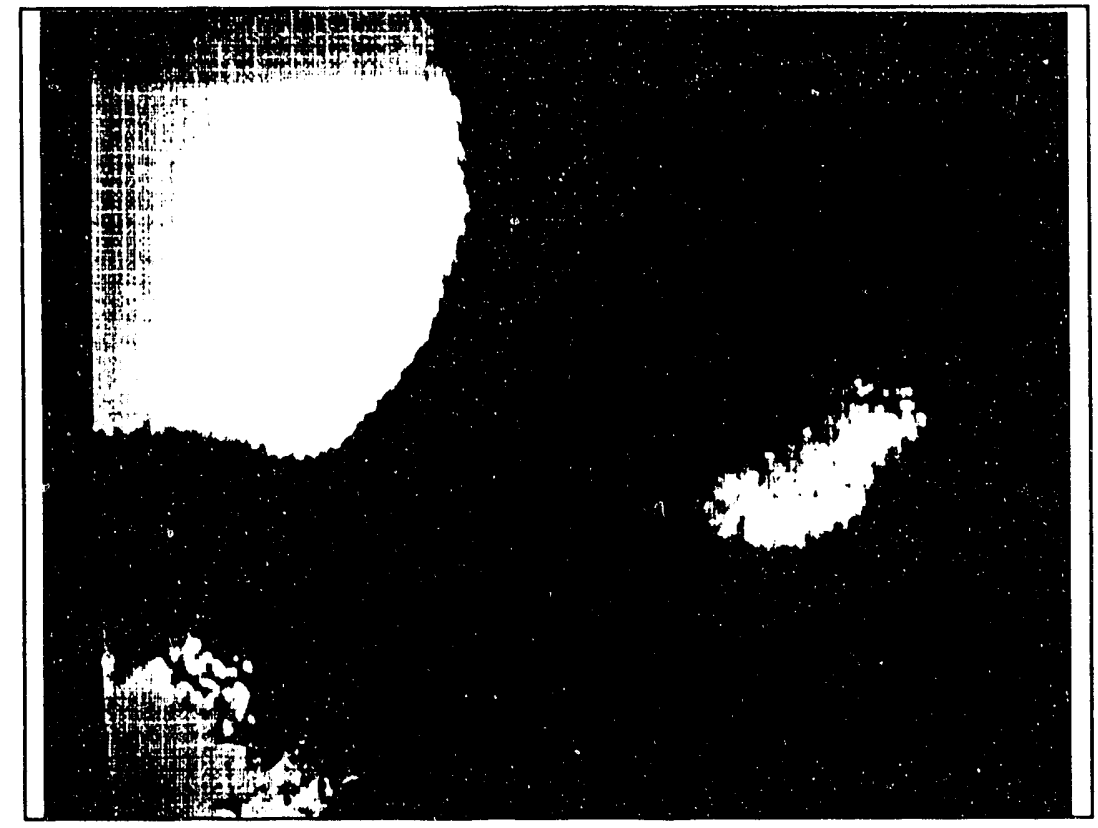

Figure 13.C Case 1 Series $1-3, T=0.066$ Second

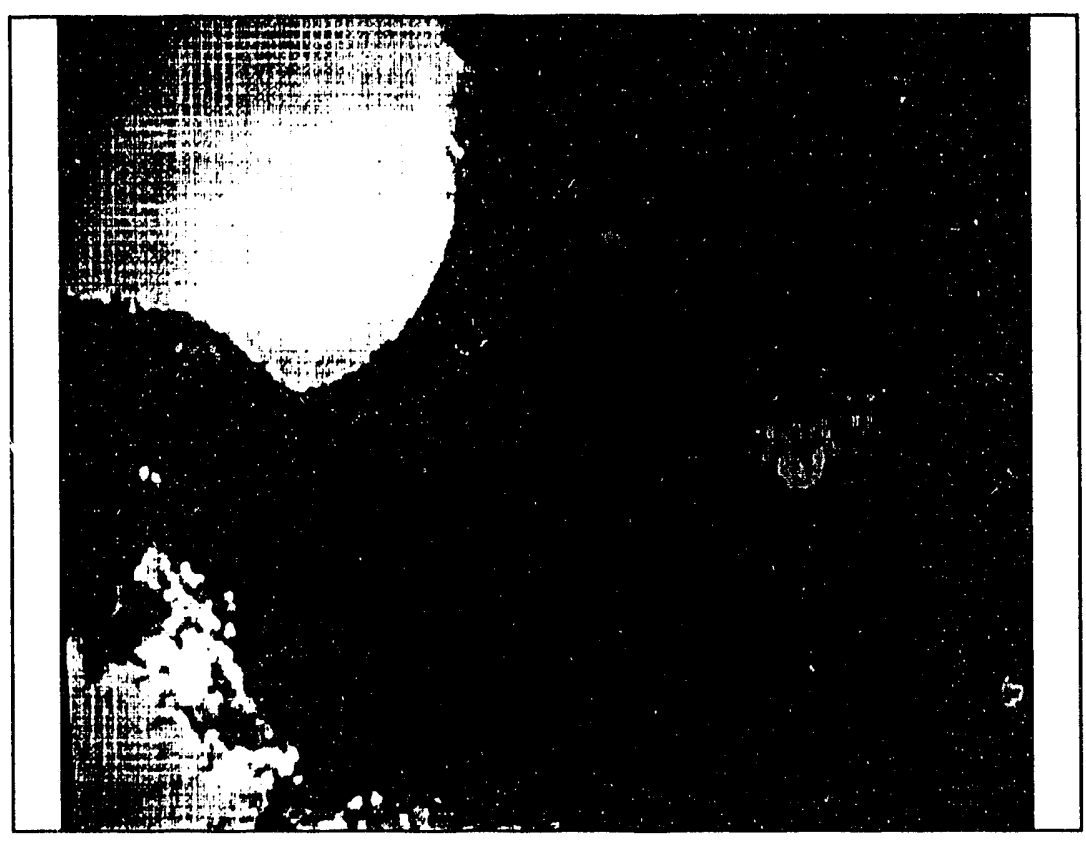

Figure 13.d Case 1 Series $1-4, T=0.100$ Second 


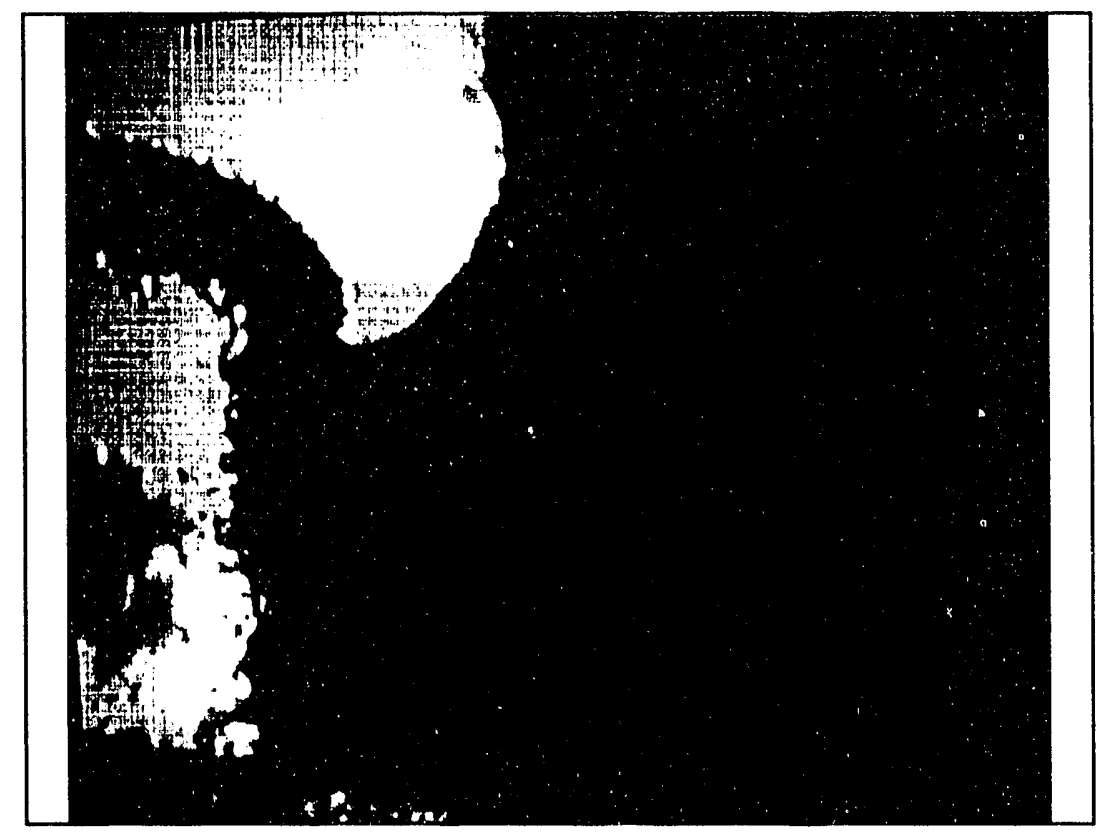

Figure 13.e Case 1 Series $1-5, T=0.133$ Second

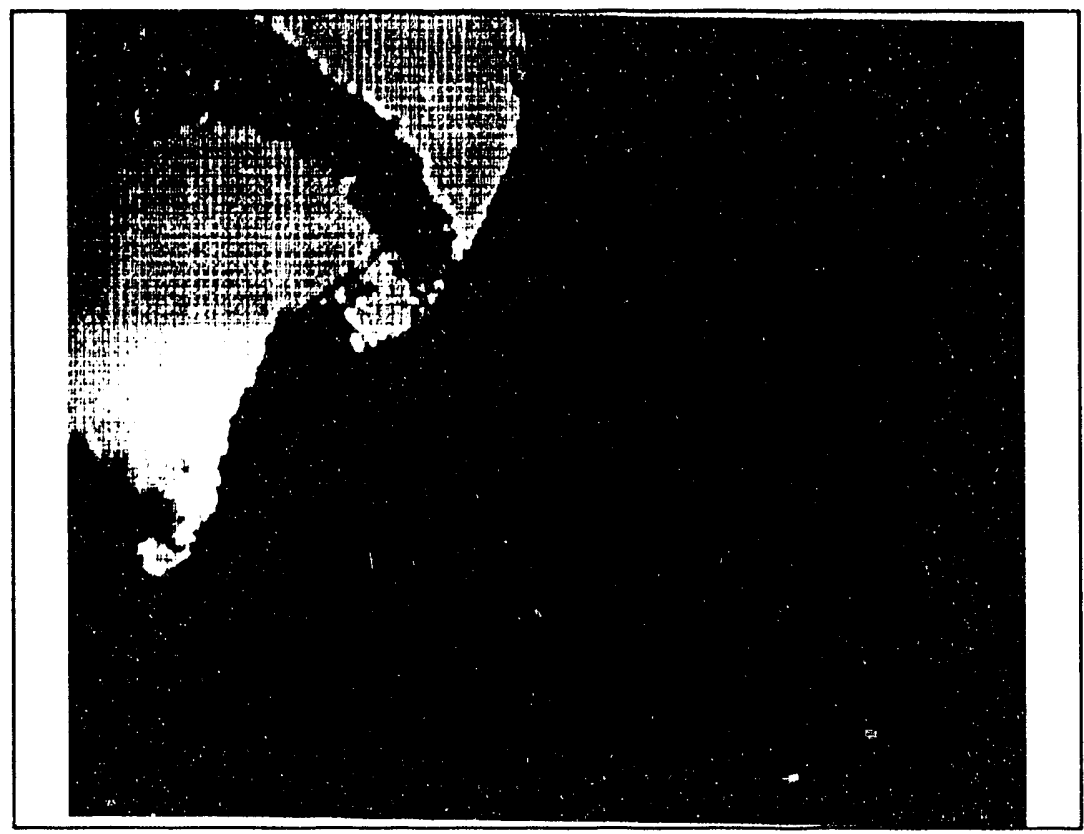

Figure 13.f Case 1 Series $1-6, T=0.166$ Second 


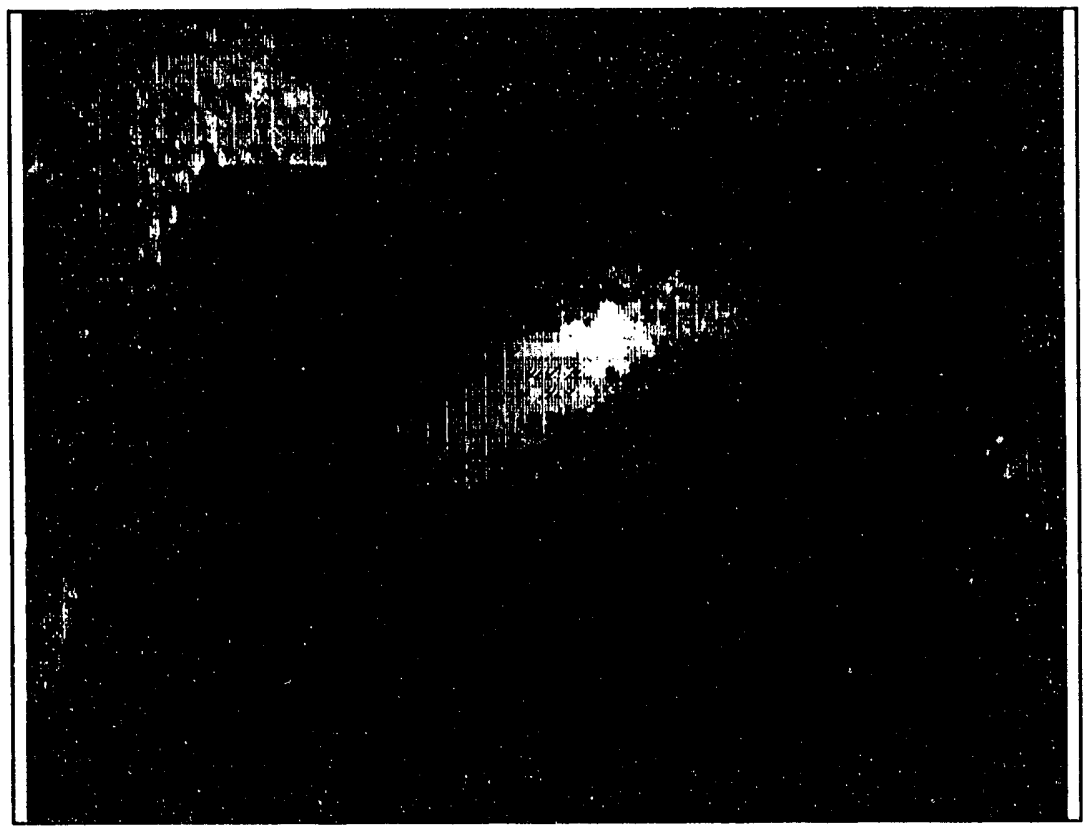

Figure 14.a Case 1 Series $2-1, \mathrm{~T}=0.000$ Second

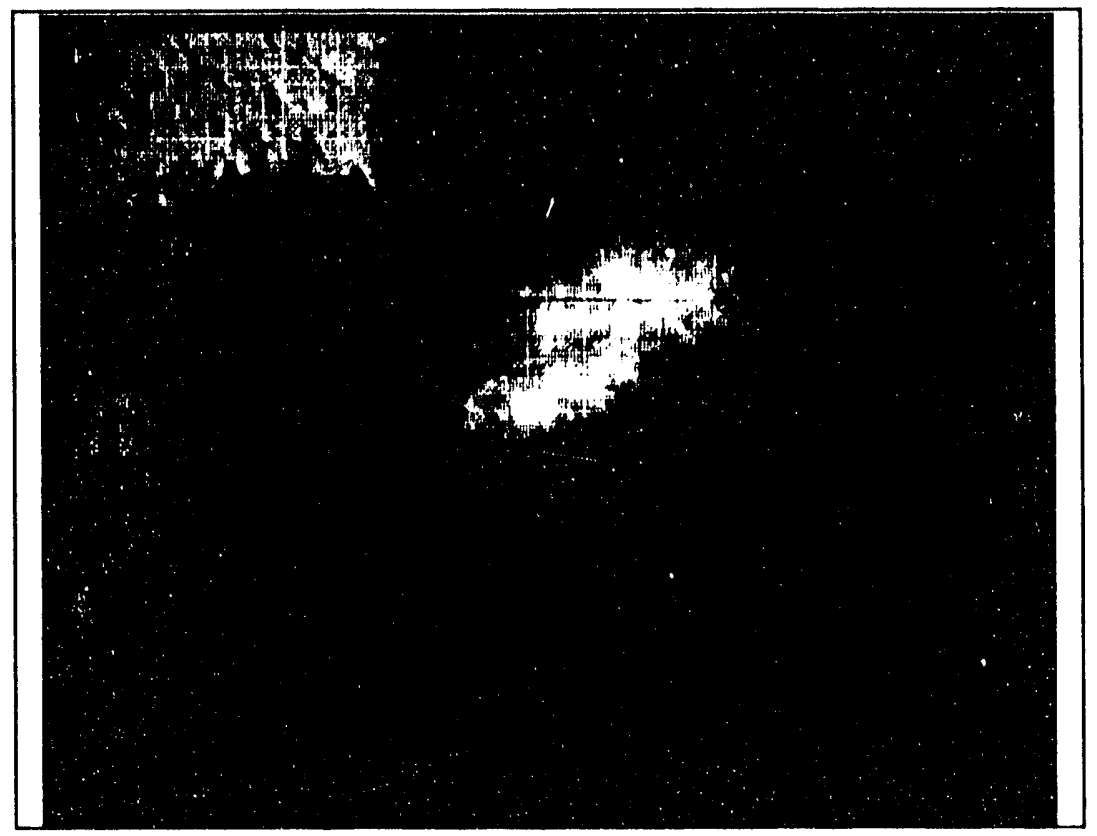

Figure $14 . \mathrm{b}$ Case 1 Series $2-2, \mathrm{~T}=0.033$ Second 


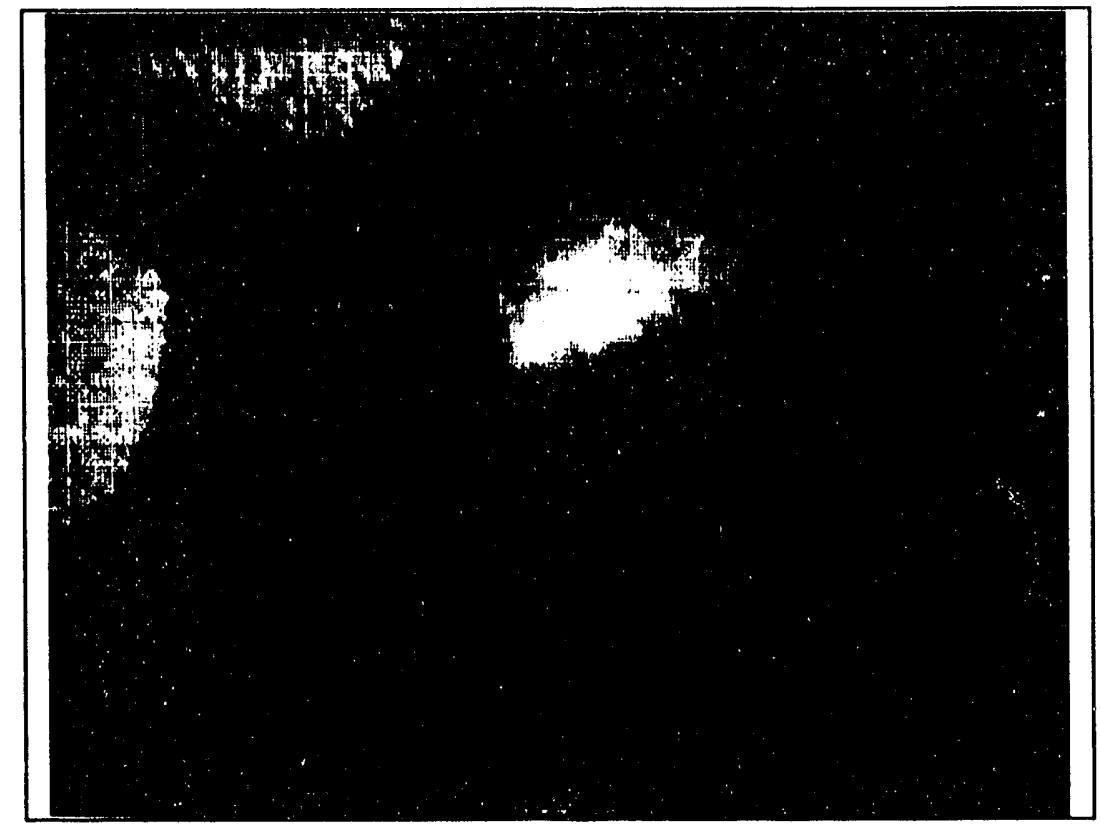

Figure 14.C Case 1 Series $2-3, \mathrm{~T}=0.066$ Second

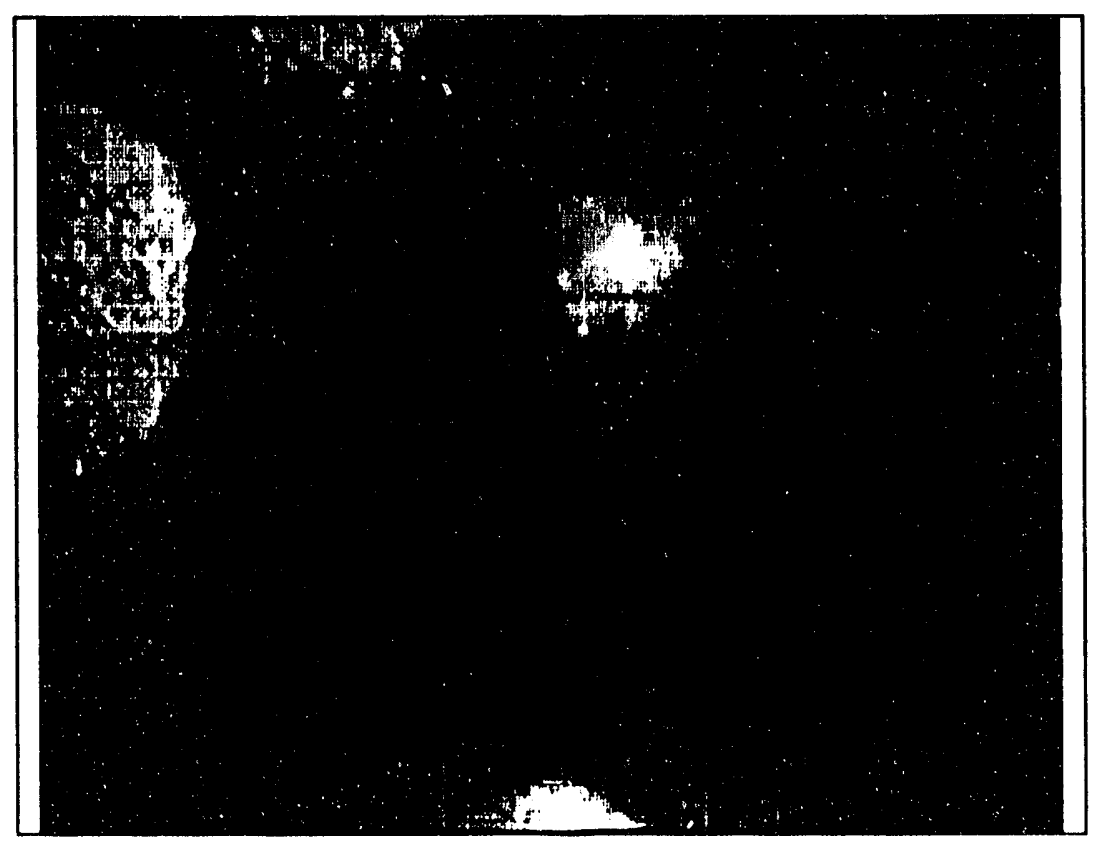

Figure 14.d Case 1 Series $2-4, T=0.100$ Second 


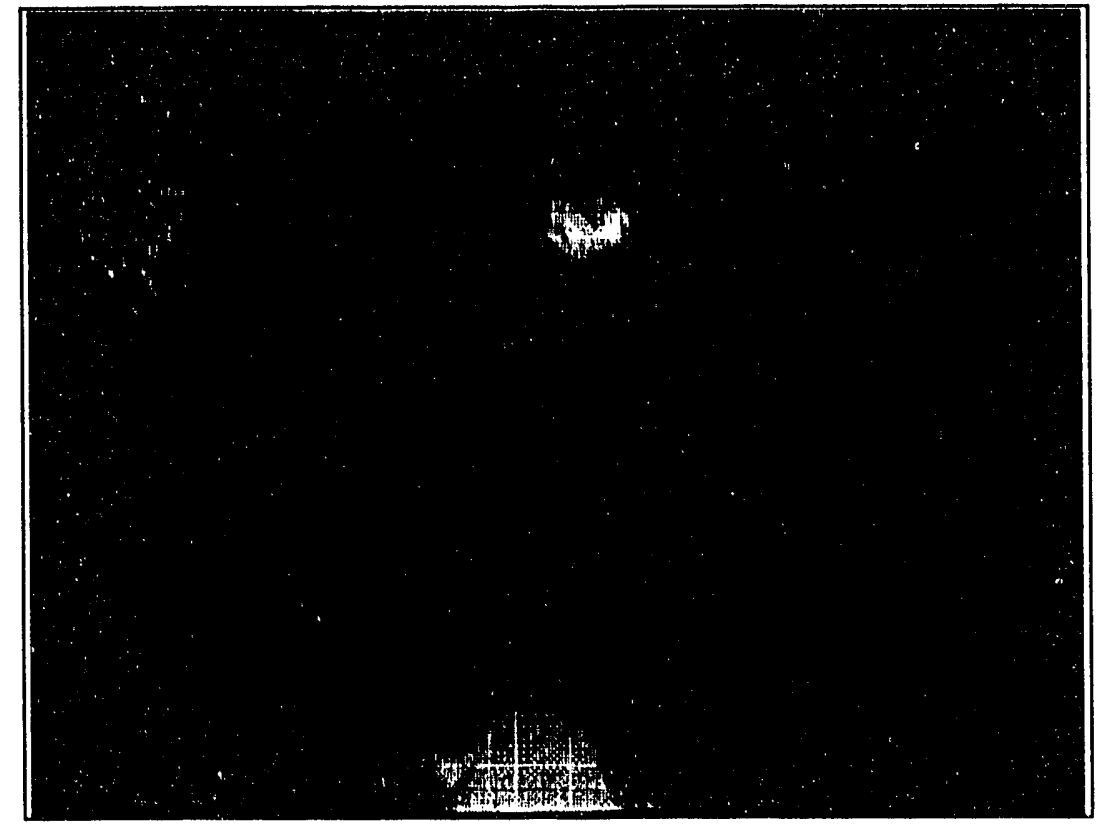

Figure 14.e Case 1 Series $2-5, \mathrm{~T}=0.133$ Second

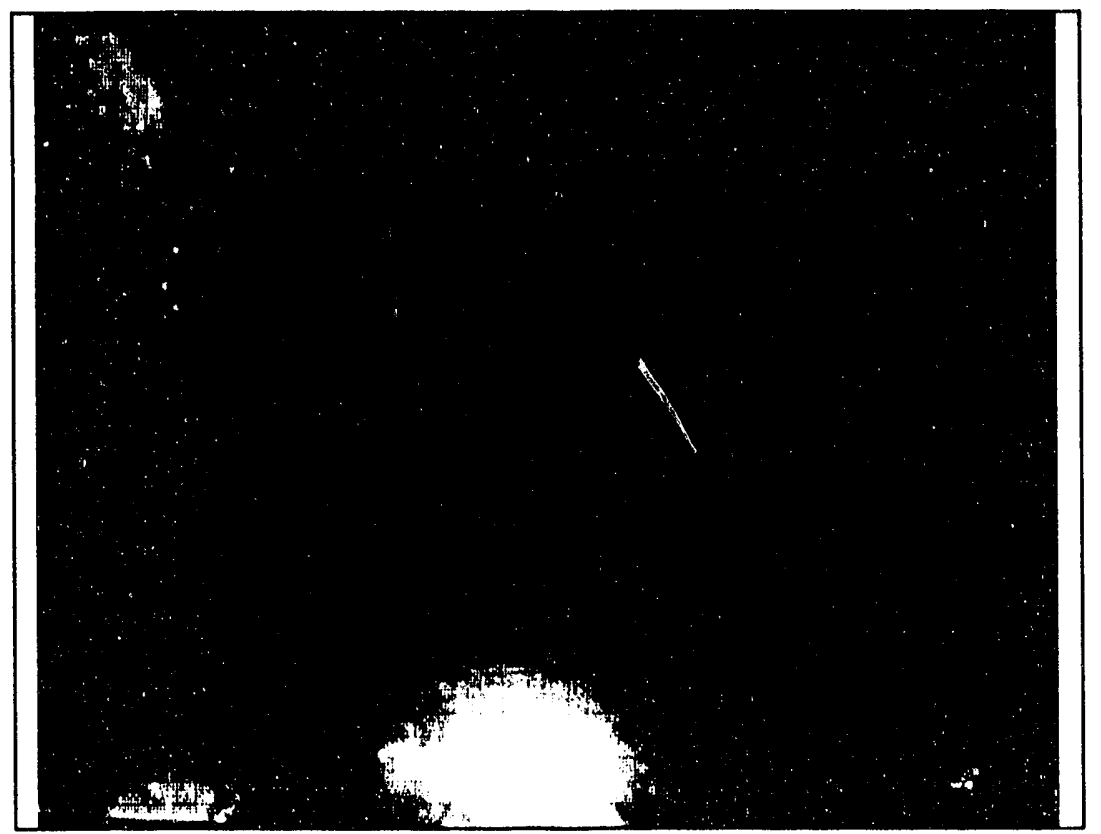

Figure 14.f Case 1 Series $2-6, T=0.166$ Second 
Generally speaking, the sizes of bubbles in fine powder fluidized bed were smaller than those in coarse particle. In order to observe the small bubbles transient behavior, we prepared a very thin depth $(3 \mathrm{~mm})$ two dimension fluidized beds.

Figures 15.a through Figure 15.e show a series of transient bubble pictures. With respect to the bubble located at the lower center, it started splitting and reducing its size in the time interval of 0.03 seconds (see Figure 15.b and $c$ ). Those collapsed bubbles disappeared into the emulsion phase in 0.1 seconds (see Figures 15.e and $f$ ). On the other hand, some bubbles did not change their shape and size as dramatically as those collapsed.

Figures 16.a through 16.e show the second series of pictures. In this series, the bubble did appear from the emulsion phase all of the sudden in the time interval of 0.033 seconds (see Figures 16.C and 16.d). The physical meaning of those findings is very important. clearly, these finding can not be expected by the classical fluidization concept (e.g., Davidson et al.,1963)

Figures $17 . \mathrm{a}$ through $17 . \mathrm{d}$ show the third series of pictures. In this picture series, the bubble disappeared into the emulsion within the time interval of 0.133 seconds (see Figures 17.a through 17.d). This disappearance rate was much slower than the first series (Figure 15). It is shown in Figures 17.a through 17.d, that the other bubble in Figure 17 behaved in a different manner from one that disappeared, i.e., it sometimes increased and sometime reduced its size.

The above observation was quite identical with these by Hallow et al. (1989, 1990) using the capacitance images. This finding indicates that a reconsideration of general bubbling phenomena in a freely bubbling fluidized bed is necessary.

4.3. Bubble Behavior and Pressure Fluctuation in Two Dimensional Fluidized Beds

We intended to characterize the transient motion of bubbles in terms of transient forces of solid particles. The pressure fluctuation data were taken simultaneously while bubble behavior was recorded by video. This approach intended, how the transient gas pressure fluctuation was caused by the transient passage of bubbles. Therefore, we achieved the observations how the gas pressure fluctuation can be correlated to the passage of bubbles across the measuring point. Figures 18 through 23 show 


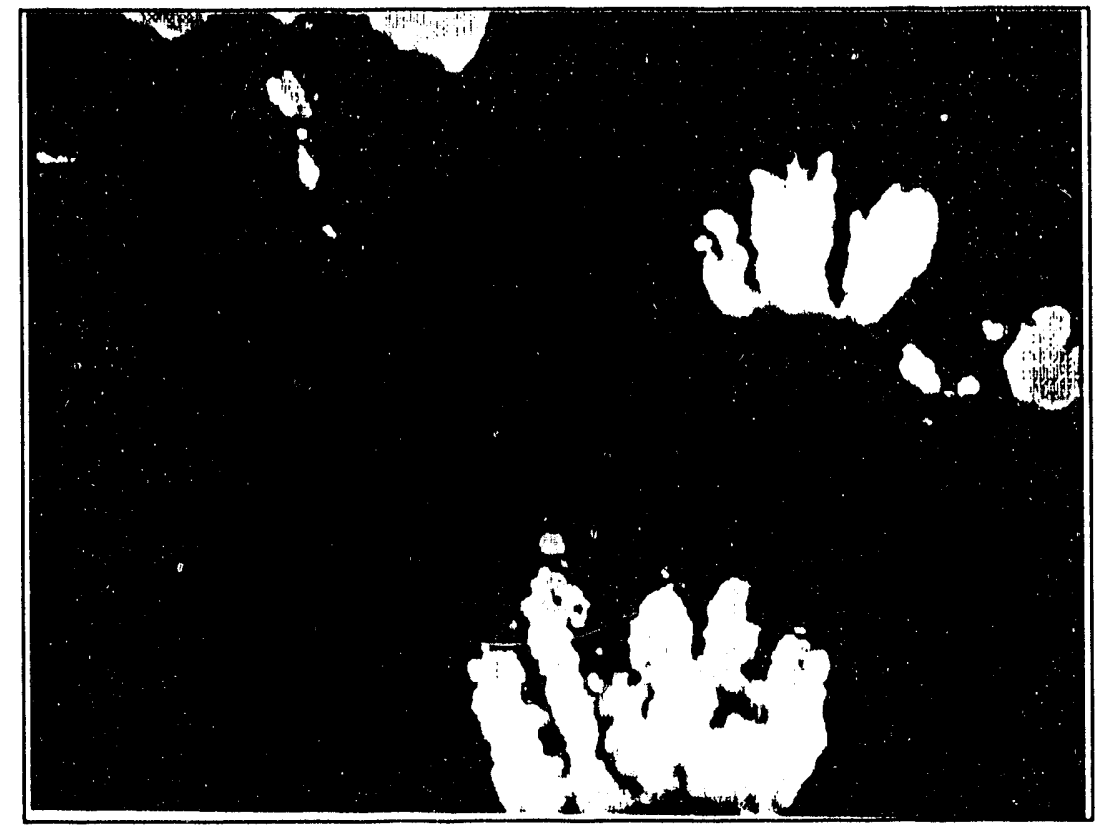

Figure 15.a Case 2 Series $1-1, T=0.000$ Second

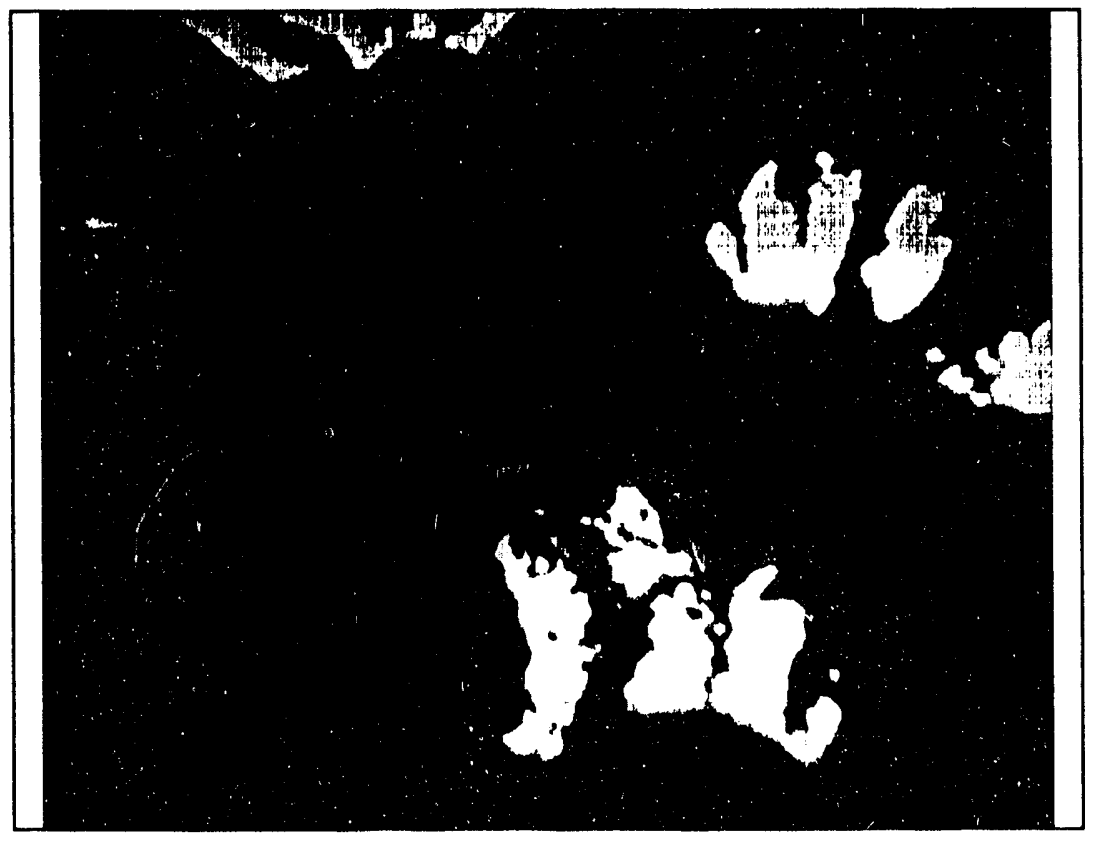

Figure 15.b Case 2 Series $1-2, T=0.033$ Second 


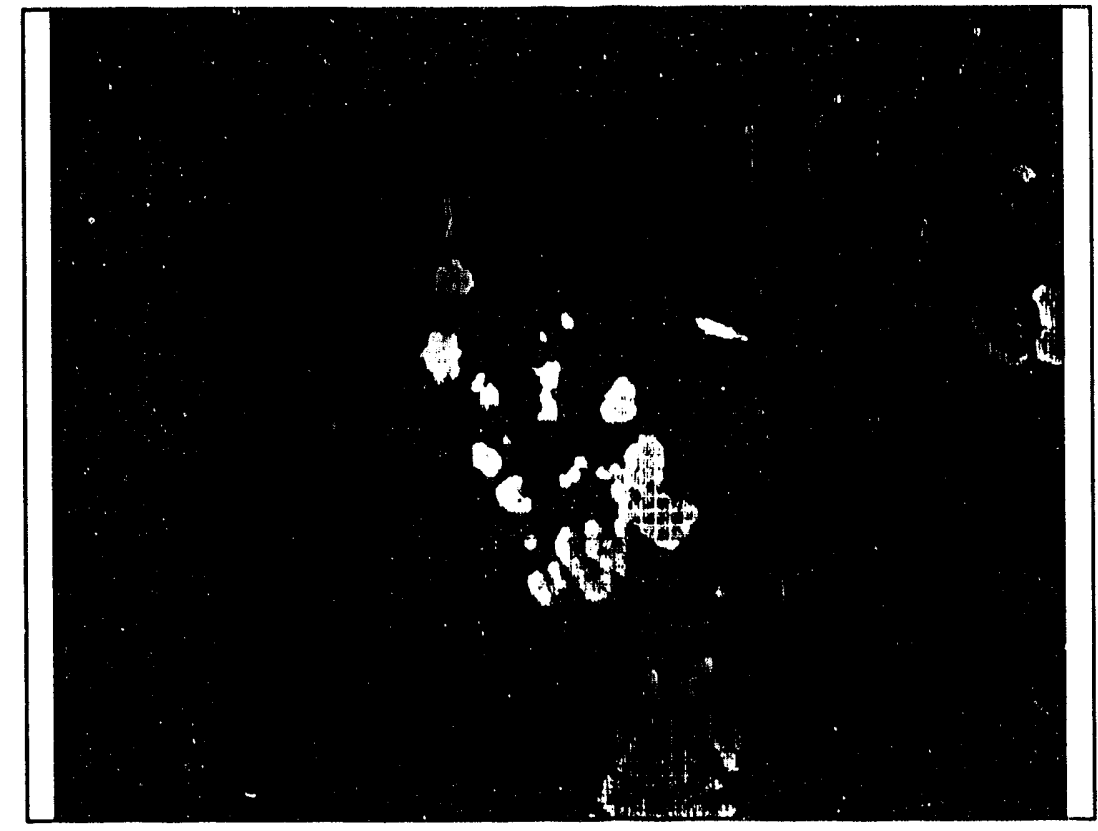

Figure 15. C Case 2 Series $1-3, \mathrm{~T}=0.066$ Second

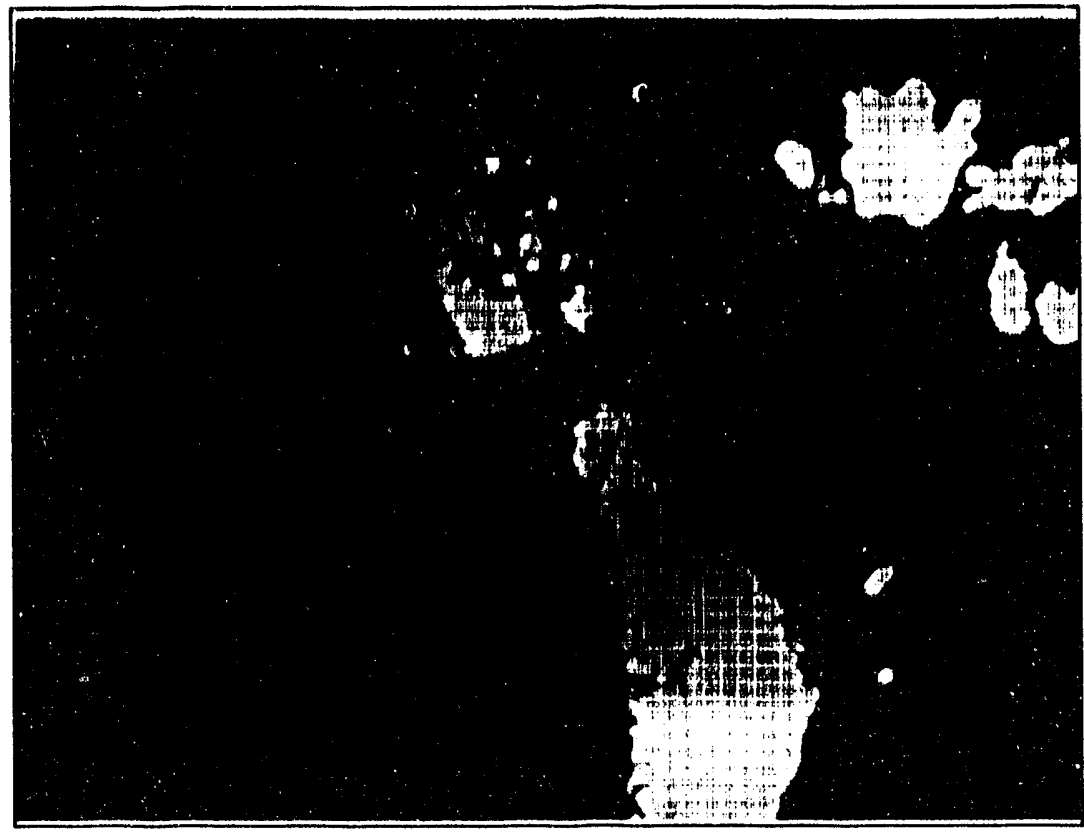

Figure 15.d Case 2 Series $1-4, T=0.100$ Second 


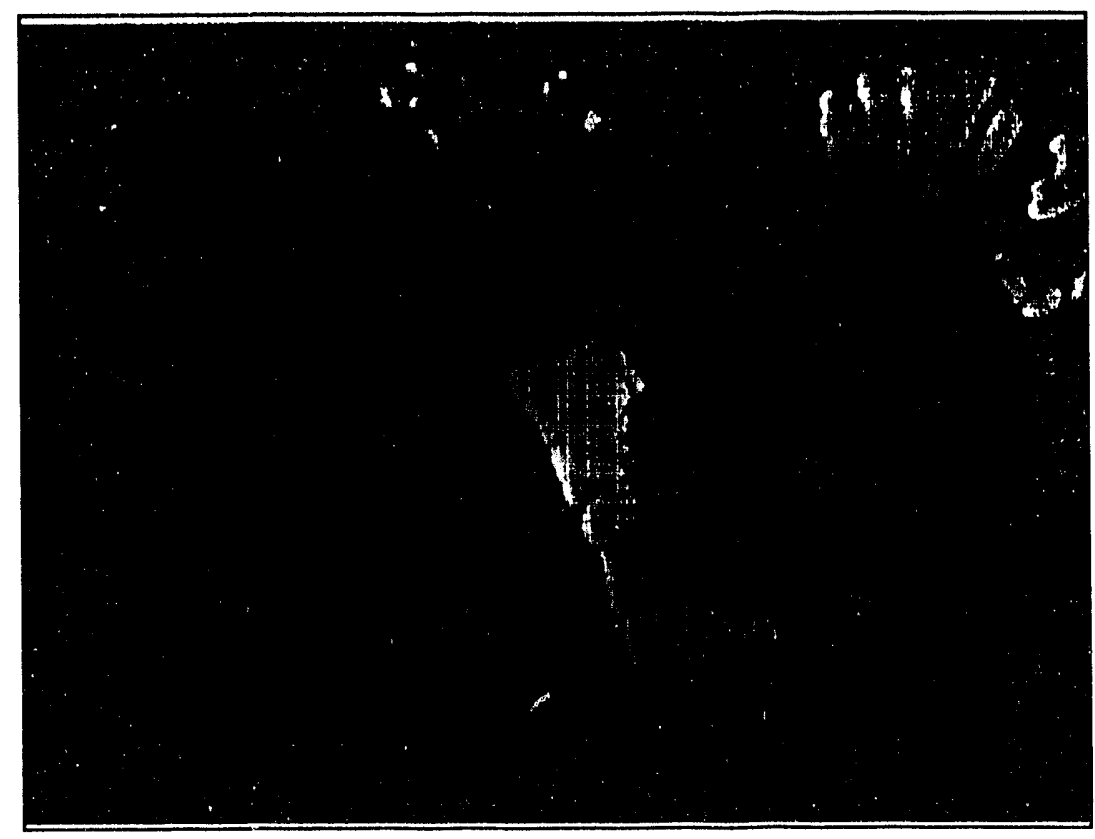

Figure 15.e Case 2 Series $1-5, \mathrm{~T}=0.133$ Second 


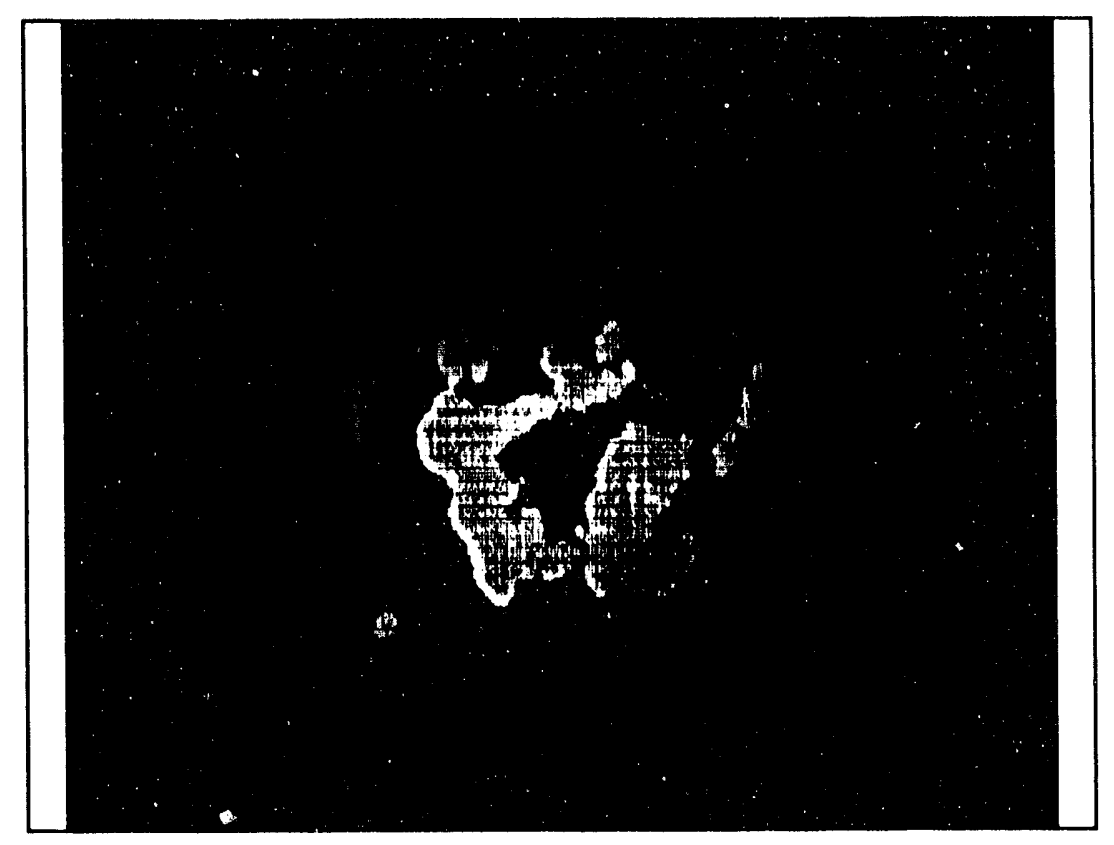

Figure 16.a Case 2 Series $2-1, \mathrm{~T}=0.000$ Second

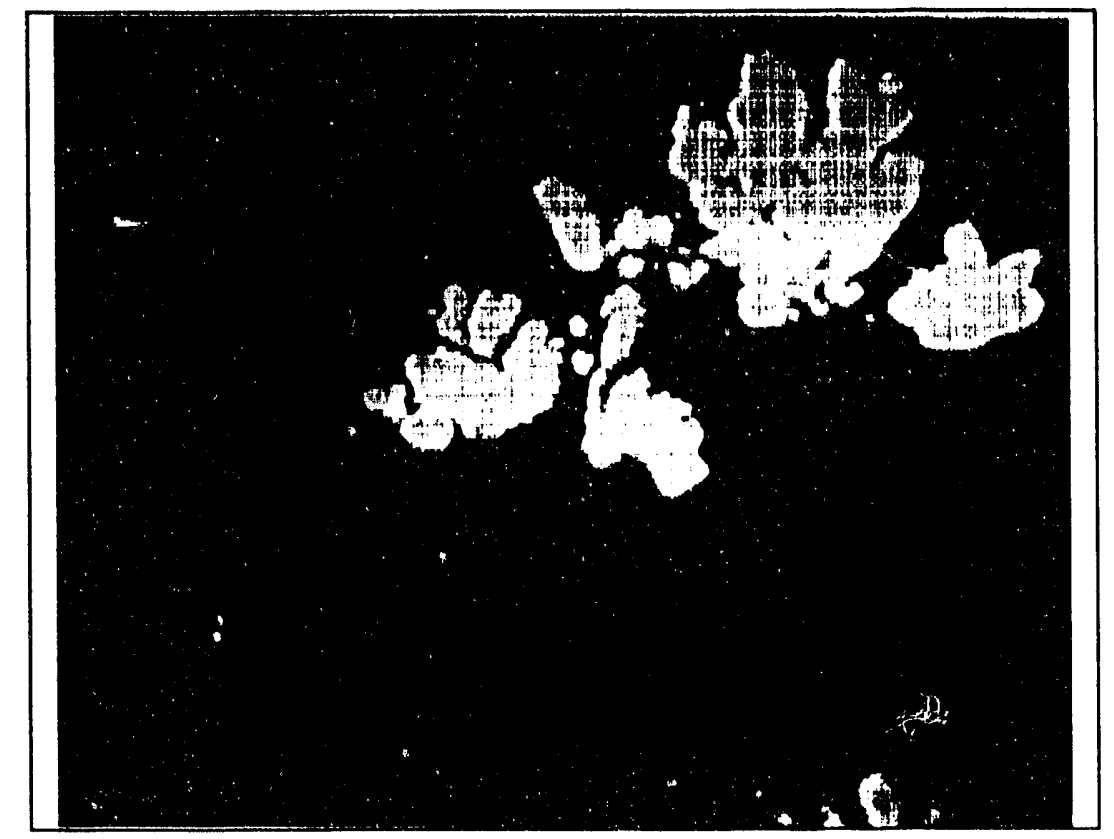

Figure 16.b Case 2 Series $2-2, T=0.033$ Second 


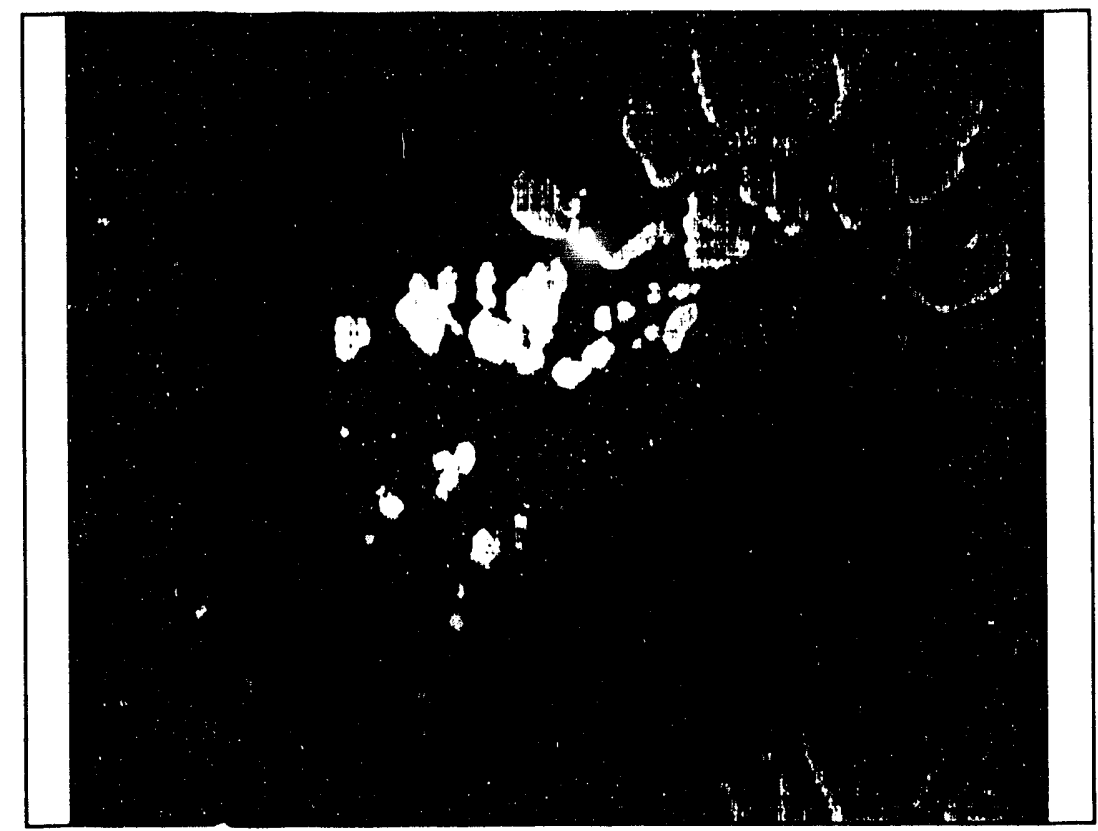

Figure 16, C Case 2 Series $2-3, \mathrm{~T}=0.066$ Second

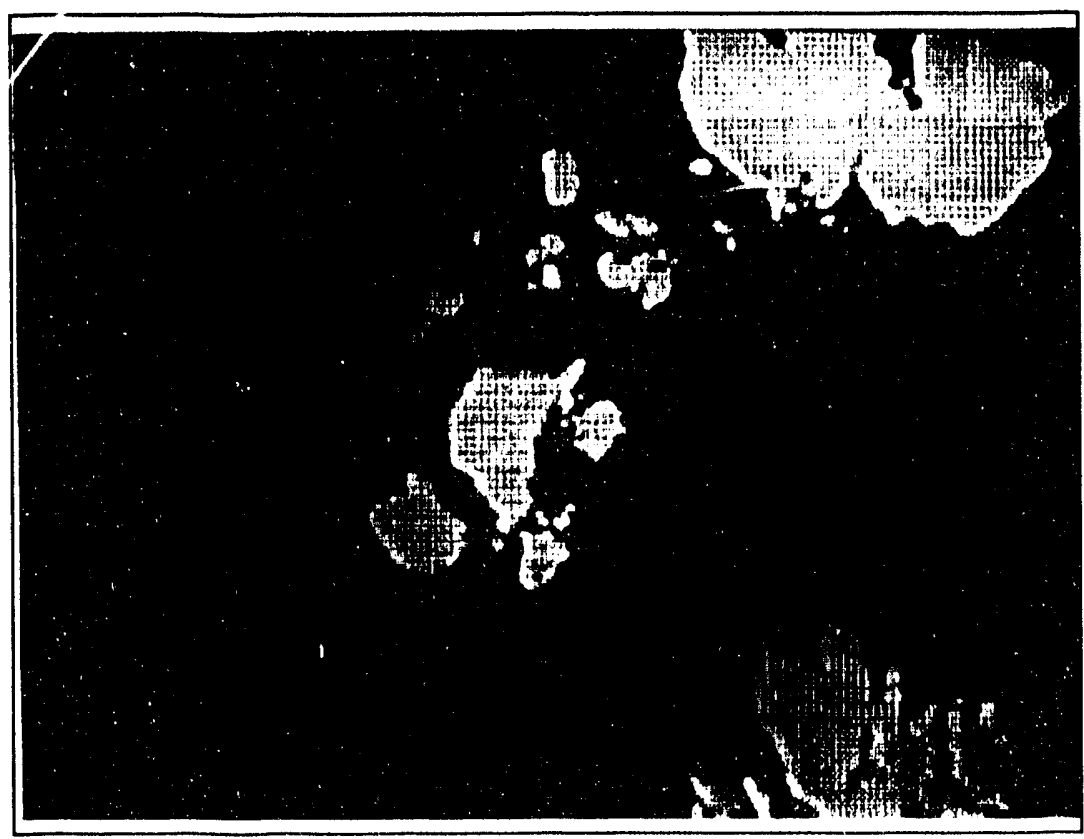

Figure 16.d Case 2 Series $2-4, T=0.100$ Second 


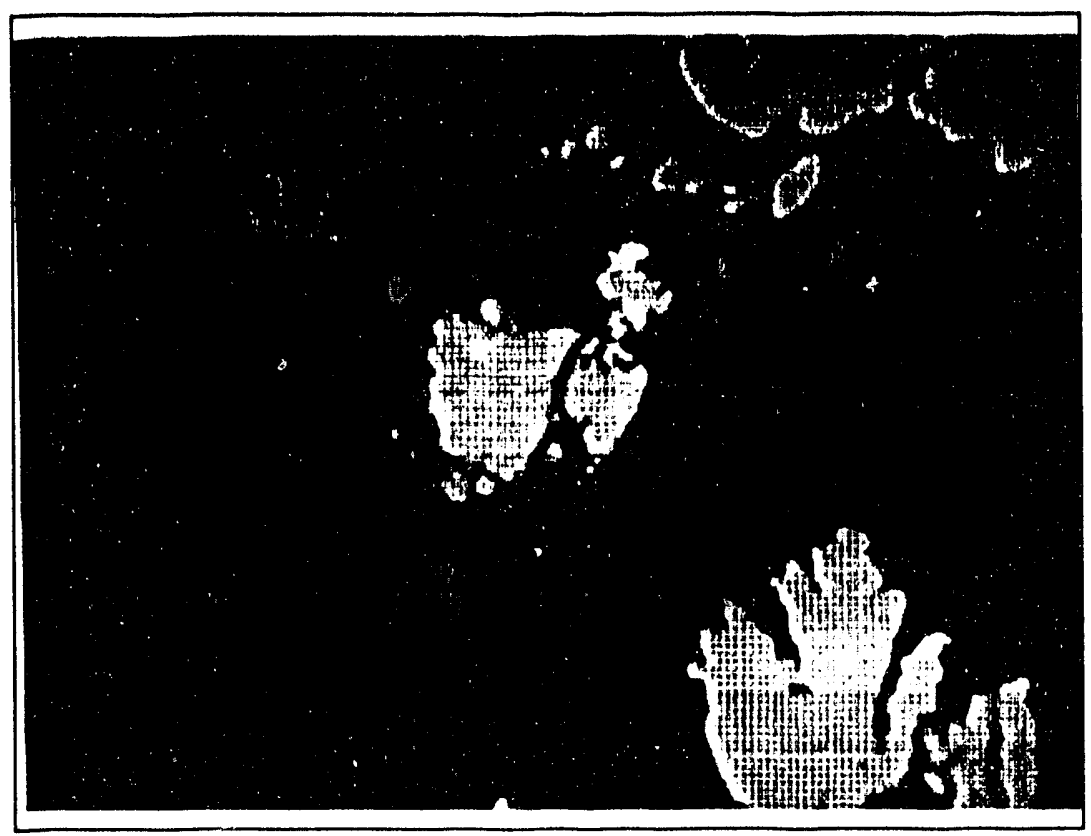

Figure 16.e Case 2 Series $2-5, T=0.133$ Second 


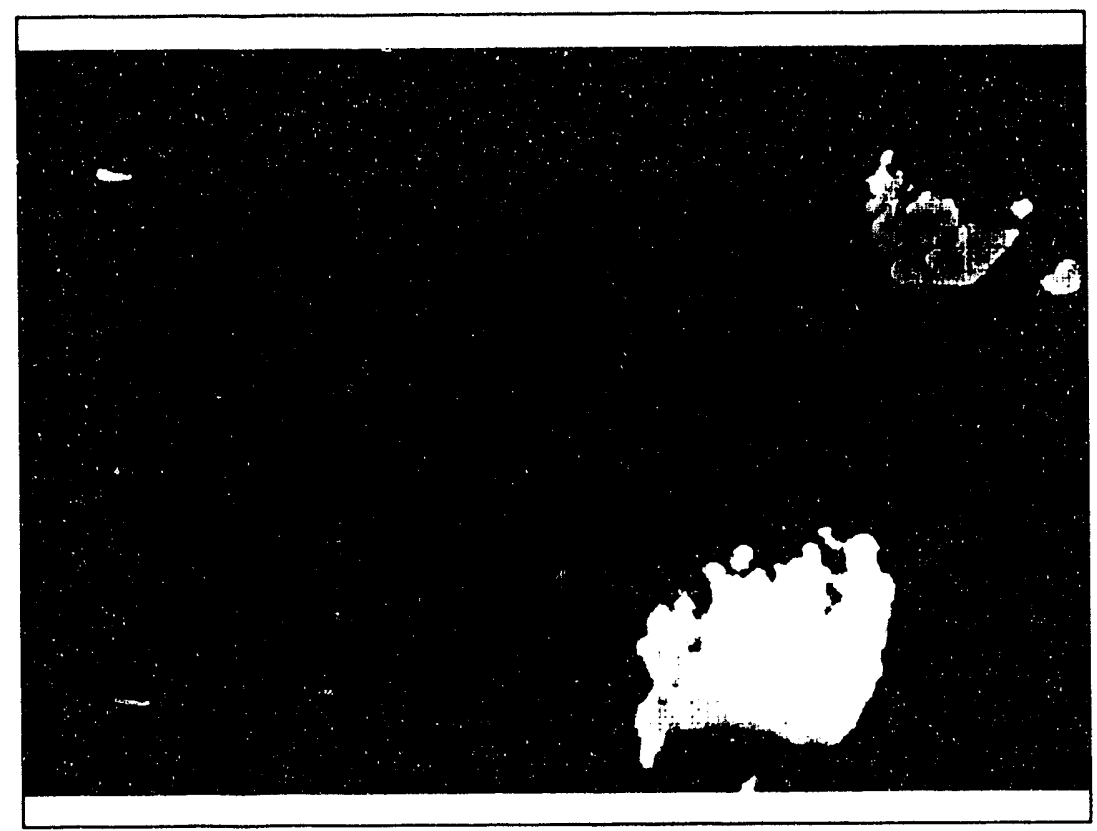

Figure 17.a Case 2 series $3-1, T=0.000$ Second

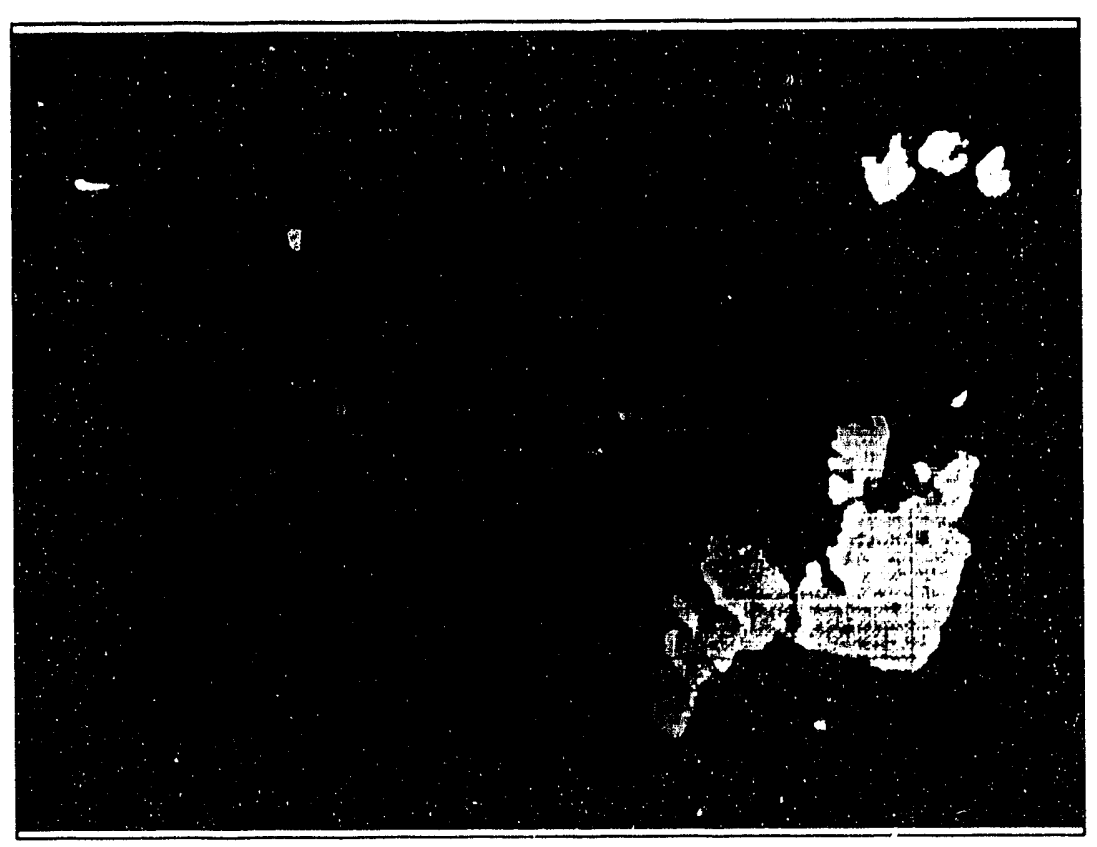

Figure $17 . \mathrm{b}$ Case 2 Series $3-2, \mathrm{~T}=0.033$ Second 


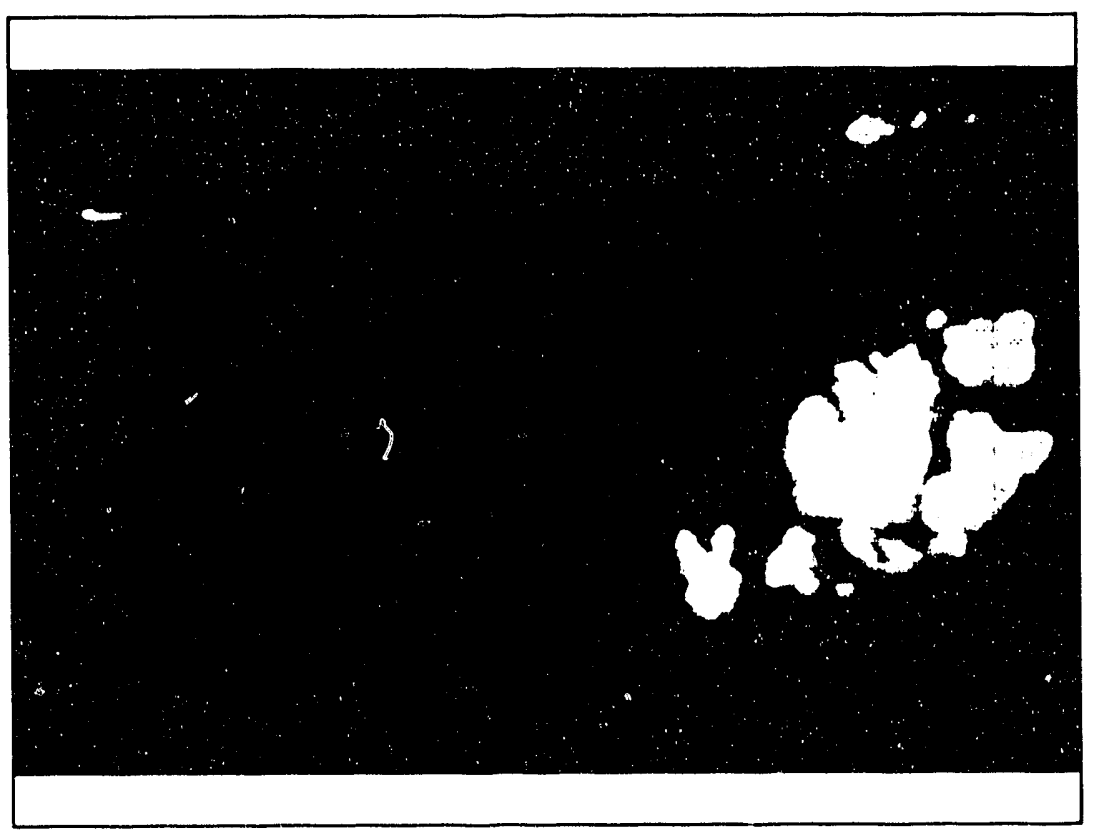

Figure 17. C Case 2 Series $3-3, T=0.066$ second

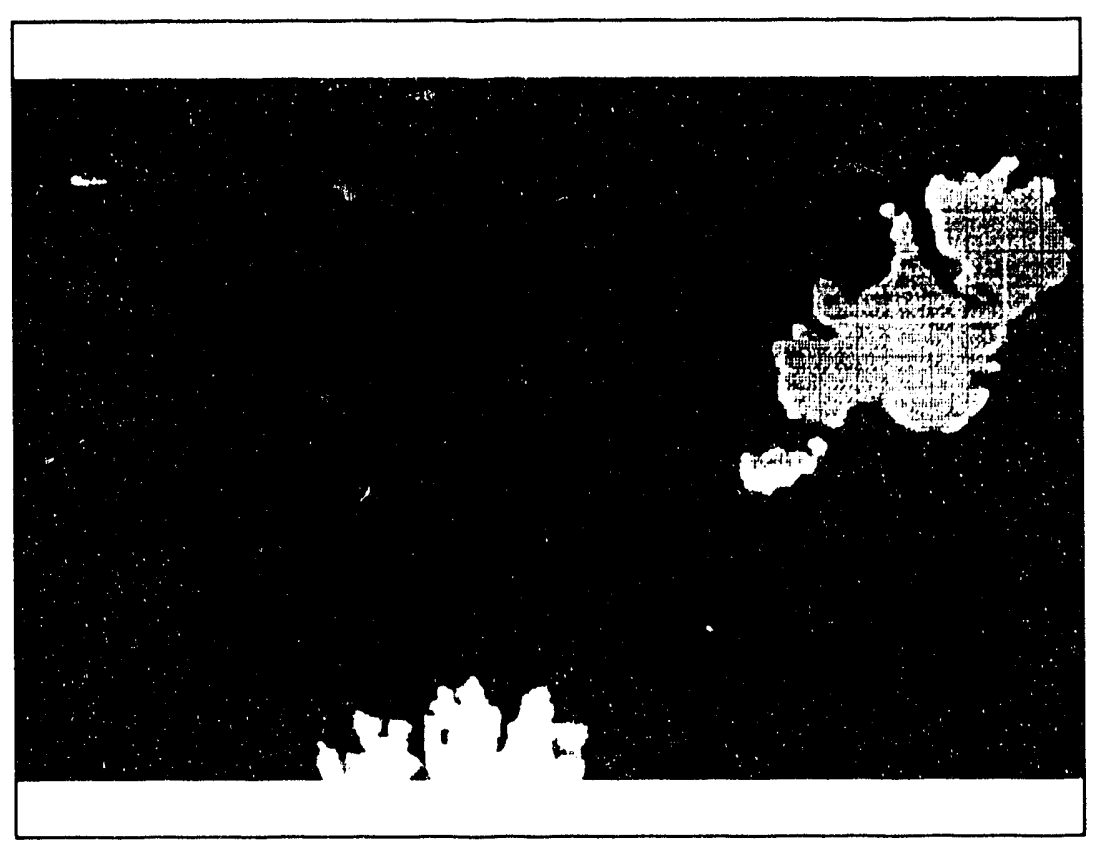

Figure 17.d Case 2 Series $3-4, \mathrm{~T}=0.100$ Second 


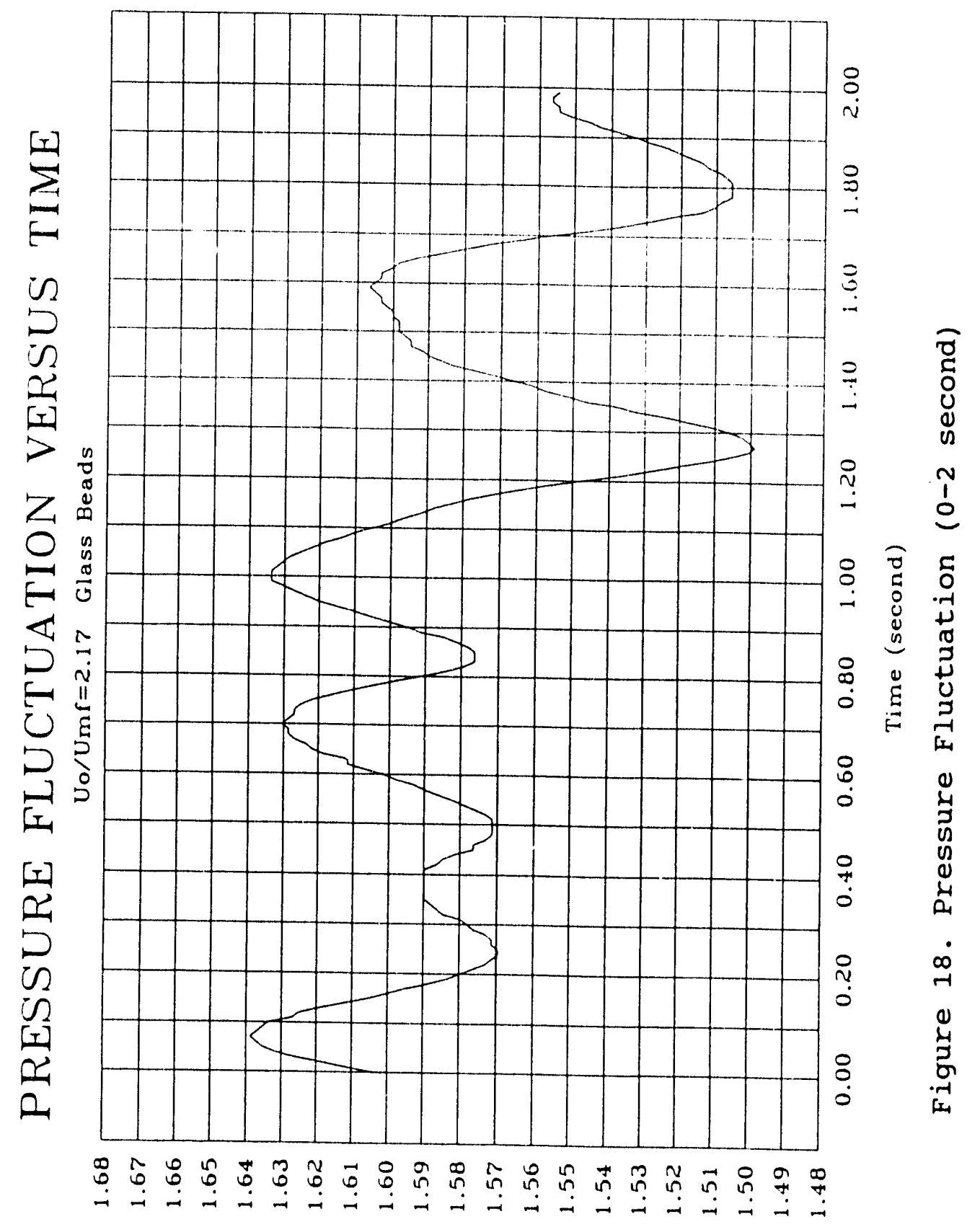

(Bdभ) Uombntonla axnssadd 


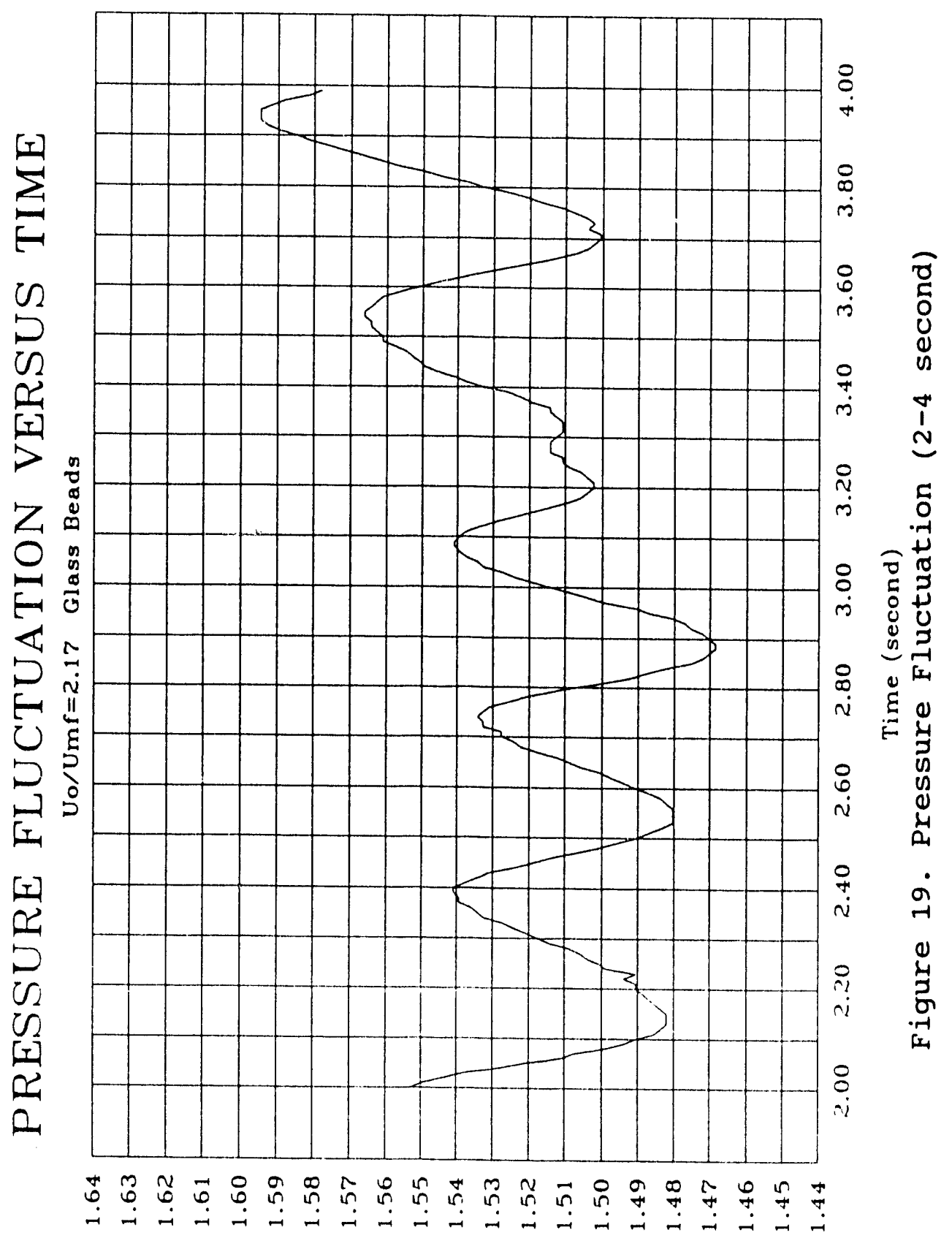

(edr) uogfenzonta axnssaxd 


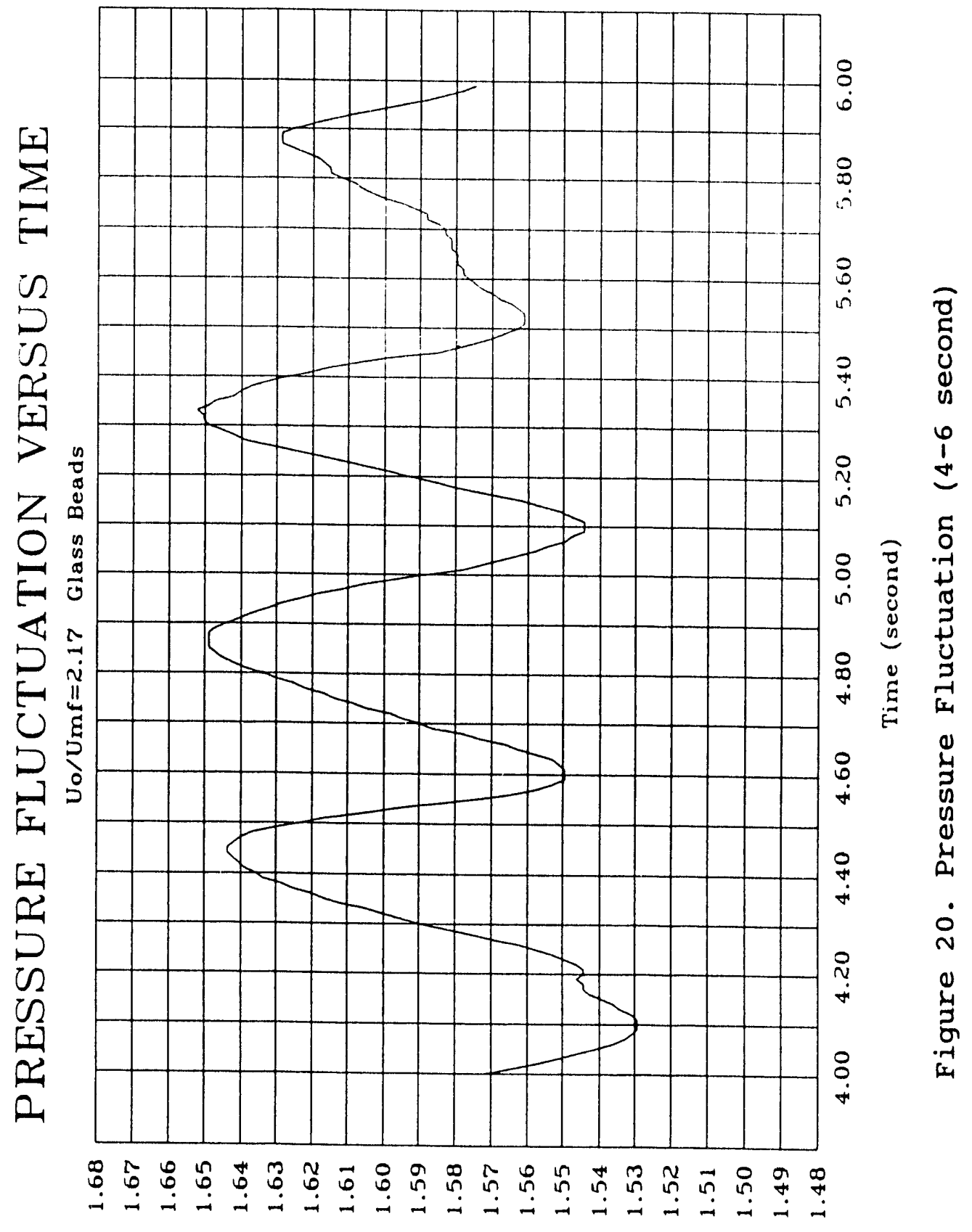

(BdY) uop̧enzonta axnssaxd 


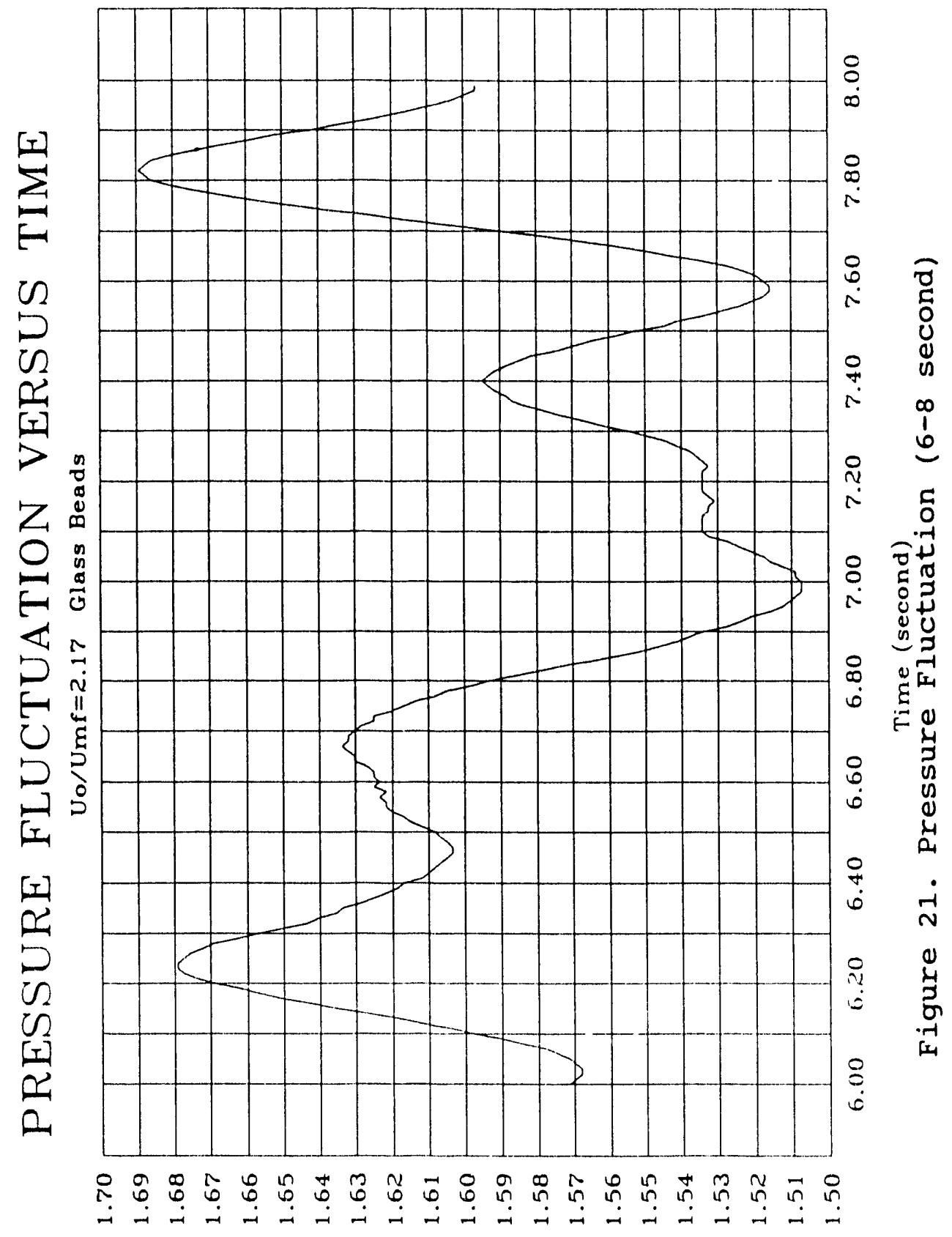

(Bdy) uomentonta axnssaxd 


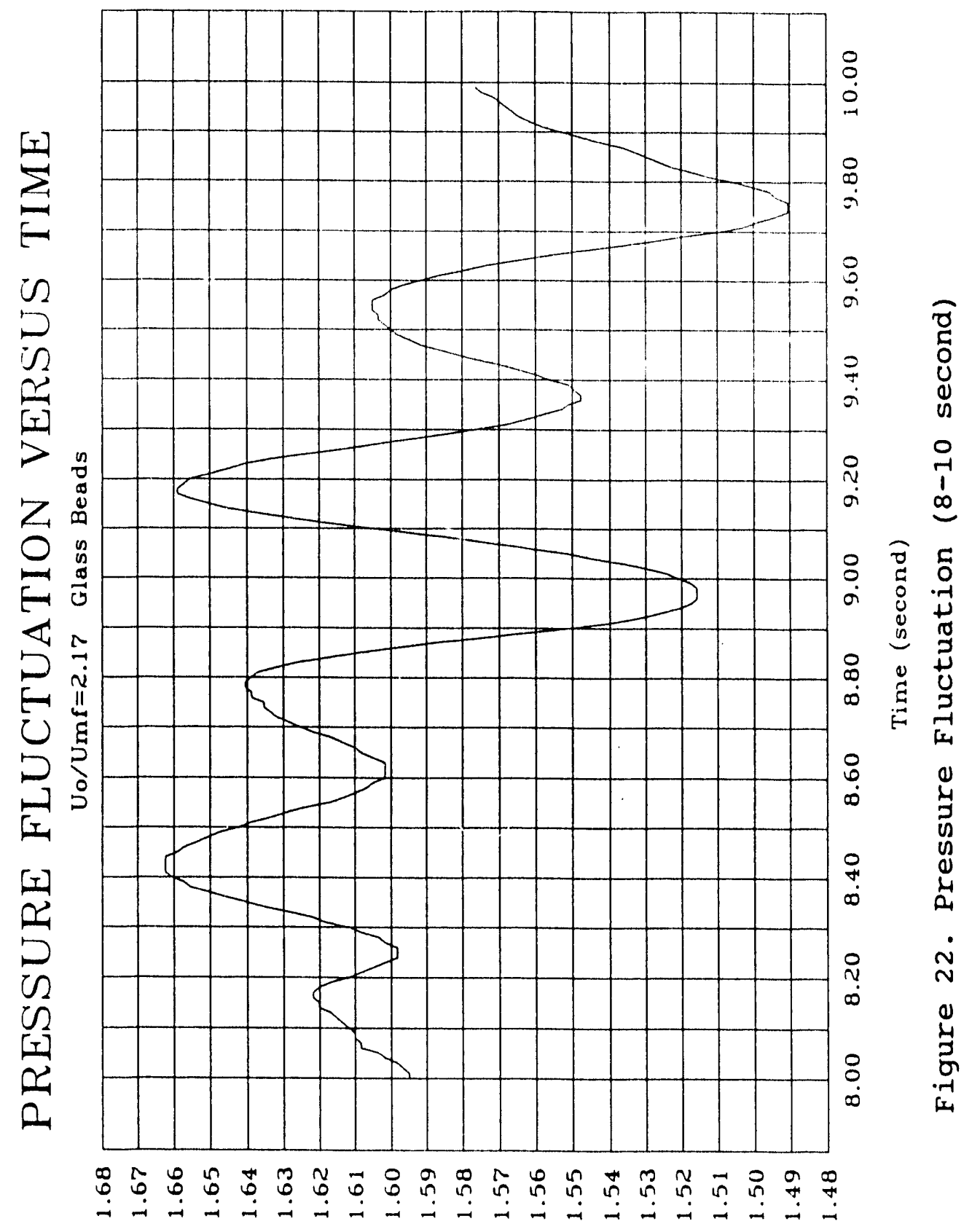

(Bdy) uomenzonis axnssaxd 


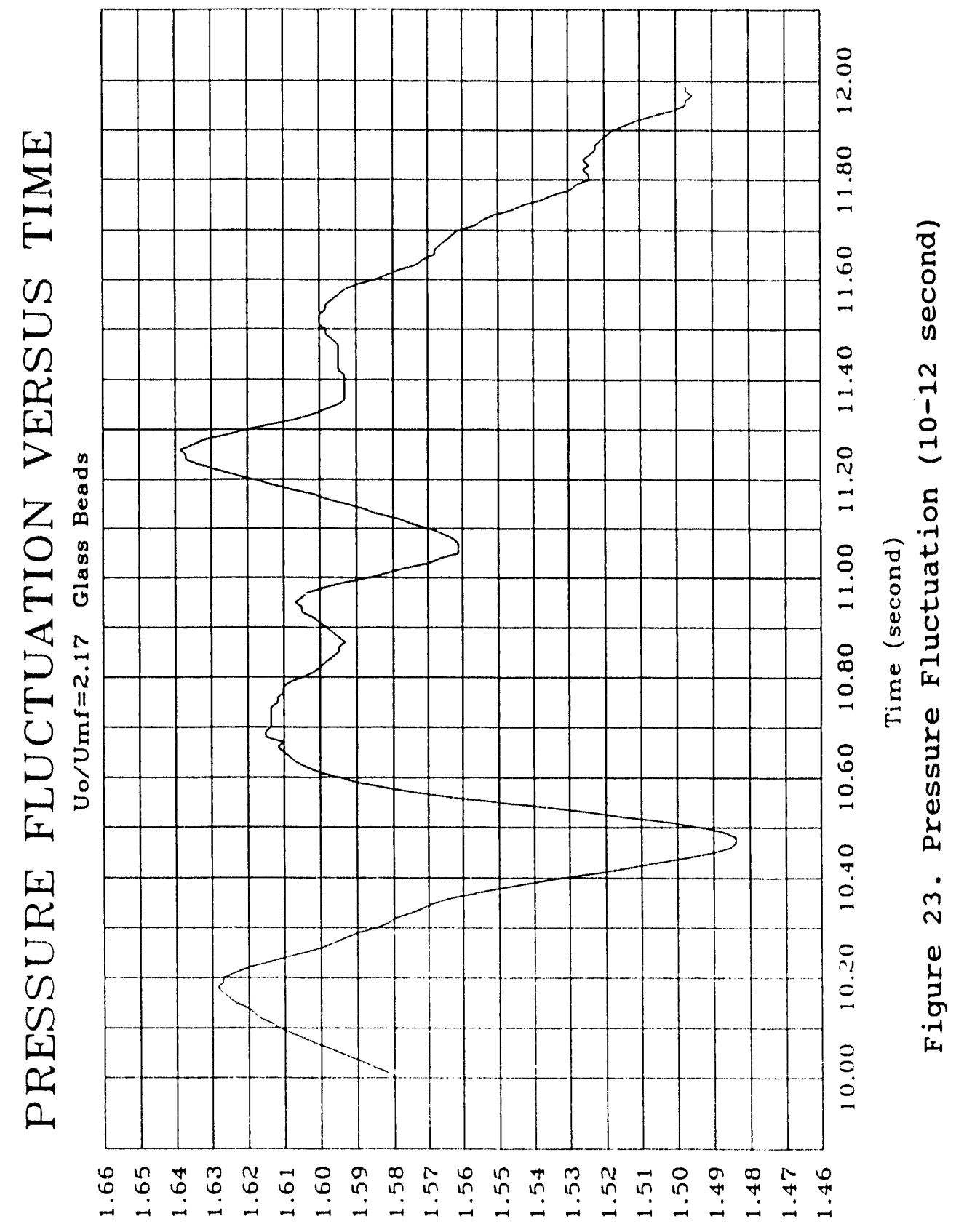

(вdभ) uoipenzonla axnssadd 
the gas pressure fluctuation from time 0 to 12 (second). The experiment was run under the following fluidization conditions: superficial gas velocity $U_{0} / U_{m f}=2.17$, bed height $H=25 \mathrm{~cm}$, bed aspect ratio $H / D_{1}=1$, bed thickness $=1 \mathrm{~cm}$, particle size $d p=1 \mathrm{~mm}$ (glass beads). The measurement point was located at the center and $18 \mathrm{~cm}$ from the bottom. Based on the analysis of the video images and the pressure fluctuation curve, the following observations were obtained.

The fluctuation of the gas pressure at a specific point in a fluidized bed is not simply caused by a single approaching or leaving bubble, but caused by the interaction of adjacent bubbles. Another reason is that the property of each bubble (or the bubble flow mechanism) may be different as discribed in the section of multi-bubble flow mechanisms coexisting in fluidized bed. A domain is defined as a certain volume element around the measurement point. The flow mechanism of the bubbles within a domain sicrongly affects the pressure fluctuation. When only the well known coalescence and splitting are predominantly prevailing the following results were obtained:

- When a group of bubbles are approaching, the gas pressure goes up. (See Figure 18. time $0.00-0.07$, and time $0.90-1.00$. )

- When a big bubble nearby is leaving the measurement point and arrives to the top of the fluidized bed, the gas pressure goes down. (See Figure 18. time $0.40-0.50$ and time $1.6-1.8$. ) The pressure reaches the minimum value when a big bubble above the measurement point is arriving to the top of the fluidized bed.

- When the above two situations occur at the same time, usually bigger bubbles dominate the pressure, and the slope of the pressure curve becomes lower and rough. (See Figure 21. time 6.5 6.75, and Figure 23. time 10.65 - 10.95.)

- When the bubble coalescence takes place vertically at higher level of the bed (near the top), the gas pressure goes down sharply.

When the big bubbles of classical definition are prevailing, many cases supported the above observations. However, when "pseudobubbles" are prevailing, the above results did not always hold true. 
4.4. Correlation Analysis on Synchronized Bubble Image and Pressure Fluctuation

We analyzed the transient local voidages in the fluidized bed (METC's 6" fluidized bed), with which we measured the transient forces of gas and solid phase simultaneously.

The correlation between the capacitance signal (local) and the transient force signal was reviewed in order to improve its reliability. It is found that the reason for relatively large scattering data points was due to the occurrence of "double peaked" voidage ("pseudo-bubble") signals, which corresponds to a newly observed "pseudo-bubbles" with different bubble flow mechanisms. Figure 24 shows two such double peaks, and Figure 25 shows their data points in correlation curve. These peaks are not clear bubbles because their voidages are low $(0.63-0.65)$. It was generally believed in the past that when a clear bubble is passing through (with higher voidage value), a sharp peak should occur with a weak turbulency at the wake. However, we observed that when a "pseudo-bubble" is passing through, still it sometimes causes a strong turbulency, resulting in the peaks in gas pressure fluctuation. This means that some "pseudo-bubble" may have a high level of the turbulent energy. The turbulent energy of each transient bubble seems to be different from one bubble to another, depending upon the characteristics of the respective bubble flow mechanisms.

We defined the characteristic of the emulsion phase with the various levels of the voidage of the bed. We also tentatively classified "pseudo-bubbles" into two classes by their voidage; regular bubbles have the voidage range above 0.74 , type $A$ pseudo-bubbles in the voidage range of $0.74-0.65$, and type $B$ pseudo-bubbles in the voidage range of 0.65-0.60. Based upon the above definition, the transient behavior of the emulsion phase (pseudo-bubbles) can also be characterized in a similar way.

The "double peak" behavior associated with $\Delta \Delta \mathrm{P}$ can be explained by the above multi-bubble flow mechanisms. The first "double peak" in Figure 24 shows a type $B$ pseudo-bubble with turbulency. Observation shows that this voidage change caused relatively higher pressure fluctuation (see Figure 26). The second "double peak" in Figure 24 shows a type B pseudo-bubble accompanying a regular bubble, and the local area (cells A-32) was occupied by the pseudo-bubble (see Figure 27 for pixel definitions). Although the regular bubble with a very high voidage is far from the local area (near the wall, see Figure 28), its tail ("pseudo- 


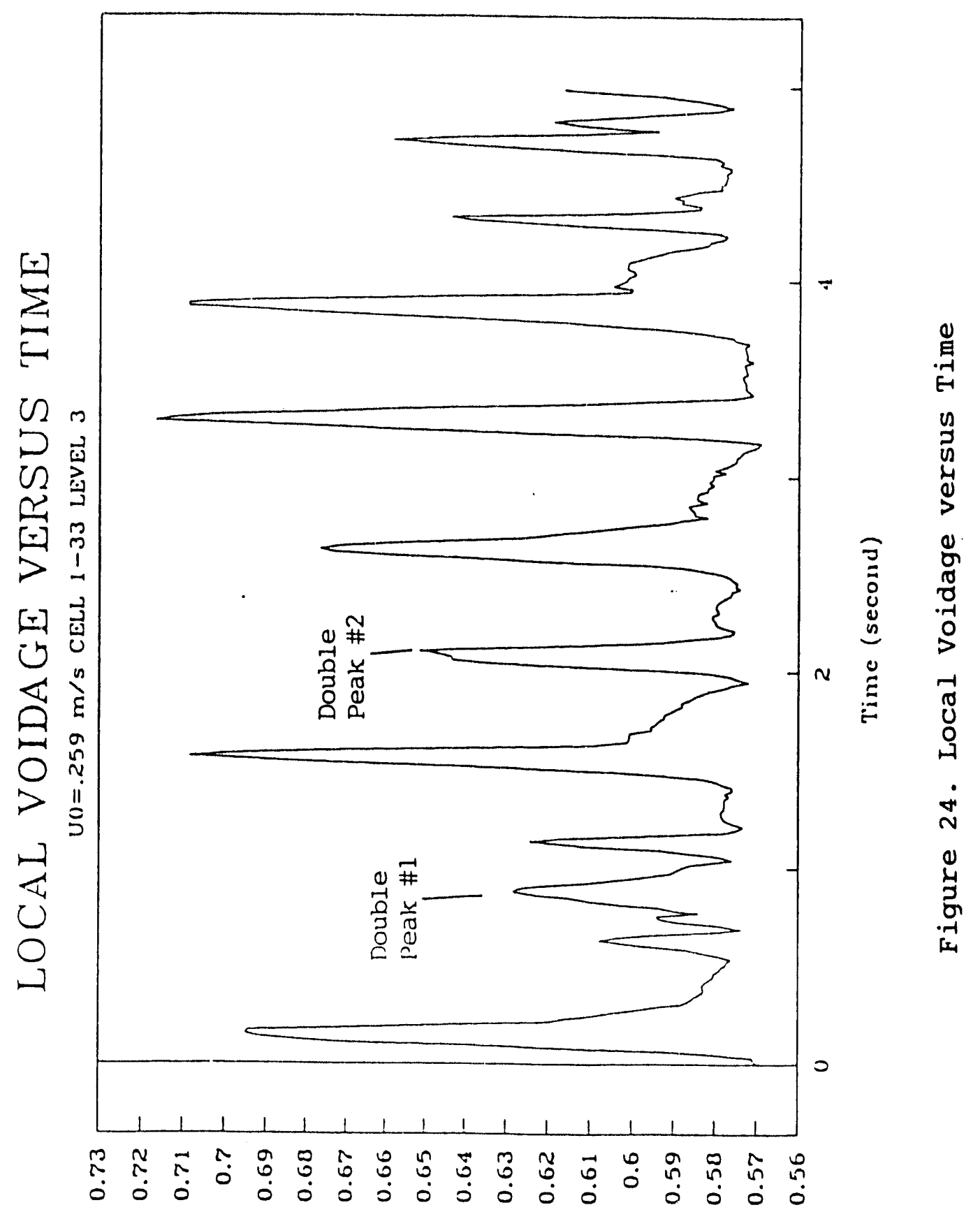

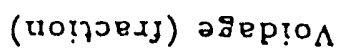




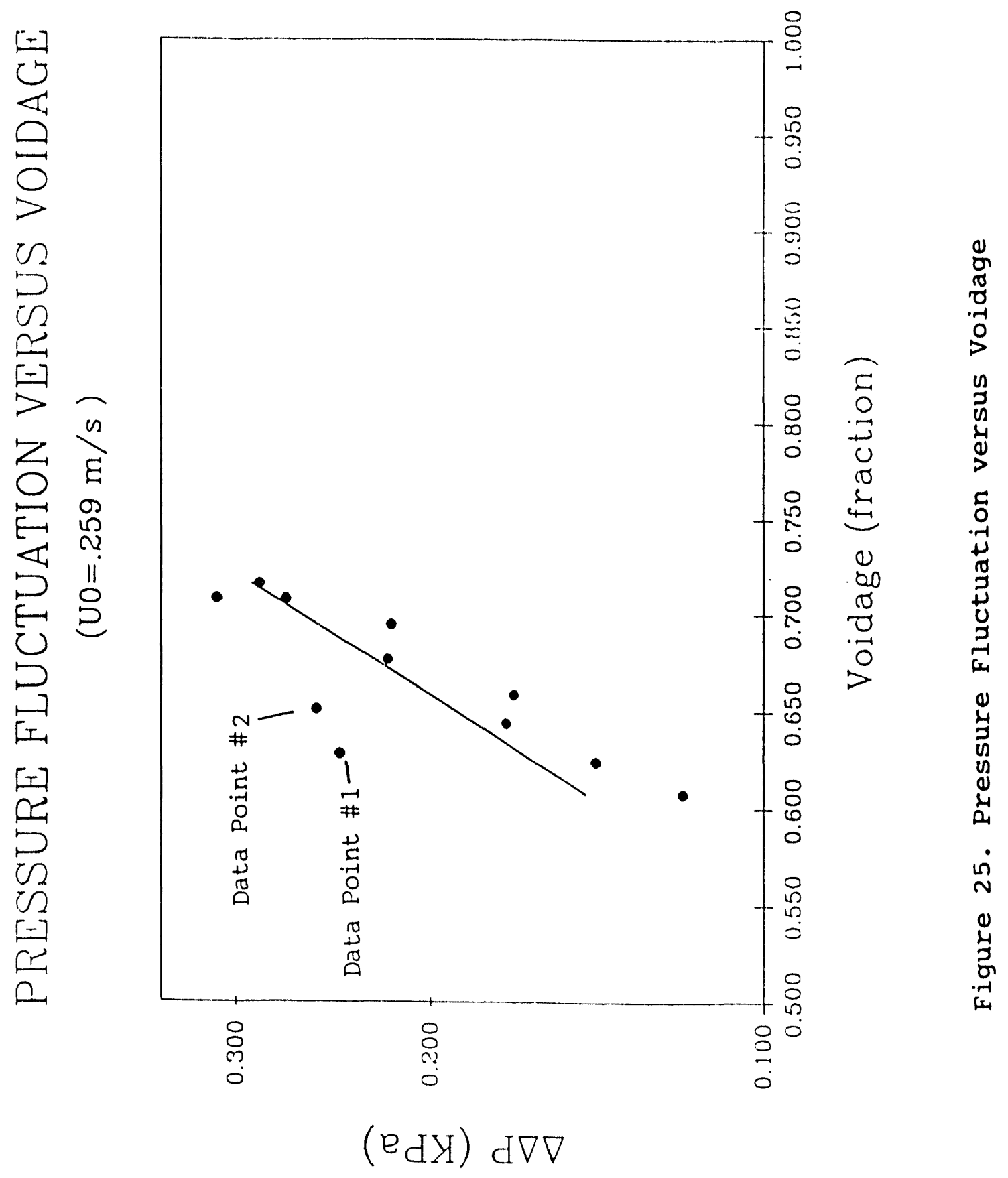




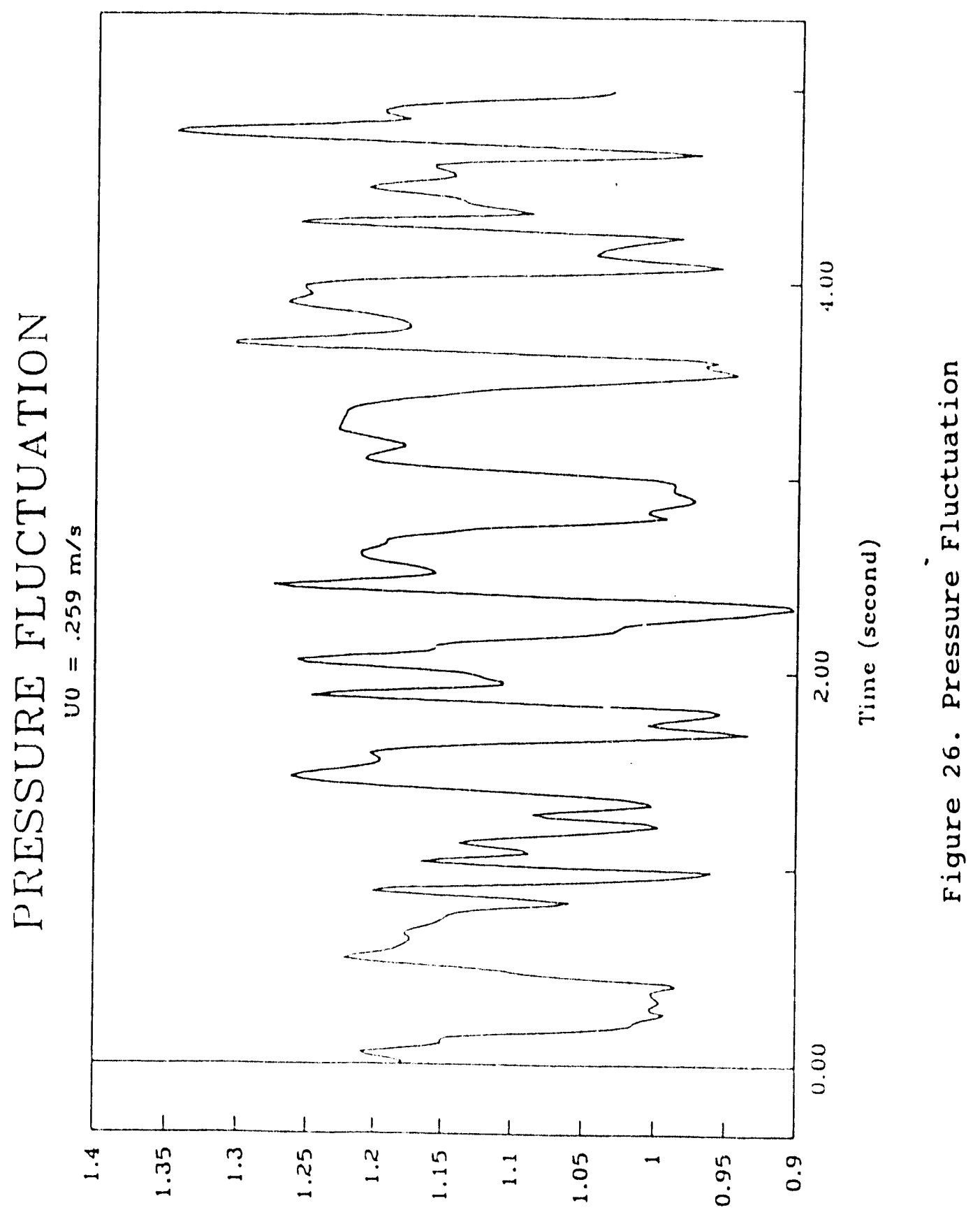

(edy) axnssoxd 


\section{Pixel Definitions}

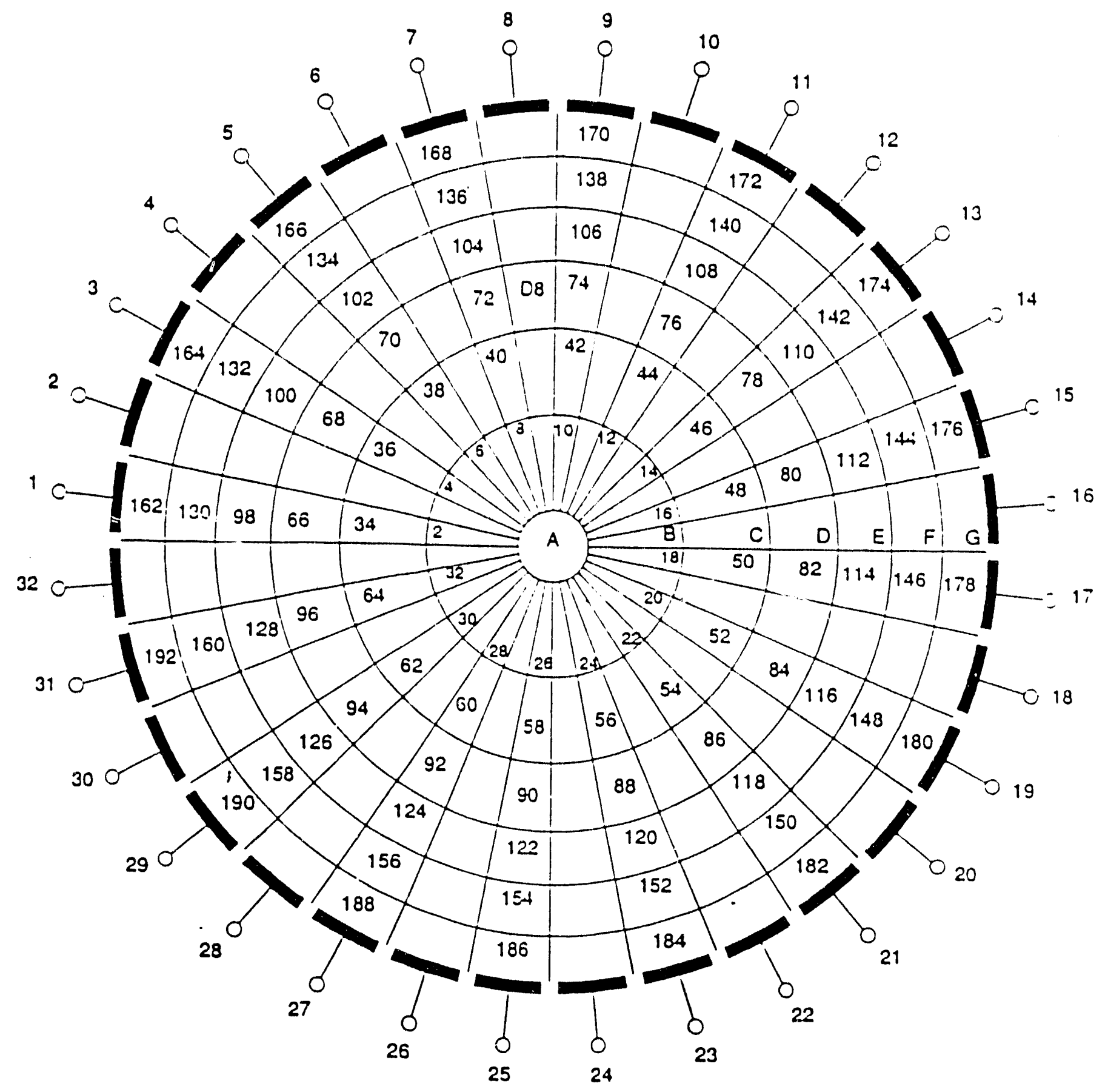

Figure 27. Pixel Definitions 


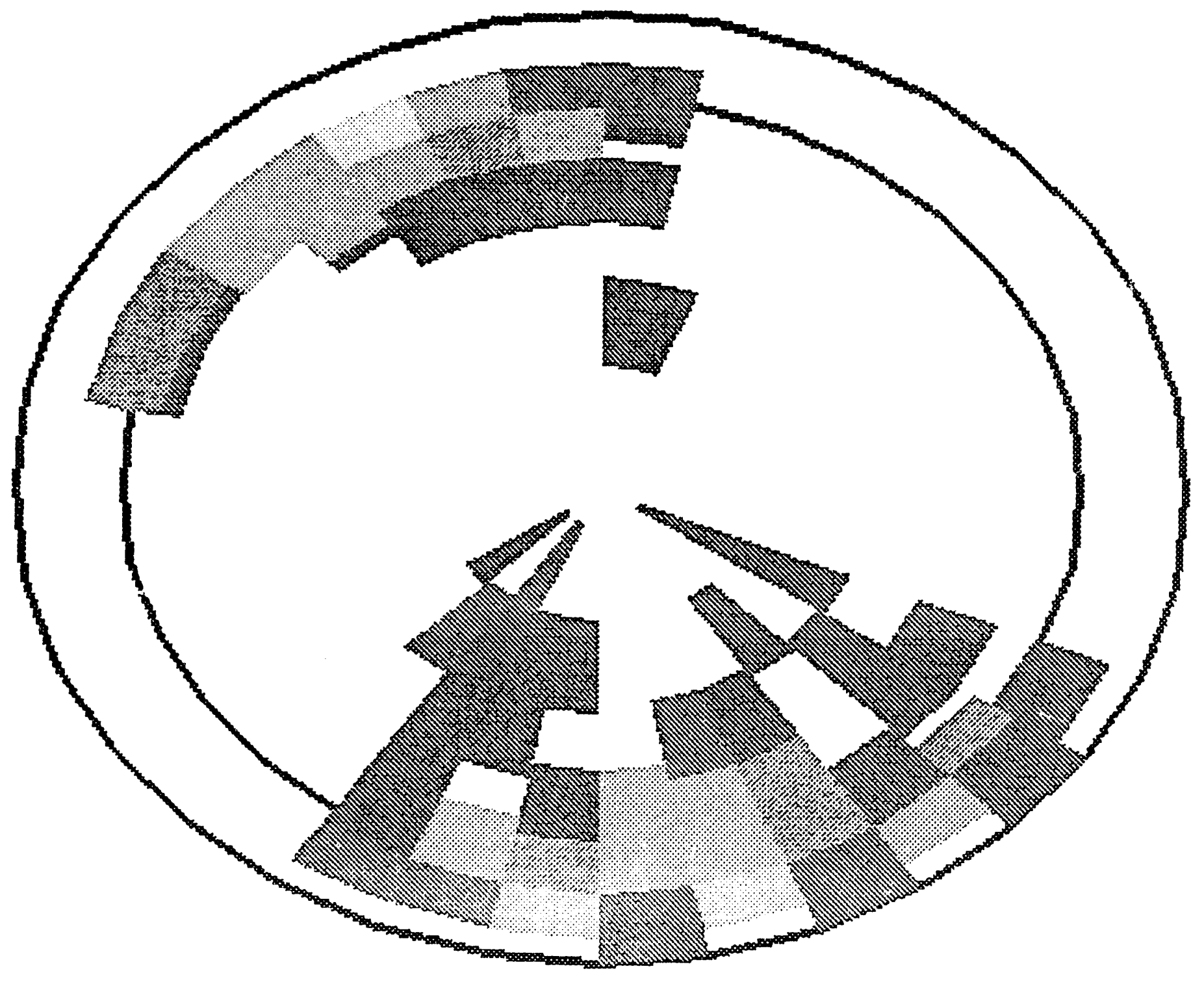

Figure 28. Regular Bubble in Nearby Domain 
bubble") still affect the local pressure fluctuation, forcing the local pressure fluctuation up. This example means that the domain definition is sometimes very important. When some bubbles with the higher turbulency energy exist in a specific domain (in a specific area around the measurement point), the gas pressure fluctuation could be pretty high at the measuremerit point, where there is even no clear bubble. In other words, the transient force at any local point can not always be explained by the local voidage.

It should be noted that the domain concept discussed here is in good agreement with our observations on two dimensional fluidized bed (see previous section). 


\section{CONCLUSION}

To understand the transient voidage signals obtained by capacitance method in a three dimensional fluidized beds (METC/DOE), the transient bubble flow characteristics were investigated in freely bubbling fluidized beds. The following conclusions were obtained through the accomplishment of this project.

1) The experimental equipment was installed and the measurement methodology was established. Namely, the transient behavior of bubbles were investigated by using both three and two dimensional fluidized beds. To characterize the behavior of transient bubbles, the bubble properties (size, shape and voidage) and its motion, both of which changing transiently, were measured by a) videorecording at the time interval of 0.033 seconds, and $b$ ) measuring transient: pressure fluctuation of gas phase at every 0.01 seconds. These data were processed by PC to accomplish the analysis of bubble transient behavior.

2) Transient characteristics of the motion and properties of bubbles were analyzed by $P C$ and video recorders. In addition to the coalescence and splitting of the known bubble flow properties, we found several other bubble flow mechanisms, e.g., the transient shedding of the size (volume) and shape of bubbles, the disappearance and reappearance of bubbles into and from the emulsion phase.

3) The important point of these multi-bubble flow mechanisms is that those newly found bubble flow mechanisms could coexist in parallel with the well known coalescence and splitting flow mechanisms.

4) The bubble rising velocity, the effective volume of transient bubbles and the voidage of the emulsion phase were also found to be very much fluctuating and transient. It is to be recognized that these characteristics were not at all constant but transiently changing.

5) Sometimes the transient and abrupt gas bulk flow exchange can happen between the bubble phase and the emulsion phase. In an extreme case, the gas in a bubble can transfer from the bubble phase to the emulsion phase in a very short period of time (bubble disappearance into the emulsin phase). Sometimes reversely the reappearance of bubbles from the emulsion phase can also happen.

6) The transient voidage signals obtained by capacitance method in 
three dimensional fluidized beds provided bubble images almost identical to those obtained by a video recording method in two dimensional fluidized beds.

7) The transient force signals and the transient voidage signals in three dimensional fluidized beds were correlated. The result shows that the transient force signals had a good correlation with the transient voidage signals but sometimes it did not. As discussed in conclusion 1, the properties of bubbles should be different from one to another, because there coexisted several bubble flow mechanisms in the freely bubbling fluidized beds in parallel.

8) Since there are several bubble flow mechanisms prevailing in parallel, there are several levels of turbulency. Therefore, among the different bubbles or between the bubbles and the emulsion phase, there should be the considerable abrupt energy exchanges. The pictures of transient motions of bubbles can support the above working hypothesis.

9) Although it was not really the goal of this project, we come up to one more important conclusion. Namely, the unexpected bubble flow mechanisms of disappearance, reappearance and abrupt change of bubble size and shape can actwily happen time to time in freely bubbling fluidized beds in parallel to the well known coalescence and splitting.

10) We will be developing the expansion of a realistic fluidization model in another on-going project based upon the accomplishment of this work. 


\section{NOMENCLATURE}

$d_{p} \quad$ Diameter of fluidized particle

$D_{1}$ Diameter of fluidized beds, or width of two dimensional fluidized bed

H Loosely packed bed height

$T_{c} \quad T i m e$ necessary to coalescence the two bubbles after the velocities of the two bubbles get the same.

$\mathrm{U}_{\mathrm{b}}$ Bubble velocity

$U_{m f}$ Minimum fluidization velocity

$U_{0} \quad$ Superficial gas velocity

$\mathrm{V}$ Bubble volume

$\Delta \Delta \mathrm{P}$ Gas phase pressure fluctuation

$\Delta \Delta \mathrm{P}_{\max }$ Maximum gas phase pressure fluctuation 


\section{BIBLIOGRAPHY}

Allahwala, S. A., 1975, Ph.D. dissertation, Monash University. Clift, R. and Grace, J. R., 1985, "Continuous Bubbling and Slugging", a chapter in Fluidization $2 / e$, edited by Davidson et al, Academic Press, London.

Davidson, J. F. et al., 1963, "Fluidized Particles", Cambridge University Press, p.50.

Geldart, D., 1973, Powder Technology, 7, 285.

Grace, J. R. and Clift, R., 1974, "On the Two-Phase Theory of Fluidization", Chem. Eng. Sci. 29, 327 .

Hallow, J. S. et al., 1989, "Preliminary Capacitance Imaging Experiments of a Fluidized Bed", A. I. ChE Annual Meeting, San Francisco.

Hallow, J. S. et al., 1990, "Advances in Fluidization Engineering", AIChe Symposium Series No. 276, Vol. 86, pp41-50.

Halow, J. et al., 1991, AIChE annual meeting, Los Angeles, USA.

Kono, H. O. et al, 1987, "Kinetic Forces of Solid Particles in Coarse Particle Fluidized Beds", Powder Technology, 52, 49.

Kono, H. O. et al., 1988, "Kinetic Behavior of Solid Particles in Fluidized Beds", Annual Report DEAC-21-86MC23249, submitted in 1988 .

Kono, H. O. et al., 1989, "Kinetic Behavior of Solid Particles in Fluidized Beds", Annual Report DEAC-21-86MC23249, submitted in 1989 .

Kono, H. O. et al., 1990, "Kinetic Behavior of Solid Particles in Fluidized Beds", Quarterly Report DEAC-21-86MC23249, submitted in Jan 1990.

Kono, H. O. et al., 1990, Powder Technology 62, 13 .

Kono, H. O. et al., 1991, "Fundamental study on Transient Bubble(slug) Behavior by Characterizing Transient Forces of Solid Particles in Fluidized Beds", Annual Report DE-FC21-87MC24207, submitted in Jan 1991. 
Kono, H. O. et al., 1991, "Plastic Deformation Coefficients of Emulsion Phase in Fluidized Beds", AIChE Annual Meeting, Nov. 1991, Los Angeles.

Kono, H. O. et al., 1992, "Plastic Deformation Coefficients of Emulsion Phase in Fluidized Beds". Submitted to Powder Technology.

orcutt, J. C. and Carpenter, B. H., 1971, Chem. Eng. Sci. 26, 1049. Rowe, P. N. et al., 1962, "Bubble in Fluidized Beds", Nature, London, 195,278 .

Rowe, P. N. and Patridge, B. A., 1965, Trans. Inst. Chem. Engrs., 43, T157.

Singh, B., 1970, Ph.D. dissertation, Monash University. 

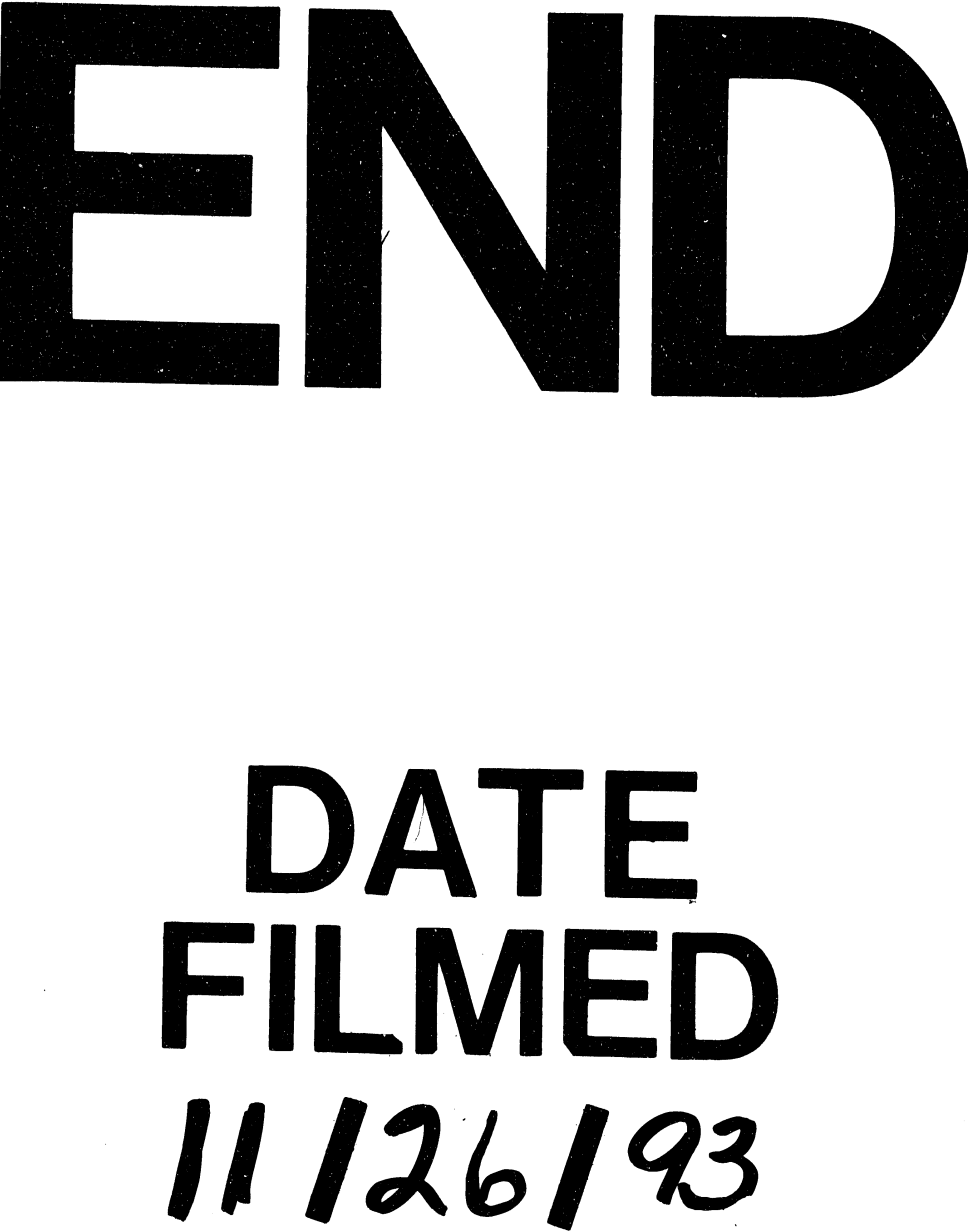

93 
